\title{
Making Money: \\ Alternative Currency use in Canada
}

by

John A. Graham, B.A. (Hons.)

A thesis submitted to the Faculty of Graduate and Postdoctoral Affairs in partial fulfillment of the requirements for the degree of

Master of Arts

in

Sociology with Concentration in Quantitative Methodology

Carleton University

Ottawa, Ontario

(C) 2015, John A. Graham 


\begin{abstract}
Drawing on national-level online news sources covering Bitcoin from 2012 until September 23, 2014, this thesis analyzes the ways in which the Canadian government has sought to socially construct Bitcoin, an electronic peer-to-peer value transfer system and currency, within the Canadian legal framework.
\end{abstract}

This thesis analyzes theoretical propositions about alternative currencies made by Geoffrey Ingham, Peter North and Edward Castronova by applying the contributions of these theorists to the present Canadian social context. 166 National Post, CBC News and Globe and Mail articles were analyzed using a mixed-methods approach, by means of a Thematic Analysis and Factor Analysis.

This study determined that the state has constructed Bitcoin as a de facto currency in Canada for the accumulation of taxes while retaining de jure currency status for the Canadian Dollar. In doing so, the state has allowed Bitcoin to proliferate in Canada as an avenue with which to advance the state's monitoring of Canadian financial activity. 


\section{Acknowledgements}

I'm not very good at these things, but I would like to acknowledge the help of a few people who made this project possible. I'd like to thank my parents, Andrew and Judy for being supportive, as well as my brother Brian, sister-in-law Julie and their family for providing me with great company, conversation and Sunday afternoon lunches.

I would like to thank my advisor Dr. George Pollard for providing constructive and helpful feedback when I needed it. I don't think I could have asked for a better advisor for this project. I would also like to thank Dr. Neil Gerlach for taking the time to review this thesis and Dr. Michael Wohl for agreeing to be the project's external.

Lastly I would like to thank green tea and the music of Richard D. James, who have for years proven themselves to be excellent study aids. 


\section{Table of Contents}

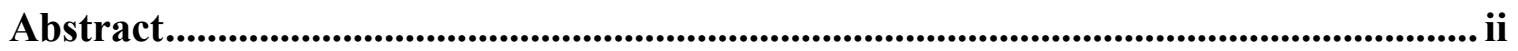

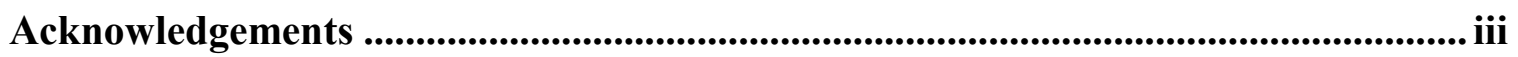

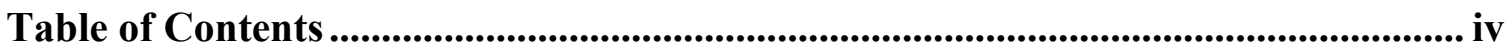

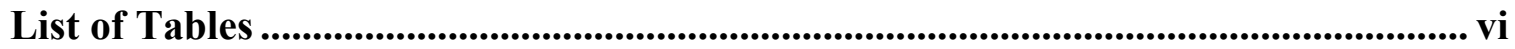

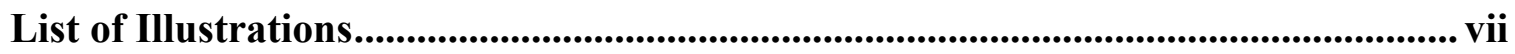

List of Appendices ........................................................................................................................ viii

Chapter 1: Basis of Present Study ......................................................................... 1

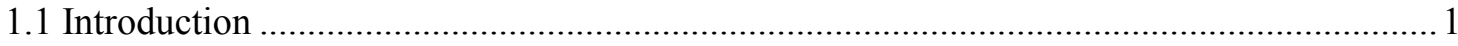

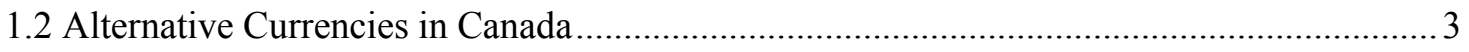

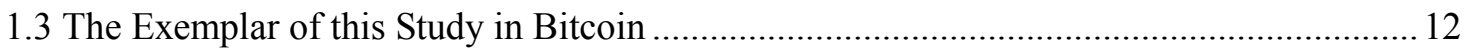

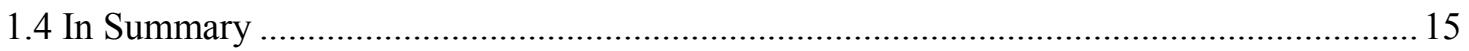

Chapter 2: Conceptualizing Alternative Currencies ....................................................... 16

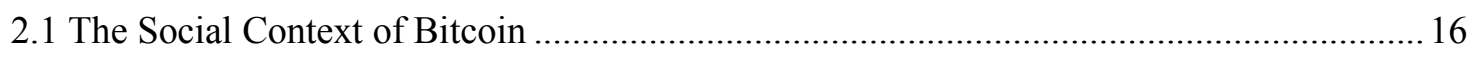

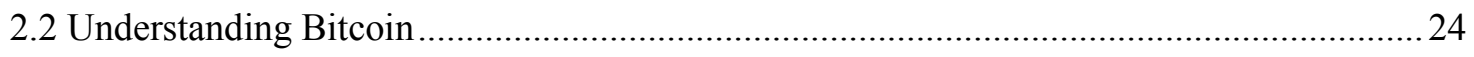

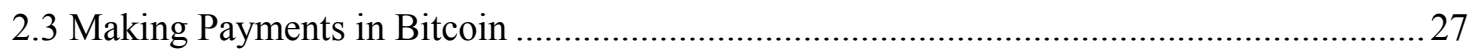

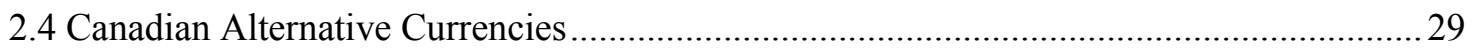

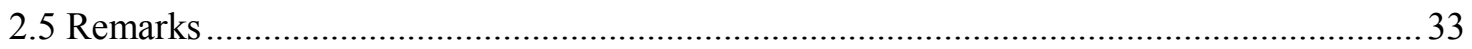

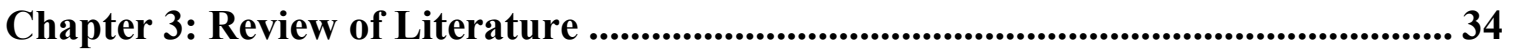

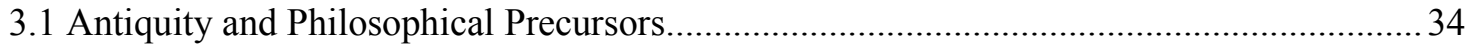

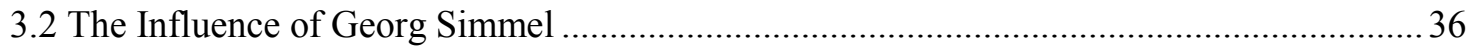

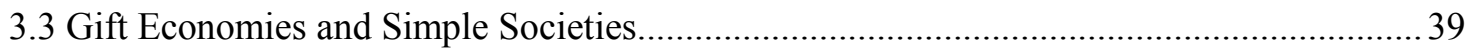

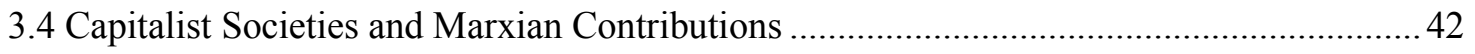

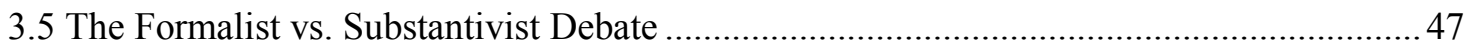




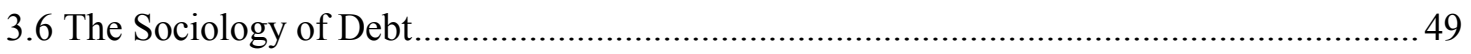

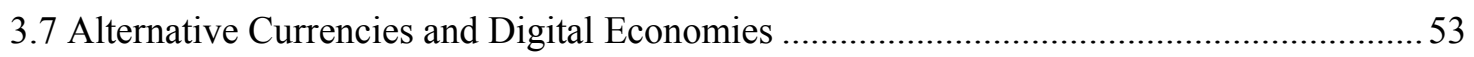

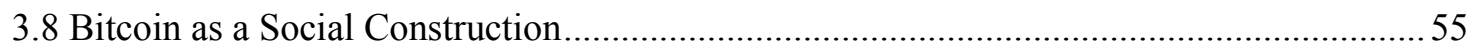

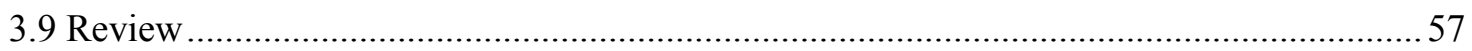

Chapter 4: Methods of the Present Study ......................................................................... 58

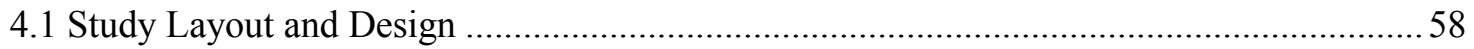

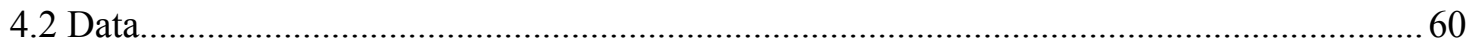

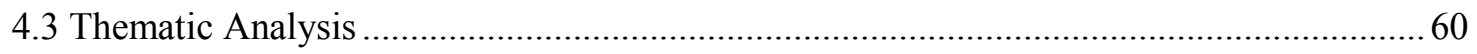

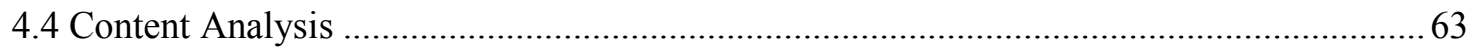

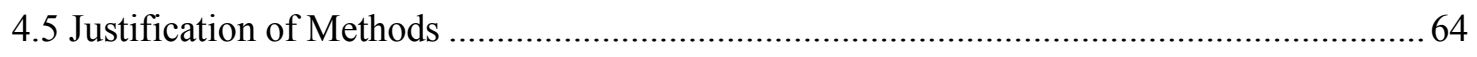

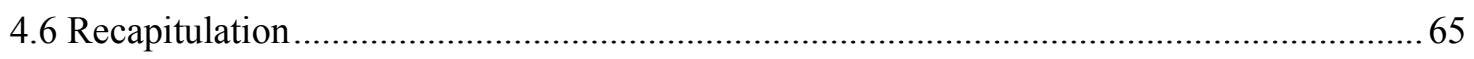

Chapter 5: Analysis of Data ................................................................................................67 67

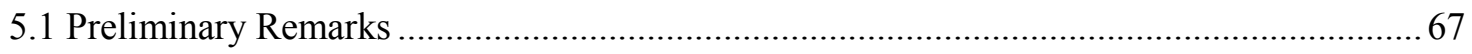

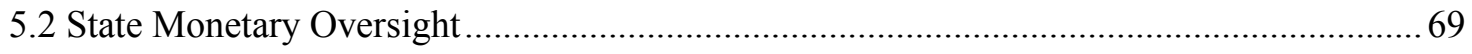

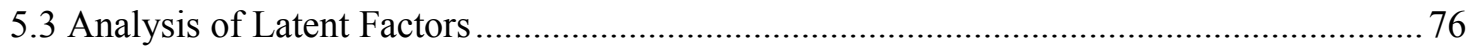

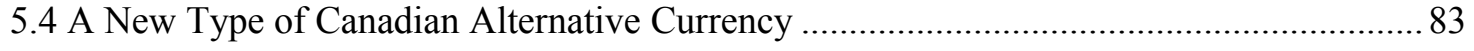

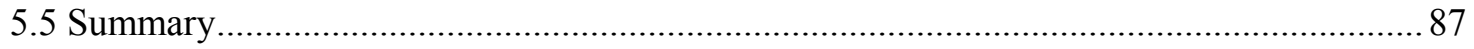

Chapter 6: Conclusion ................................................................................................................... 90

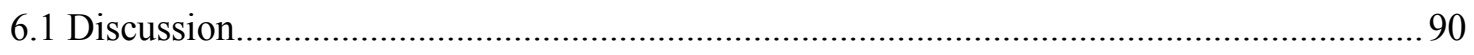

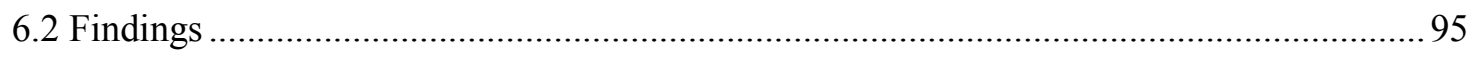

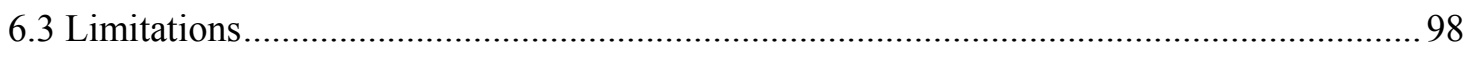

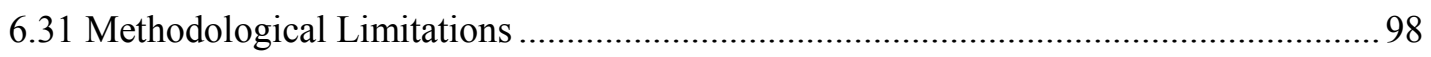

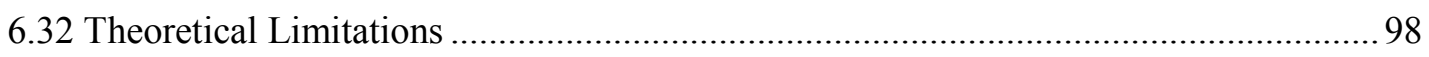

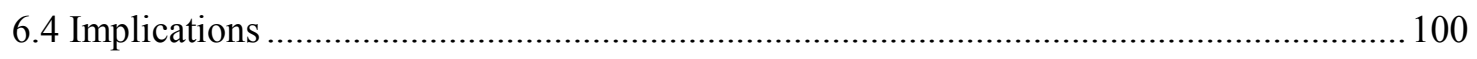




\section{List of Tables}

Table 1: Canadian Remittances over \$1 million (USD), 2014. (World Bank, 2015)...... 13

Table 2: Correlation Matrix for the Two Factor Model.................................................. 76

Table 3: Frequency of Themes Used with prevalence (\%) indicated ............................... 78

Table 4: Principal Axis Factoring with Iterated Communalities ..................................... 80 


\section{List of Illustrations}

Illustration 1: How Credit Card transactions are processed (Heggestuen, 2014). 28

Illustration 2: Example of a QR code, a form of square-shaped barcode which contains digital information. The QR code above contains the URL of the Carleton University Department of Sociology and Anthropology website at https://carleton.ca/socanth/....... 29

Illustration 3: Dialectical relationship between use value, value and exchange value in Das Kapital; Harvey (2010, p.11)

Illustration 4: Thematic map, indicating main thematic branches of property, taxation, crime, finance and the Bank of Canada.

Illustration 5: Bitcoin price in USD, October 1, 2013 to September 30, 2014 showing a Bitcoin "Bubble" rising until December 2013. Negative press and consumer fears drove down price with the collapse of Mt. Gox Bitcoin exchange, February 2014. Data retrieved from www.coindesk.com 92 


\section{List of Appendices}

Appendix A: List of CBC Resources Used................................117

Appendix B: List of Globe and Mail Resources Used........................119

Appendix C: List of National Post Resources Used...........................120

Appendix D: Codebook.................................................... 123

Appendix E: Articles for Qualitative Analysis............................. 126 


\section{Chapter 1: Basis of Present Study}

\subsection{Introduction}

Money is social in that it allows for two or more parties to exchange commodities or services. Sociologically speaking, money is the facilitator of social relations and the means of perpetuating class divisions. Rather than being ancillary to social relations, money, in the early $21^{\text {st }}$ century developed into a vast and complex set of value transfer systems. It is for this reason that money has become the grounds for social research in its own right. One recent form of currency, Bitcoin, exists independently of the state, with no banks, no central issuing authority and no consumer protection. The present study argues that there exists a divergence between media and state interests concerning the manner in which Bitcoin is approached in Canada. This thesis examines the dynamics through which the Canadian Government has facilitated Bitcoin adoption and use in Canada between April 2012 and September 2014, and deconstructs media reporting of Bitcoin. In doing so this paper argues that media interests, in stark contrast to the state, rest in readership attainment rather than inherent ideological predispositions.

The present study raises three propositions in relation to the sociology of money. In doing so, this study will demonstrate the many ways that sociologists have tried and, often failed, to grasp the social nature of money. This is accomplished by using examples and evidence from contemporary social developments. The first of such ideas comes from Geoffrey Ingham (2001; 2004), a modern proponent of the State Theory of Money and of neo-Chartalism. Ingham argues that 'moneyness' is ascribed by a state rather than something that results from market exchanges 
between people (2001, p.317). This study will discuss the many ways in which this view is incorrect, as monetary value is derived from people directly rather than from state influence.

Second, Castronova (2014) argues digital currencies cause problems for state governments because they allow for commerce that is difficult to tax. It is argued, in this study, that Bitcoin, in Canada, demonstrates characteristics of a 'legitimization process' akin to a social construction, as discussed by Berger and Luckmann (1967, p.24-25), in order to allow for the accumulation of tax revenue conducted on transactions that take place using digital currency.

Finally, some characteristics of alternative currencies proposed by Peter North (2007, p.148), such as geographic density, perpetual use and idealistic fervor, allow for the prolongation of currency use. As Lee and colleagues have also asserted (in North, 2007, p.176-7), currencies, of either the fiat or alternative variety, are most effectively adapted to communities where individuals earn their livelihoods in them. This study applies these ideas to the present Canadian social climate in order to test these assertions. Having been written before the advent of digital currencies, the postulations in North (2007) require revision in order to apply more succinctly to our current social context.

The news media are drawn upon in this study as it provides a trove of publically-available information concerning the interests and actions of the Canadian state. The news media this study draws upon disseminate information to the public, which leads to the formulation of personal opinion and in a broader sense a monetary social construction. Because money is inherently social and as state actions and media institutions rely heavily on disseminated information, information passed to the Canadian readership can be contrasted with state actions concerning alternative digital currencies. Evidence can then be accumulated that contrasts the publically available media 
information with agency mandates, senate reports and state legislation to provide richer meaning behind the types of connections that exist between media and state interests.

\subsection{Alternative Currencies in Canada}

Why we need money can be difficult to answer. Our society is geared toward a system of proprietary commerce sustained through constant, undisturbed, fast-paced exchanges. Should a society suffice to reproduce itself, without the concept of ownership or property, money is by its very essence unneeded. A society idealizing the accumulation of wealth and capital necessitates the rapid exchange of commodity for money and vice versa. Such a society demands the existence of money to act as a medium of exchange, unit of account and store of value, to accommodate said system. In this paper I will demonstrate that the Canadian history of such a system is multifaceted and the manner in which money is used is often perplexing. Money changes forms through time and across space and in doing so lays the groundwork of our society.

In attempting to understand Bitcoin, as a novel form of money, online news from the $\mathrm{CBC}$, Globe and Mail and National Post ${ }^{l}$ were analyzed over a 900-day period. To supplement, contemporary federal legislation is drawn upon, as are federal agency mandates and the findings of the Senate Standing Committee on Banking, Trade and Commerce concerning digital, alternative currencies.

At first we must recognize that there exists a difference between 'money' and 'currency' (Dodd, 2005). Money is an abstract quality attributable to nearly anything, applied by society to

\footnotetext{
${ }^{1}$ Within the present study, publications found within the Financial Post and National Post are considered as though they belong to the same editorial corpus unless otherwise specified.
} 
different things at different times and places (Castronova, 2014, p.48). Nigel Dodd proposes three types of money: state-issued currencies or those issued by a group of states, forms of money issued by corporations and forms of money issued by local communities (Dodd, 2005, p. 388). This paper demonstrates the differences between the state-issued currencies and local community money described by Dodd (2005).

There are a few often cited characteristics that make something money, namely that something is a unit of account, a store of value and acts as a medium or facilitator of exchange (Lehdonvirta \& Castronova, 2014, p.179; Ali, Barrdear, Clews, \& Southgate, 2014b, p.3-5; Ferguson, 2008, p.24-25; Ingham, 2001).

Currency as a concept is markedly less abstract than money. The currency we are most accustomed to in our daily lives is actually what can be more succinctly referred to as a fiat currency, that is, currency sustained at most by state decree that it is valid in exchange (Galbraith, 1975, p.63). A fiat currency retains value through none other than this state decree. Bitcoin, contrarily, is not a fiat currency. Rather Bitcoin is an example of an alternative currency. Our national currency is constructed as an effective medium of exchange, unit of account and store of value. Canadian Dollars as a fiat currency are widely accepted, they stem from state institutions and are payable to the state in the form of taxes. The Canadian Dollar is an example of a fiat currency; it retains value because the Canadian government says so. An alternative currency is that which, to varying degrees of success, hold many of the same characteristics of a normative or fiat currency like Canadian Dollars but contrarily exist independently of state interest in civic duties like the payment of taxes or fines. In this manner alternative currencies exist alongside or opposed to state currencies, existing in tandem with national or multinational monetary systems. They can be either benign or threatening to state power and fulfill varying social purposes or intentions. 
In addition to being an alternative currency, Bitcoin is also a digital currency, an internetbased form of currency. Vigna and Casey (2015) argue there are three contemporary state approaches to digital currencies: the overtly hostile, the accommodating and the passive. This study finds the Canadian state has opted an accommodating approach to Bitcoin and other and digital currencies. The state has done this to allow for the raising of tax revenue without stifling technological innovations. Integrating Bitcoin and other digital currencies also acts as a means with which to expand the state power to stop money laundering and terrorist financing.

Alternative currencies are far from being a new thing in Canada. From the mid- $17^{\text {th }}$ century onward, historical developments have provided a strong environment for various forms of money, scrip and alternative currencies of varying type and purpose. A holistic history of Canadian currency is worthy of much scholastic attention. The introductory account of monetary history presented below lacks some of these intricacies but demonstrates some of the many ways in which money has changed in Canada in form and purpose over time and across space.

Money is exceedingly versatile. It exists in many forms depending on a plethora of interwoven social, spatial, technological and economic factors. North America has been the host of many novel alternative currency schemes. For example, tobacco was a monetary equivalent in Virginia and Maryland from the $17^{\text {th }}$ to $19^{\text {th }}$ centuries, being a cash crop indigenous to the region (Galbraith, 1975, p.48-50). In terms of tangibility, that which we come to associate as money often depends simply on what is available.

To use a Canadian example, alternative currencies in Canada can be traced back to at least 'Made Beaver' (Carlos \& Nicholas, 1990), a unit of account used by the Hudson's Bay Company 
in British North America. Made Beaver was used to index commodities, defining value by attributing objects or consumer goods to their worth in beaver pelts.

This system was however not without its abuses. In circumstances where a small beaver pelt had the same value in exchange as a larger one or, in the previous example, tobacco stems were worth as much in exchange as fresh tobacco leaves, people tended to hold onto the higher quality money form, using instead that which was less desirable in their exchanges. This illustrates Gresham's 'Law,' which posits that when two forms of currency are mutually exchangeable, people hang onto the good currency while choosing to exchange the bad (Galbraith, 1975, p.10). That which is considered 'good' or 'bad' is merely a social perception. Proponents of this 'law' are often skeptical of alternative currency proponents (North, 2010, p.38). In the latter part of the seventeenth century the demand for beaver pelts was insatiable, furthering exploration into the continent (Innis, 1967, p.21-22). Beaver pelts were not only used as a means of taxation, but were invaluable in barter exchange (Innis, 1945, p.28), with a quarter of trading profits going to the Hudson's Bay Company.

New forms of money often depend on the resources available. In 1685, a lack of funds in New France meant the French Intendant de Meulles had to meet an increasing demand for money for use in exchanges by cutting playing cards into fours, marking them with a stamp of legitimacy and issuing them as currency (Innis, 1945, p.28-29). These cards would be redeemable when the annual shipment of coinage finally docked at the new continent. This system of playing card money was important in New France for about sixty-five years (Neufeld, 1964, p.1). With time, a more steady currency had been implemented but was fraught with governmental difficulties. By the time the French rule came to an end in 1763 , the currency had depreciated in value. 
At the time of the American Revolutionary War, a few years later, both Quebec and the British colonies had become skeptical of the rebellious southern colonists and their use of paper money (Hammond, 1967, p.135). This distaste for paper money complicated matters for the English Canadians, who at this time were suffering monetary scarcity similar to that which was experienced by the French colonists a few decades earlier (Hammond, 1967). This predisposition against paper currency lasted into the late eighteenth century (Hammond, 1967, p.138).

Shortly thereafter, during the War of 1812, the need for a dependable currency was realized in the issuance of 'army bills' to fund the war effort. These bills were signed by the Commander of the Forces and payable at the Army Bill Office, in Quebec, or in drafts in London (Hammond, 1967, p.141). The army bills had been a success during the war and had removed the prejudice against paper money, especially among the agrarian populace. After the war, a replacement money was called for, which paved way for Canadian banking institutions (1967, p.142). The hesitancy toward paper money had lagged the growth of Canadian banking. Canadian banking was not truly established until 1817 with the Bank of Montreal, developing a banking system a full 35 years after the Americans (Hammond, 1967, p.135-6).

A paper currency is representative of a fractional banking system and, as such, the socially engrained distaste for paper currency among Canadians was a possible cause for the late blooming of Canadian finance. In simple terms, fractional reserve banking systems are those where a bank makes loans against its deposits (Castronova, 2014, p.51), accruing risk as the amount it lends out in paper surpasses the assets or coinage that remain in reserve. ${ }^{2}$ Historically, paper bills were given out by a bank to indicate the slip was worth a certain value of gold or other previous metal at the

\footnotetext{
${ }^{2}$ Which is conceptually where the term 'inflation' arises from.
} 
bank which produced the slip. ${ }^{3}$ Of course, when unchecked this system is potential grounds for abuse as banks have an incentive to lend out as much as possible in order to accrue interest. This means that as banks lend out more and more money, it may increase the amount of money it produces in a fractional reserve system. This becomes "a process of social reality construction that borders on the magical" (Castronova, 2014, p.52).

The fractional reserve banking system and its potential for collapse were well-known by Canadians by the time Canadian banking came to fruition. When Louis XIV of France was strapped for cash, he sought out new monetary policies with the intention of avoiding the nation's third bankruptcy in just under a century (Ferguson, 2008, p.139). In 1716, Louis XIV had given the Scottish economist John Law the green light to establish the Banque Générale, in France, with capital worth six million livres tournois over a twenty year contract (Galbraith, 1975, p.22-23; Ferguson, 2008, p.140).

The notes had become legal tender in France, acceptable both for the payment of taxes and for day-to-day uses. The Banque lent out 100 million livres in notes in the spring of 1719 (Galbraith, 1975, p.25), increasing this total by 300 million livres in notes by summertime and then further increasing it again by another 800 million livres in the latter half of that same year. This was a demonstration of the ways in which scarcity can have an impact on monetary value; the addition of each new bill was diluting the value of the livres already in circulation. With time this overinflated system of money had collapsed (1975, p.27), and in early 1720 the overextended paper supply had stopped being redeemable at the point of sale, causing what can be described as a 'run

\footnotetext{
${ }^{3}$ In some respects this ppaper currency was better for common people than a coin alternative. For example if you believe a $\$ 20$ bill holds the same monetary value as 20 loonies, 400 nickels, or what-have-you, the bill is preferable for you in transit.
} 
on the bank.' In France people rushed to redeem the paper for the more valuable coinage (Galbraith, 1975, p.27), crippling the financial state of France in the process.

Although a banking system had taken root in Canada by the early decades of the $19^{\text {th }}$ century, a national monetary system was slow to develop in Canada. It was not until Confederation that a sound banking system and form of currency finally arose (Easterbrook \& Aitken, 1956, p.384). Until Confederation in 1867, provinces continued to have control over the issuance of Treasury notes that could be used for the payment of taxes (Hammond, 1967, p.154). This meant there were a multitude of currencies in use in varying denominations across the provinces.

The first national coins in the Dominion of Canada were minted in England as no minting facilities in Canada had by the 1850s existed (Royal Canadian Mint, n.d., p.3). When waiting for a shipment to arrive in 1870, the government issued banknotes called "shinplasters" (Royal Canadian Mint, n.d., p.4). This marked a time when the government began to take over paper money production, though with limited exceptions. Banks were free to issue their own notes in any denomination until 1881 (Royal Canadian Mint, n.d., p.4) at which point banks were restricted from producing bills other than $\$ 5$ denominations or multiples thereof.

The task of producing bank notes has historically been left to printing companies such as BA International and the Canadian Bank Note Company (CBNC). The CBNC was established in 1897 and mandated with producing secure printed products for the Canadian Government (Canadian Bank Note Company, n.d. a). The CBNC was and remains a for-profit organization that produces Canadian currency. The CBNC also produces many products for the government, such as postage stamps, passports and passport ID systems, drivers' licenses and other forms of identification, citizenship documents, travelers' cheques, lottery machines, lottery tickets, stocks 
and bonds certificates (Canadian Bank Note Company, n.d. a; Industry Canada, 2015). As well as currently being the exclusive supplier of Canadian polymer banknotes, the Canadian Bank Note Company is also the exclusive supplier of Canadian Tire 'Money' (Canadian Bank Note Company, n.d. b).

The introduction of Canadian polymer banknotes in 2011 was not without social consequences. The new bills are resilient, having been tested prior to release by being boiled, frozen and run through washing machines (National Post, 1 Jan 2013). The polymer banknotes are expected to last over twice as long as cotton-based ones in circulation (Boesveld, 21 Jun 2011). As such, fewer bank notes need to be created in order to replace those that get damaged or worn by use (CBC News, 1 Dec 2011). This is the reason why BA International, a subsidiary of Munichbased Gieseke \& Devrient and Canadian bank note producer since 1866 (CBC News, 1 Dec 2011), began laying off its Ottawa staff in 2011. As of writing, the entire Canadian banknote supply is currently manufactured by the CBNC, a privately owned and operated enterprise ${ }^{4}$.

Returning briefly to the $20^{\text {th }}$ century, we find that Canada was the epicentre for some new ways of thinking about money. Social Credit was pioneered during the Great Depression by the former English soldier Major C. H. Douglas (Galbraith, 1975, p.53). Social Credit was a scheme devised to combat a monetary system that Douglas felt caused poverty to flourish in a world that seemed to be overproducing commodities (North, 2007, p.66-67); workers' wages were insufficient for purchasing the goods they produced. The result of such social circumstance meant

\footnotetext{
${ }^{4}$ In theory this bottleneck in the Canadian monetary supply makes the collective bargaining power of the Canadian Bank Note Company staff quite powerful. To take an example from history, in April 1989, Argentina literally ran out of money (Ferguson, 2008, p.113), but as the printers had gone on strike there was no way to rectify this problem. This exacerbated Argentina's financial problems, leading to 'hyperinflation,' riots and social unrest (2008, p.113114).
} 
either a lack of consumption on part of the masses or individuals were forced to rely on credit from banks for purchases with interest, causing a form of debt enslavement.

The system provides a 'Social Dividend,' (Galbraith, 1975, p.224) a form of alternative cash payable to citizens at large, which would then be spent, thereby stimulating the economy. This was in effect an alternative currency. This caught on in Alberta, electing Social Credit candidate William Aberhart as Premier in 1935 (North, 2007, p.72); however, as provinces at this time had no authority over monetary issuance and the province could not accept its self-issued scrip back in taxation, little direct power was to be had in affecting systematic change. The Social Credit Party in Alberta had also held power until 1976 (North, 2007, p.72) and a similar Social Credit Party in British Columbia was in power from 1952 to 1972. Social Credit was also popular in Quebec (North, 2007, p.72) with the Parti Creditiste winning 29 seats in Quebec in 1962.

As we have seen, monetary systems are complex and evolve according to social and technological circumstances. Canada has been the hotbed of many new ways of changing the tangible essence of money as well as thinking about the theory that underlies it. As we progress into the $21^{\text {st }}$ century, we find an increasingly digital world incorporating many new value transfer systems. In due course, this thesis will provide specific examples of two Canadian alternative currencies, Canadian Tire 'Money' and LETS, in order to demonstrate that the specific social dynamics of any given money form result from the communities that use them. We will also find that this is true of Bitcoin. 


\subsection{The Exemplar of this Study in Bitcoin}

Bitcoin is an electronic, peer-to-peer currency that was developed in 2008 and implemented the following year by the pseudonymous person or persons known as Satoshi Nakamoto (2008b; Champagne, 2014). The transaction network, the technology and the cryptographic protocol are denoted with a capital "B" as in Bitcoin, while the currency transferred across this network is denoted with a lower-case "b" as in bitcoin.

Bitcoin exists independently of the state and requires no intermediary institutions, such as central banks (Nakamoto, 2008a). It relies, instead, upon a decentralized transaction ledger called the 'Blockchain,' hosted globally on many computers and appended on all such computers in unison to avoid tampering or attempts to spend funds twice. Unlike fiat currencies, such as the Canadian Dollar, Bitcoin is issued through algorithms to individuals known as 'miners.' Miners devote computing power to verifying transactions across the network in exchange for a chance at attaining a bitcoin payout. Although some authors try to mask this human element of Bitcoin by referring to miners through their equipment rather than as people (see: Carignan, 2014, p.135; Champagne, 2014, p.368-369), ignoring this human element of the Bitcoin network is a mistake. In just a few short years, Bitcoin has amassed over 13 million units in circulation with over 2 million users (Ali et al., 2014[a], p.6), with each bitcoin produced solely through this mining process. The value of any given bitcoin rests solely in the price at which people are willing to pay.

This Bitcoin payout miners receive for verifying transactions diminishes with time (Antonopoulos, 2015), simulating a scarcity curve of precious metals such as gold or silver ${ }^{5}$. Although miners verify transactions on the network for profit, the network and technology itself

\footnotetext{
${ }^{5}$ A 'precious' metal is not herein meant to indicate that preciousness is an intrinsic quality or value but rather the idea of something being precious is a collective social attribution given to the bullion, coinage or raw materials.
} 
is not owned by anyone. In stark contrast to Canadian monetary, fiscal and economic policy, the Bitcoin protocol is theoretically capable of sustaining itself without human intervention.

Bitcoin is entirely intangible and exists solely as digital information. Despite the incorporeal nature of the currency, it has real world implications that can affect how we act or think. Even more peculiar, is that the value of a bitcoin is not backed by any tangible currency or asset. That a BTC costs about $\$ 300$, at the time of writing, and holds this amount in purchasing power rests as the product of a sufficient number of people believing it is so. This means that Bitcoin is the most abstract form of money presently devised. The logical consequence of these peculiarities is that a million dollars or more of monetary value can be held on a storage medium no larger than a postage stamp, without being backed by material goods or precious metals.

Bitcoin also provides some benefits to society that escape our present monetary system. For example Bitcoin has shown to be effective at stopping the expensive business of international remittances (Casey and Vigna, 2015). Remittances are used by workers in the "Global North" to

\begin{tabular}{|c|l|c|}
\hline \multicolumn{2}{|l|}{$\mathbf{2 0 1 4}$} & Remittance (USD; in millions) \\
\hline All & World & $\mathbf{2 3 , 1 4 5 . 1}$ \\
\hline 1. & China & $4,199.5$ \\
\hline 2. & India & $2,767.2$ \\
\hline 3. & Philippines & $2,075.3$ \\
\hline 4. & France & $1,278.4$ \\
\hline 5. & Lebanon & 955.6 \\
\hline 6. & Italy & 897.7 \\
\hline 7. & Vietnam & 842.9 \\
\hline 8. & Germany & 760.3 \\
\hline 9. & United States & 687.9 \\
\hline 10. & Belgium & 509.4 \\
\hline & $\ldots$ & \\
\hline 139. & Antigua and Barbuda & 1.0 \\
\hline
\end{tabular}

Table 1: Canadian Remittances over \$1 million (USD), 2014. (World Bank, 2015).

send money home to their families in impoverished nations, a process that levies hefty fees on disadvantaged families. In 2014, Canada sent \$23.1 Billion in remittances worldwide, primarily to 
Asia (World Bank, 2015). This process disproportionately hurts the poor while benefiting companies like Western Union who transfer funds internationally. This perpetuates poverty and exacerbating a global divide in wealth.

An example of the effectiveness of Bitcoin at transferring money to remedy the "middlemanning' of remittances can be seen on 22 November 2013, when \$149 million USD worth of bitcoin was transferred from one digital wallet to another. ${ }^{6}$ No transaction fees were charged for doing so and the transaction was verified by bitcoin miners within the hour. ${ }^{7}$ As long as two devices are connected to the internet, bitcoin is theoretically transferrable between them regardless of distance.

Market economies, such as our own, are abstract and amorphous. Markets are diverse, dynamic and built on human actions (North, 2010, p.59), with alternative currencies often arising from human reactions to market changes like financial crises. Some alternative currencies are tangible, as with Canadian Tire 'Money,' whereas others like Bitcoin have real-world value despite being entirely digital in nature. Alternative currencies, as with fiat currencies, take many forms depending on technical, historical and social factors. Money functions because people believe that value exists between buyers and sellers, and is exclusively social in that it requires the valuation of two or more parties to work.

\footnotetext{
${ }^{6}$ Bitcoin uses public-key cryptography. A digital wallet contains both a private and a public key used to verify one owns a certain number of coins on the global, decentralized public ledger of bitcoin transactions (Antonopoulos, 2015, 84-85). A user signs transactions with this key pair gain access to their 'wallet'. Because bitcoins are intangible and exist solely in the form of transaction outputs on the Blockchain ledger, the word wallet in the traditional sense is a bit of a misnomer.

${ }^{7}$ https://blockchain.info/tx/1c12443203a48f42cdf7b1acee5b4b1c1 fedc144cb909a3bf5edbffafb0cd204
} 


\subsection{In Summary}

What one should carry on into the following pages and chapters is simply that money can take many forms, exist to serve various social functions and in doing so fuel social changes. Money can bubble as with $18^{\text {th }}$ century France, be spent on war as with 1812 , or accrued as taxes. Money can be issued, manufactured and accepted both publically and privately.

Bitcoin was created with the intention that no central authority is required to oversee the issuance of funds or mediate the transfer of value. Bitcoin was designed to have few or no transaction fees and to allow for a direct transference of value between individuals without any intermediary such as a bank (Nakamoto, 2008b; Bradbury, 2013, p.5).

The way in which the Canadian state has allowed for Bitcoin to be incorporated into our society is grounds for testing postulations and presuppositions provided by sociologists that focus on money in the abstract. In looking at online media and legal documents provided by the Canadian federal government, it will be argued in the chapters that follow that Bitcoin has been shaped around state policy, coinciding with some theorizations while putting others into question.

The following chapters will discuss Canadian alternative currencies in more detail, provide the theoretical considerations that underlie the Sociological sub-discipline of monetary theory, discuss the methods and analysis of data collected for this exercise and provide a conclusion that discusses room for further room for scholarship going forward. 


\section{Chapter 2: Conceptualizing Alternative Currencies}

To better understand the subject matter of this thesis, is it important to appreciate some of the social and technical aspects of Bitcoin and its use by Canadians. As well, this chapter will introduce and discuss some other Canadian alternative currencies, primarily LETS and Canadian Tire 'Money,' to allow for a better understanding of alternative currencies and to appreciate the breadth of alternative currencies more generally. Finally, because Bitcoin is an entirely new way of doing commerce, this section will provide background information to understand the distinctly social dynamics inherent within the payment system.

\subsection{The Social Context of Bitcoin}

No technology created by a community of like-minded people can ever be detached from the social context that gave rise to its existence. Although adherents of Bitcoin like to taut the lack of human involvement presently found in Bitcoin, the technology was derived from years of digital currency developments by a loose-knit group of crypto-anarchists and free-market libertarian idealists that believe state non-involvement in economic matters is ideal.

Bitcoin was not borne out of a vacuum. Rather, it was the culmination of 20 years of research into distributed systems and currencies (Antonopoulos, 2015, p.215). The technology of Bitcoin had some inauspicious beginnings with Cypherpunks: people that saw the digitization of life enabled authorities to harvest data (Popper, 2015, p.8). The Cypherpunk Manifesto, delivered to a mailing list of enthusiasts in 1993 by Berkeley mathematician Eric Hughes begins with the line "Privacy is necessary for an open society in the electronic age" (Hughes, 1993). Some of the 
earliest adopters to Bitcoin were Cypherpunks, such as Hal Finney, the co-developer of Pretty Good Privacy (or "PGP”) encryption, along with Phil Zimmerman (Popper, 2015, p.10). ${ }^{8}$

But the Bitcoin technology itself was the culmination of many failed attempts at devising digital money (Popper, 2015). Copying files from word documents to mp3 files are notoriously simple in a digital world. Creating digital money that is immune to this risk is difficult. Libertarian programmers like those that devised Bitcoin recognized that a central system of authority could in theory control the money supply to avoid forgeries or copies. A short-lived project by David Chaum called DigiCash sought to make online money as anonymous as tangible fiat currency. However because all transactions had to be confirmed by his central organization, trust was inherently required in the institution he founded to oversee the project $(2015, \mathrm{p} .12)$. Such a system of digital currency was susceptible to the types of abuse and tampering found with fiat currencies today, issues the cypherpunks wished to avoid.

Adam Back (Popper, 2015, p.17) devised a system called hashcash in 1997 that he disseminated on the Cypherpunk mailing list. Hashcash was effective in that required no central authority to issue funds or oversee the system. Hashcash would later become a precursor to Bitcoin but fell short in that each unit generated could only be spent once. To understand the context of Back's contribution, he wrote that if this type of project inevitably succeeds, "the banks will become the obsolete dinosaurs they deserve to become" $(2015, \mathrm{p} .19)$.

\footnotetext{
${ }^{8}$ Zimmerman was an antinuclear activist who was intent on giving dissidents a method of communication outside of governmental purview (Popper, 2015, p.10). Working in the late 1980s, Zimmerman helped spark a movement of anarchist coders. His civil disobedience nearly landed him in jail (Greenberg, 2013, p.52-53). PGP is still used today by journalists, privacy advocates and various anti-state actors. Glenn Greenwald recounts in his book No Place to Hide (2014) that Edward Snowden attempted to communicate with him through PGP, as this was one of the few technologies available that still eluded the NSA's system of ubiquitous online surveillance.
} 
Bitcoin would eventually reconcile these projects to incorporate the positive elements of both while simultaneously succeeding in removing the drawbacks inherent to each of the prerequisite systems. Bitcoin was to allow for the finite generation of coinage made possible by Back's hashcash with the anonymity afforded by Chaum's DigiCash. The result was an anonymous and finite resource that could be generated by users and overseen by no lone person or institution. Forgeries and central authorities were avoided by making use of a democratic sharing of network power among users and a public ledger of all transactions called the "Blockchain," which will be discussed in the following section. The fundamental security of the network was held together by the strong cryptographic algorithms advocated by these initial contributors and the community with which they worked and shared ideas.

This project came to a head in 2008 amidst the inflationary monetary policies of the American Federal Reserve System. A current problem with the Bitcoin literature is that few formal, primary sources exist on the history of Bitcoin and those that do exist tend to intersperse factual information with either overt libertarian polemics (see: Carignan, 2014) or simply lack a sufficiently academic tone, style, composition and rigour (see: Miller, 2015). As such one tends to rely on the creator of the technology as a means of rectifying this paucity of literature.

The creator of Bitcoin, Satoshi Nakamoto, was skeptical of state institutional power, having devised Bitcoin in such a way as to circumvent the unilateral ability of states to remove centralized institutions at the source (Nakamoto in Champagne, 2014, p.44). ${ }^{9}$ Bitcoin was envisioned as a way of removing the state from digital commerce while allowing for online purchases that provide the

\footnotetext{
${ }^{9}$ We find a familiar case of this with Napster, a former peer-to-peer music file sharing site. Napster was vulnerable to state influence because it was a geographically centralized. Presently peer-to-peer file sharing has moved toward "torrents," which have no physical location and exist only on the computers of those sharing the files and those receiving them. This complicates the unilateral capability of state institutions to hinder the exchange of digital information, for better or worse.
} 
same level of anonymity that cash does. But as Polanyi correctly recognized (2001 [1944]), attempts to unhinge market activity from a society that gives rise to it is an impossibility. Markets are abstractions comprised of people. Sociologically it is ludicrous to suggest that economic activity can rest as a socially contextless aspect of human activity. Nonetheless, it was the interest of deregulation and state non-interference in digital commerce that was eventually realized in Bitcoin. Nakamoto devised Bitcoin as a system built upon libertarian notions of self-interested parties, engaging in personally beneficial actions, as a means of propagating the Bitcoin network (Nakamoto in Champagne, 2014, p.72-73). Perhaps his most well-known ideological act came in 2009 when he commenced the Bitcoin project by imprinting into the Bitcoin protocol a hexadecimal text string which reads "The Times 03/Jan/2009 Chancellor on brink of second bailout for banks [sic]" (Ali, Barrdear, Clews \& Southgate, 2014a) referring to not only the newspaper article released that day but also to the libertarian opposition to Quantitative Easing; an expansionary monetary policy that manufactured billions of artificial U.S. dollars in order to mitigate the economic fallout of the Great Recession.

The structure of Bitcoin itself, relying on a non-inflationary currency and freely-auditable source code, was devised with two main issues in mind. First, Bitcoin was to be a transparent alternative to inflationary institutions like the Federal Reserve in the United States. ${ }^{10}$ Secondly Bitcoin was by its very nature a contribution the ongoing open-source movement that continues to eschew proprietary software licensing. Although open source projects may seem at odds with a libertarian respect for property rights, the full transparency of Bitcoin's source code was required

\footnotetext{
${ }^{10}$ As of writing, the libertarian candidate running for the President of the United States of America, Rand Paul, accepts campaign contributions made in Bitcoin. Paul's father, former Congressman Ron Paul, ran for President in 2008. The elder Paul gained some notoriety for his anti-inflationary monetary policy and anti-Federal Reserve rhetoric in response to the bank bailouts that resulted from the Emergency Economic Stabilization Act of 2008.
} 
in order to provide Bitcoin with a sense of legitimacy and trustworthiness. For Bitcoin adherents, fully auditable algorithms were, and still are, seen as more trustworthy than humans when it comes to monetary policy.

The Bitcoin source code is freely available for anyone to see or adapt for personal use (Champagne, 2014, p.1). This freedom of access and use meant that the Bitcoin protocol has been used for many years by enthusiasts to develop hundreds or thousands of their own "Alt-coin" Bitcoin derivatives since 2009 (Antonopoulos, 2015, p. 215). ${ }^{11}$ Many communities were quickly built around these new currencies with their own subcultures. Each currency, such as Dogecoin or Litecoin, have communities that revolve around their respective currencies and the currencies have in turn shaped these groups in a recursive manner.

Bitcoin today can still find itself within libertarian sub-groups, although this says nothing of the other Alt-coins. According to an online survey in February 2013 (Smyth, 2013), the average age of Bitcoin users is $32.1,44.3 \%$ of respondents self-identify as libertarian or anarcho-capitalist and an overwhelming $95.2 \%$ of Bitcoin users are male. The community has in this way tailored the currency in a certain direction, with the currency in turn formulating and cementing the community around a united identity.

In terms of usability, Bitcoin can be used at many brick-and-mortar stores or online establishments. For example, Bitcoin is usable at online locations such as Wordpress, at the Shopify base of over 70,000 online stores and at the Foodler online delivery and take-out service which includes over 13,000 restaurants worldwide. Bitcoin will also soon also be accepted at Expedia, Dell, DISH Network, and the Chicago "Sun-Times" (CoinDesk, 2014). Although many

\footnotetext{
${ }^{11}$ The open-source nature of Bitcoin means that anyone is free to use the source code to develop their own form of digital currency. It does not mean anyone can change the protocol to Bitcoin itself.
} 
stores in Canada do not allow for Bitcoin use, the online shopping website eGifter.com allows a work-around that grants Bitcoin users the ability to purchase commodities at Amazon.com as well as brick-and mortar establishments such as Home Depot, CVS, Kmart, or Sears (O’Connor, 2014). Bitcoin has recently been accepted through PayPal for online purchases as well as by the Wikimedia Foundation for charitable donations.

Despite there being many legal and innocuous uses for Bitcoin, one must also recognize that Bitcoin has been used for various nefarious or morally questionable actions as well. Because Bitcoin was designed as a currency with an anti-government or even anti-statist set of inclinations, the currency has attracted a user base that has associated it with criminal uses as well as legitimate ones. Popper (2015) discusses the biographical details and social contexts of several Bitcoin proponents, advocates and pioneers, such as Charlie Shrem ${ }^{12}$ who was recently sentenced for money laundering and Roger Ver who pled guilty in 2002 for selling explosives on eBay. Ver eventually renounced his US citizenship (Popper, 2015) in attempt to avoid paying US taxes.

Although it is simple to point to specific case studies of deviancy among Bitcoin users, it is worth noting that Bitcoin has been associated with broad criminal trends as well. Hurlburt and Bojanova describe the criminal aspects of the Bitcoin subculture in this manner (2014, p.12):

The gambit of illicit activities associated with Bitcoin cover a wide range, including sales of illegal goods, drugs, and weapons; assassinations; Ponzi schemes; money laundering; illegal [Bitcoin] mining; unlawful gambling; and outright theft.

\footnotetext{
12 This study found that the National Post used Mr. Shrem as an authoritative source on Bitcoin on 8 June 2012, prior to his sentencing and later conviction.
} 
Bitcoin has also been associated with the online marketplace Silk Road (Gervais et al., 2014: 59), which sold drugs, weapons and other forms of contraband. Ross Ulbricht, a libertarian entrepreneur, was sentenced early in 2015 for having run Silk Road.

Sizeable thefts of Bitcoin have also occurred, but because of the lack of regulation inherent with Bitcoin these thefts are seldom if ever reversed. One heist from the OzCoin mining pool of 923 BTC (\$135,000 USD) (Gervais et al., 2014: 56). On another occasion, a thief or thieves made off with 43,000 BTC from a Bitcoin trading platform (Moore \& Christin, 2013: 25). On yet another occasion in 2011 a theft occurred in which thieves made off with about a half a million Bitcoin (Peck, 2012: 56). As a point of reference, these latter two examples would each be worth several million Canadian dollars' worth of funds lost as a result of criminal behavior. The lack of regulation, consumer protection and state oversight inherent to Bitcoin means that there are few sources to turn to in order when one hopes to resolve problems that arise with or through Bitcoin.

Bitcoin also has some unsavoury roots with assassinations (Hurlburt and Bojanova, 2014). One of the forerunners of the Bitcoin project, a crypto-anarchist and one-time Intel worker Jim Bell, envisioned an online gambling system where funds would be anonymously bet on the most accurate predictions of when assassinations of public figures occur. The idea was that as the betting pool increased in size, the financial incentive grew for the assassination to become realized. After attracting the attention of federal agents, Bell was raided by the Internal Revenue Service and arrested in 1997 (Peck, 2012: 52-3). In another unfortunate instance, Ross Ulbricht, the man introduced above as the kingpin of the Bitcoin-using Silk Road online contraband marketplace, had also hired assassins using Bitcoin to kill individuals that threatened his business (Greenberg, 2 Feb 2015). Evidently, as with cash, some find that Bitcoin is worth killing for. 
Bitcoin has also been questioned for its role in money laundering and other financial crimes. Statistical analyses of the public Bitcoin public transaction record or 'Blockchain' have demonstrated that large Bitcoin funds have been found funnelled into various smaller bitcoin addresses, resembling what appears to be obfuscation or an attempt at money laundering (Ron \& Shamir, 2013). In another criminal instance a National Science Foundation researcher in the United States received a government-wide suspension for misusing a government supercomputer to mine between $\$ 8000$ to $\$ 10000$ worth of Bitcoins before being caught (National Science Foundation, 2014). Lastly an emerging trend with Bitcoin is to use it for the purpose of extortion. 'Ransomware,' a type of malware, has recently become popular. This type of malicious software acts to restrict access to files or servers by encrypting them, thereby forcing a victim to pay a Bitcoin ransom in order to have the malicious software removed.

In summary, Bitcoin is a technology and monetary system that was initially devised by a loose-knit group of crypto-anarchists and free-market libertarian idealists. In such circles, state non-interference in economic activity is an ideal. This is because state interference is seen by these groups as imposition on, or factor working against, personal liberty. Inevitably, an environment that allows for statelessness raises the potential for lawlessness or criminality. Bitcoin was devised initially as the culmination of varying aspects of many digital currency projects ${ }^{13}$ by several different state-averting individuals, and has held tightly to this libertarian underpinning. This community continues to evolve, as do the varying purposes with which Bitcoin are used.

\footnotetext{
${ }^{13}$ Not all of which could be discussed due to spatial constraints.
} 


\subsection{Understanding Bitcoin}

Bitcoin exists as an emergent property of online social relations conducted by libertarian and anarcho-capitalist subgroups. It is an alternative currency in the sense that it runs parallel to state fiat currencies such as the Dollar, Euro or Ruble, but is distinctly virtual, having no tangible existence apart from what exists on digital storage mediums. With Bitcoin an arrangement of binary on a hard drive can theoretically contain vast stores of digital value, only so long as the binary is arranged in the proper sequence.

The role of the state in overseeing, producing and regulating money is deeply rooted in Western society. ${ }^{14}$ Chartalism ${ }^{15}$ was pioneered by George Friedrich Knapp (Ingham, 2004, p.47), who postulated that money is not a medium that arises from exchange but rather acts as a tool for settling debts, especially those levied by the state in the form of taxation. Chartalism supposes that money becomes valid and possesses value because it has this special relationship with the state (Ingham, 2004, p.48). That which is money then becomes limited and discounts a possibility for heterodoxy of money forms. Ingham (2004) is critical of many money theories.

Despite his criticality, Ingham (in Beckert, 2006, p.1228) draws most from the state theory of money proposed by Knapp and the belief of Weber that money is the result social struggle. Ingham $(2001 ; 2004)$ has posited that the primary purpose of money is to settle debt relations, primarily those that exist between a given state and the individuals subjected to its authority. Chartalism was proposed by Knapp, holding that money may take any form so long as it acts as the medium of tax payment deemed acceptable by the state (Graeber, 2011, p.47-8).

\footnotetext{
${ }^{14}$ However money is by no means exclusive to such social systems. As an extreme example, one finds that even the Democratic People's Republic of Korea has found a use for money.

${ }^{15}$ Deriving from the latin charta for 'token'.
} 
More than this, money in an explicitly social sense requires an analysis of explicitly societal factors. Ingham argues states do not need to create money, however the state legitimation of a money form is imperative in ensuring the value of a currency persists for any length of time (Ingham, 2001 in North, 2007, p.26). In other words, money has value only because a state says so. Bitcoin, straddling the line between overt acceptance and overt state naissance, is in a liminal, legal grey area that is in the process of being ironed out. This grey area allows us to test the Chartalist assertion that a state is required in order for currency value to perpetuate.

Primary sources on Bitcoin include a whitepaper from the creator of the technology himself, ${ }^{16}$ Satoshi Nakamoto. The paper Nakamoto wrote on this topic (2008b) highlights the basics of the Bitcoin payment system and digital protocol: a peer-to-peer payment system devoid of banking institutions. A compendium of correspondence between Nakamoto and early opensource developers, detractors and other interested parties during the development process has also been published (Champagne, 2014). Champagne (2014) detailing how this currency has origins in libertarian philosophy, provides primary texts from Nakamoto in the form of emails and forum posts. In it, Nakamoto (in Champagne, 2014) discusses technical concerns regarding protocol vulnerabilities, the Bitcoin 'mining' process, and adoption by users.

Because Bitcoin exists independently of the state and requires no intermediary institutions such as central banks (Nakamoto, 2008a), it relies instead upon a decentralized transaction ledger called the 'Blockchain.' The Blockchain is hosted globally on many computers and appended in unison to avoid tampering. Ensuring counterfeiting doesn't occur in a digital environment can be difficult. Rather than altruistically giving away free computer power for their service (Nakamoto,

\footnotetext{
${ }^{16}$ Presumed in most correspondence as a 'he,' although the name is often presumed to be a pseudonym. Nakamoto may be female or any number of individuals working together behind the sole moniker.
} 
2008b, p.4), miners verify transactions in ten minute chunks, called 'blocks,' and in doing so compete with one another for a reward in the form of a Bitcoin payout for their efforts (Champagne, 2014, p.10-11). Miners also accumulate fees payed to them in exchange for their service in processing transactions.

The bitcoin payout granted to miners diminishes with time (Antonopoulos, 2015), simulating a scarcity curve of precious metals such as gold or silver ${ }^{17}$. This means Bitcoin is a fundamentally deflationary currency (Castronova, 2014, p.163), as every four years the payout for verifying Bitcoin transactions decreases by half (Champagne, 2014, p.14-15). The final reward paid out to miners will occur around the year 2140, with the expectation that an increased use of the network means that there will be a rise in transaction fees to accumulate by miners, thereby perpetuating the economic incentive to continue verifying transactions.

Although Bitcoin miners verify transactions for profit, the network and technology itself is not owned or operated by anyone. In stark contrast to Canadian monetary, fiscal and economic policy, the Bitcoin protocol is theoretically capable of sustaining itself indefinitely without any human intervention.

Lastly, Bitcoin has led to the creation of a plethora of digital currency derivatives, each with its own distinct community and sense of purpose. As alluded to in the previous section, an 'Alt Coin' is a type of alternative currency based on the Bitcoin Blockchain (Antonopoulos, 2015, p.218). Because Bitcoin is an open-source project, anyone with the technological know-how is able to use the source code available online to create their own digital currency. These analogues, such as Dogecoin, Litecoin and Peercoin, are referred to by the Financial Post as "imitators" of

\footnotetext{
${ }^{17} \mathrm{~A}$ 'precious' metal is not herein meant to indicate that preciousness is an intrinsic quality or value but rather the idea of something being precious is a collective social attribution given to the bullion, coinage or raw materials.
} 
Bitcoin (Gokturk, 20 May 2014). The Financial Post also argues these digital currencies compete with one another for acceptance (Braga, 20 January 2014).$^{18}$ The nature of these currencies and the communities that use them demonstrate the extent with which the communities give rise to currency and that the currency in turn can propagate the community that uses it.

There is thus a social dimension inherent in money: currencies have differing communities and purposes even when there is a similar technological composition. For example, one article in the present study (Parkinson, 31 Jan 2014) mentions how the Dogecoin community was responsible for funding the two-man Jamaican bobsled team members Winston Watt and Marvin Dixon at the 2014 Winter Olympics in Sochi, Russia. On another occasion, 4000 Dogecoin users successfully collected funds for building a well in Tana, Kenya. This philanthropy staunchly contrasts the libertarian nature of Bitcoin and its proponents who seem more motivated by profit than building a sense of community.

\subsection{Making Payments in Bitcoin}

It is difficult to describe the entire inner workings of Bitcoin within the scope of a given thesis, as doing so would require explaining an entire system with which to conduct commerce. In the previous section, we've seen that Bitcoin has no central authority such as banks. This section will very briefly mention how one can use bitcoin to make day-to-day purchases without intermediary institutions.

\footnotetext{
${ }^{18}$ After having spent six months observing and participating in the Dogecoin community at Reddit.com, the idea of competition would likely be dismissed by most adherents of Dogecoin as a characteristic fundamentally opposed to what the currency stands for.
} 
First, one should recognize how conventional online payment systems work. Sending a payment to a merchant is a quite convoluted process with many back-end institutions that serve to avoid fraud and protect consumers. Attempting to send payments to a teller at a

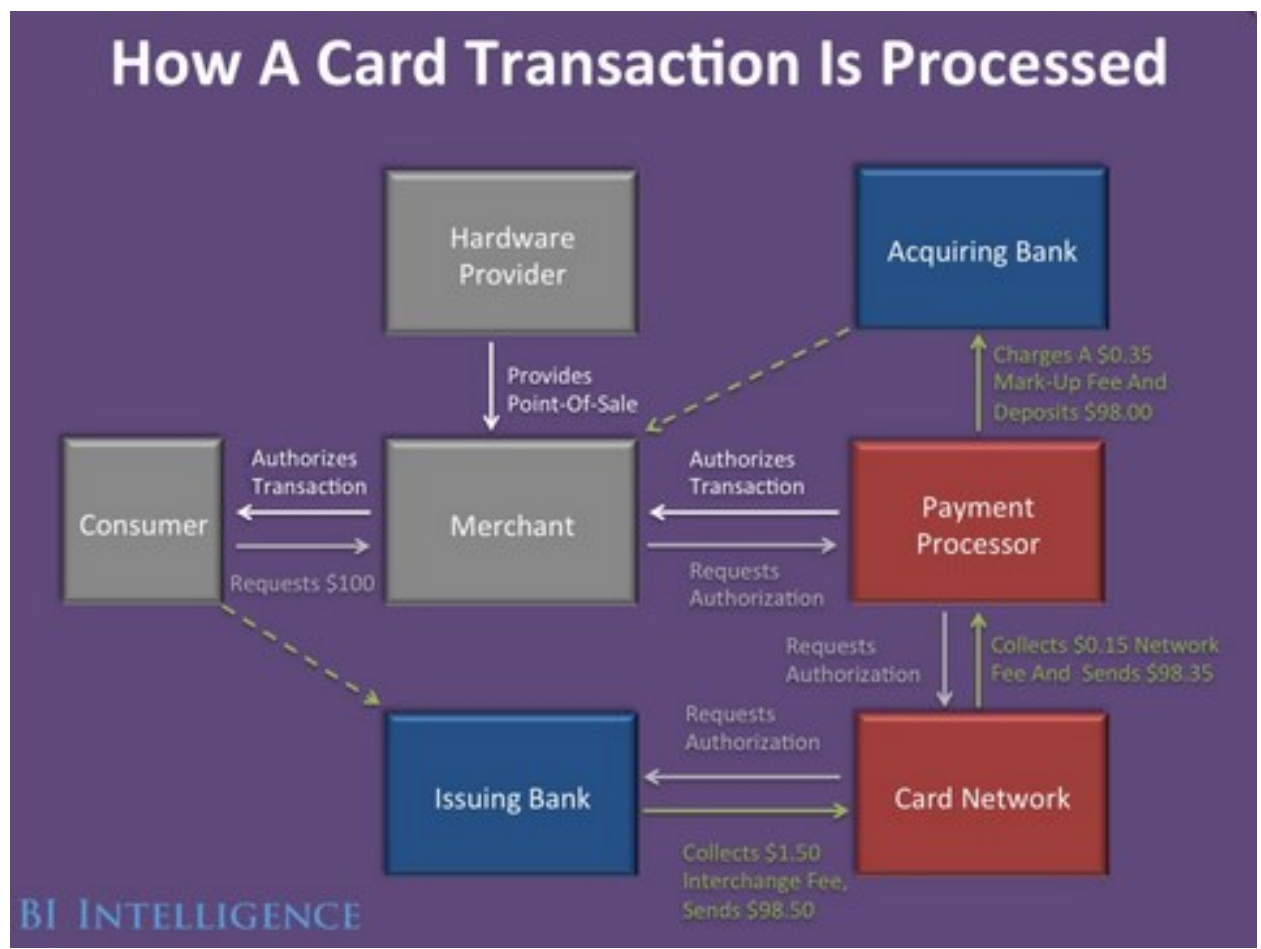

Illustration 1: How Credit Card transactions are processed (Heggestuen, 2014).

Shopper's Drug Mart or Burger King can be a complex and largely black-boxed process involving the sender's bank, the receiver's bank, and intermediaries such as the credit card networks Visa or Master Card. As can be seen in Illustration 1 above, these back-end institutions also acquire fees for their services (Heggestuen, 2014).

Bitcoin contrarily avoids the need for debit or credit card networks and banks by ensuring that each payment made between individuals or groups across the Bitcoin network is sent directly. Just as you would ask someone for their email address in order to send them an email, you would ask for a bitcoin address in order to send bitcoin (Antonopoulos, 2015, xix). The consumer sends funds to a merchant either by scanning the QR code that contains the merchant's bitcoin address, 
or by inputting the alphanumeric sequence allocated to the merchant's bitcoin address. An amount is selected by the sender and the funds are sent. The receiving party will have acknowledged the

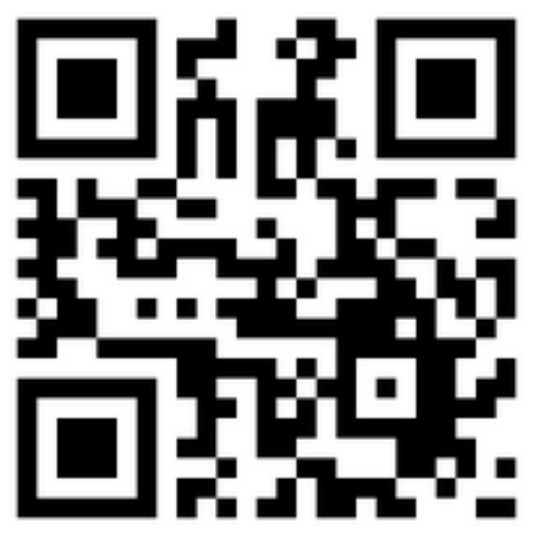

Illustration 2: Example of a $Q R$ code, a form of square-shaped barcode which contains digital information. The QR code above contains the URL of the Carleton University Department of Sociology and Anthropology website at https://carleton.ca/socanth/.

funds in their account within a few seconds to a few minutes and the transaction is verified by Bitcoin miners across the globe. The miners append this new transaction to the publically verifiable list of transactions on the Blockchain and the process is complete.

Bitcoin acts as both a peer-to-peer payment network and as a non-fiat digitized currency that can be transmitted across that network. Determining how much a given individual has in Bitcoin can be difficult, as it is possible for an individual to own many wallets, each containing a different, specified sum.

\subsection{Canadian Alternative Currencies}

There are many Canadian alternative currencies from the $20^{\text {th }}$ century onward that are important in demonstrating, through their use, the ways in which communities help to develop currencies. The subject is worthy of many books, however this section will limit itself to a select 
few alternative currencies: Canadian Tire 'Money,' the LETSystem, and 'altcoins' like Dogecoin and Litecoin.

Canadian Tire 'Money' ('CTM') is perhaps the most recognizable alternative currency used by Canadians. CTM is circulated when one makes a purchases at Canadian Tire store or gas station. CTM is a form of monetary 'scrip,' a substitute for legal tender. CTM doubles as a payment method and as a loyalty program in that the bills are given out at the check-out line and are redeemable upon re-entry. The denominations range from $\$ .05$ to $\$ 2$ and have for many decades sported the fictional character Sandy McTire. CTM first began in 1958 (Grady, 1999) after its invention by Murial Billes, the wife of Alfred Jackson Billes, who co-founded the Canadian Tire company with his brother John William in 1922. Reports of total circulated CTM vary, with estimates ranging from $\$ 30$ million in total circulation (Daniels, 2000) to over $\$ 100$ million worth dispensed per year (“Trail Times," 2006). Most estimates seem to converge at around $\$ 100$ million in total circulation (George-Cosh, 10 May 2012; CBC News, 24 Jan 2013).

Canadian Tire 'Money' is deeply rooted in Canadian national heritage. CTM has been decreasing in value with time, from a 5\% return on purchases in 1999 to just $0.4 \%$ in 2012 (Strauss, 2012). CTM has recently gone virtual with its rewards program introduced on 28 October 2014, which is shortly after the article collection period for this study (Kopun, 2014). Digital CTM offers ten times the rewards points to those who use the Canadian Tire Options MasterCard, in stores or in select locations (Kopun, 2014).

In exchange for the promise of increased rewards, Canadian Tire uses the spending habits of card users to determine the probability of whether or not a person will pay their bill on time and perform other analytics (Duhigg, 12 May 2009). CTM has recently been made available as $e$ - 
Canadian Tire 'Money'. The mobile app associated with the virtual alternative currency can make use of GPS to locate the nearest Canadian Tire store from one's home or current location (Canadian Tire Corporation, 2015a). The Canadian Tire Privacy Charter provides a list of other purposes provided by digital services such as e-Canadian Tire Money (Canadian Tire Corporation, 2015b): to provide data for purposes of tracking and analyzing purchases, analyzing shopping patterns, assess account activity, observe payment histories for marketing purposes, tracking and analyzing website usage to tailor advertisements, conducting statistical analyses and surveys, assessing the credit worthiness of patrons on an ongoing basis and collecting money owed to Canadian Tire. These analytics provide the company with data in return for customer use.

Increasingly virtual rewards systems are relied on to avoid the cost of producing a tangible scrip that costs money to produce and decays with time. As we have seen previously, Canadian Tire 'Money' in its current tangible form is still printed by the Canadian Bank Note Company (2015), the company tasked with producing Canadian polymer bank notes.

The social uses of CTM are numerous, and apart from its normative uses as a monetary substitute has also been used for some unconventional purposes. In Calgary, Alberta, a bar accepted CTM as payment in the 1990s (Myers, 2005), as did a bar in Cornwall, Ontario until 1998 (Grady, 1999). A West Edmonton liquor store also accepted CTM in exchange for purchases in 2006 (Trail Times, 2006).

CTM has also been used for philanthropic purposes. In August 2003, CTM was successfully collected to help raise funds for new ophthalmoscopes for Eagle Ridge Hospital (Coquitlam Now, 2003) and in 2007 donations of CTM were used to purchase over \$2,200 worth of sleeping bags, socks and blankets for homeless Vancouverites (Chan, 2007). 
Some uses of CTM have been downright unconventional. Toronto singer and songwriter Corin Raymond managed to fund the recording of his album Paper Nickels in 2011, through donations made in CTM, after discovering a studio that would accept it as a means of payment. The 25 kilograms of donated Canadian Tire bills accumulated for this purpose were just shy of $\$ 6,200$ (Canadian Broadcasting Corporation, 24 Jan 2013). Evidently, the supposed role of a currency, in theory, need not coincide with the ways in which they are socially utilized.

Canadian Tire 'Money' is of course just the tip of the alternative currency iceberg. The Local Exchange Trading System, more often known just as "LETS," is a communal exchange network that was invented in British Columbia by Michael Linton (North, 2007, p.85). It uses LETS Credits and a centralized ledger so that the local community can exchanges skills, goods and services while increasing and perpetuating community ties through economic networks. By keeping economics local, LETS keeps participants from having to worry about fluctuations in the external money supply, or the possibility of money 'fleeing' local communities.

Since its inception in 1983, LETS has been implemented at various times and in various places across Canada. By analyzing LETS in conjunction with another 'community currency' called HOURS (Raddon, 2003), the LETSystem in Toronto was the basis of some contemporary sociological fieldwork. Raddon (2003) noticed that as people within the LETS network become more acquainted, the system had an ability to induce reverse-bartering among adherents, whereby buyers would ask sellers to raise their price while sellers, having been acquainted with the buyers, were reluctant to do so. LETS demonstrates a hybrid system of bartering and the form of reciprocal indebtedness Marcel Mauss ${ }^{19}$ (2011) regards as the economic basis of gift economies.

\footnotetext{
${ }^{19}$ For more on this, see Chapter 3: Review of Literature.
} 
We are often used to thinking of money, and its manifestation in currency, as monolithic in nature. What the above instances have shown is that people imbue currencies with a sense of purpose or utility depending on a number of factors. For a given technical, historical, social and geographic climate a currency may adapt to the social conditions in varying ways, thus producing a distinct and unique form of money.

\subsection{Remarks}

It is in a given community that a currency is imbued with a sense of moral expectations and a purpose. It is also how a community views the money it uses that the process of value creation begins to take hold. These alternative currencies can be corporate, as with Canadian Tire 'Money,' community-based as with LETS or even global and technologically sophisticated as with Bitcoin and its analogue 'alt coins'.

Now that Bitcoin has been properly introduced, and some background information has been provided on other Canadian alternative currencies, the next chapter will discuss the literature reviewed for this study. 


\section{Chapter 3: Review of Literature}

The Sociology of Money is a desultory subfield. Although literature exists, it tends to be philosophically unfocussed. Each sociologist embarking on this path of scholarship appears to a greater or lesser degree to have his or her own epistemological interests and theoretical foundations, without drawing inspiration from the wider network of other contemporary economic sociologists. In other words although there are some scholars on the topic, there are very few schools of thought on the sociological analysis of money.

As Zelizer observes (1993, p.195), sociologists in this area confront a paradox: sociologists will acknowledge that money is a central element of modern society, yet has left it a relatively unanalyzed topic of scholarship. As Randall Collins suggests (1979, p.190), it is as if money has been ignored for simply not being 'sociological enough' for any serious, holistic or comprehensive inquiry. This chapter will show both the eminent works in this area as well as the breadth of the literature surrounding the thesis subject. This is accomplished by borrowing ideas from classical political economy, economic anthropology, economic sociology, contemporary debt theorists and research conducted on digital marketplaces and alternative currencies.

\subsection{Antiquity and Philosophical Precursors}

Some of the earliest contributions to the sociology of money rest in antiquity. Aristotle (1946, p.22-27) was one of the earliest monetary theorists whose work survives to this day. His contribution is fairly limited, having discussed the concept of currency and two forms of commodity use in just one chapter of The Politics. The two uses are the practical application of a commodity and the ability for it to be exchanged. Aristotle expands on this by using the example 
of a pair of shoes that can be either used as something to wear or exchanged for something else. This notion of use and exchange in relation to money was incorporated into the work of Adam Smith (2003, p.41) and, later, more comprehensively, by Karl Marx (1990; 1993). ${ }^{20}$

As an early Political Economist, Smith had rather simple assumptions about the human condition. His writing on international economics was heavily predisposed to issues of commodity scarcity, supply and demand. Smith was obsessed with currency defacement, a practice he was adamantly opposed to (see: Smith, 2007, p.36). Currency debasement occurs when a monarch, state authority or other issuer forges coins, generally of a silver or gold composition, diluting them with materials of lesser value in order to stretch the monetary supply past what could be maintained through natural reserves.

John Kenneth Galbraith (1975) uses currency devaluation in this manner, as the impetus for one of his publications on the subject of money. People choosing one currency over another often rests in the perception of value. This is known as Gresham's Law (North, 2010, p.38; Castronova, 2014, p.45), the economic postulation that "bad money drives out good." The Law is primarily concerned with commodity money, as when a value is stamped on coinage by the state. In cases where a state dilutes its gold with copper, the social valuation of the coin decreases. This is due to the generally held belief in gold's superior value relative to copper. Rather than any intrinsic difference between these ores, the differences that spawn this belief are simply historical and rest solely in social convention.

\footnotetext{
${ }^{20}$ This concept is referred to in Marx as use value and exchange value, or in Smith's Wealth of Nations as value in use or value in exchange. The concepts refer to the same general idea. Marx spends more time on the subject than Smith, and although the terms refer to the same inherent properties of commodities, the specificity of their usages are best understood within the broader argument of each writer.
} 
Smith (2007, p.156) was also upset at coin clipping, a practice he called 'evil,' where one would slice the edges off of a coin in order to melt these coin clippings into bullion, boosting exchange value over and above that which could be derived from the coinage alone. Smithian political economy centres on individuals pursuing self-interested ends, calculating costs and benefits and making free and rational choices (Martinelli \& Smelser, 1991, p.2). Weber supplemented this idea, stating it was not merely interest, but tradition and emotion that help drive individual behaviour (in Swedberg, 1998, p.35).

Smith (2007) has provided only few, limited contributions to money from what could be considered a sociological perspective. First, Smith (2007, p.28; p.258) and, later, David Ricardo (2004; p.6-7) would each pioneer a Labour Theory of Value that laid the foundation for Marx's critique of Capitalism (1990; 1991; 1992). Second, Smith's 'natural' propensity to truck and barter (2007) provided a precursor to what Marx would later develop into his concept of commodity fetishism (1990, p.165): the isolation and seeming invisibility of social relations required for the production of the commodities we consume. These concepts largely exist outside the purview of the present study, with any further contributions discussed in and through their relation to Marx, below.

\subsection{The Influence of Georg Simmel}

It is important to discuss the role Georg Simmel had on Sociology with his Philosophy of Money (2004). Simmel is a controversial figure in the sub-field of economic sociology and continues to act as both the basis for contemporary academics and as a target for detractors. 
Simmel (2004, p.138) states money universally facilitates exchange by expressing the relative values of objects, quantifying their value through demand and ultimately arriving at economic values realised through exchange. ${ }^{21}$ But this understanding of value is tautological. As David Graeber notes (2001, p.35) this raises a problem for Simmel: if value is only realized through exchange, it can be difficult to understand why and how one values family heirlooms, which hold value in spite of circulation rather than through it. Simple circulation, insofar as it is to be understood here is that which can be found in Marx, namely, as the mechanism for the conversion of commodities into money and vice versa (Nicolaus, 1993, p.17). Simmel (2004, p.72) skirts around this logic by only going as far as saying value is a correlate of demand for objects that comprise the economy. This noticeably leaves out valuations of sentimental interest.

Simmel (2004) was reviewed by George Herbert Mead (1901, p.616-619) and Emile Durkheim (in Durkheim and Baehr, 1979, p.321-328). Mead (1901, p.618) wrote that for Simmel (2004) economic relations are based on a system of exchangeability and money is simply the relational entity that objectively describes standards of value between and among commodities. Zelizer (1993, p.196) wrote that for Simmel, money was liberating in the sense that social relations conducted through money can be conducted not on a traditional basis, but rather allows an individual to freely conduct business with whomever they desire. This view on personal liberty in commerce would later act as the basis for James Ferguson to charge that Simmel was a poster boy for free-market conservatives (Ferguson, 1988, p.504).

Durkheim said, of the Philosophy of Money, that it lacked academic rigor (Durkheim and Baehr, 1979, p.326) and charged that Simmel put the book together without accuracy or evidence.

\footnotetext{
${ }^{21}$ Which is curious, because Simmel also states that the question of what compromises value is ultimately unanswerable (2004, p.64).
} 
Durkheim also noted (1979, p.326-7) that Simmel had failed to distinguish between paper or "fiduciary"22 money and coinage. Durkheim's vitriol escalated to stating the latter half of Simmel's book was methodologically imprecise and presented in an illogical manner (Durkheim \& Baehr, 1979). This critique of Durkheim stems from Simmel's curious choice of abstaining entirely from academic referencing: Simmel (2004) chose to include zero bibliographic entries with no footnotes or endnotes.

Taking this into consideration, the ideas of Simmel are often convoluted. It is through the various interpretations of Simmel that his ideas become more immediately accessible. In the equation that follows, commodities or 'goods' are represented on the left side of the equation, with money to the right (Altmann, 1994, p.133-134). What this accomplishes is to demonstrate how a commodity and its monetary equivalent can have overall social significance:

$$
\text { [1] } \quad \mathrm{g}=\frac{\mathrm{m}}{\mathrm{M}}
$$

Let us use this by applying it to an example. With apples, $g$ represents a single apple whose value is to be realized in exchange and $m$ represents the amount of money exchanged for it. $G$ represents the total number of apples in the society where the exchange occurs, and $M$ is the total sum of money in that same society. Money for Simmel makes sense of how we attribute value to the world around us by bridging the gap between individual actions and overarching societal phenomena; individual acts of exchange can according to Simmel help explain overall societal demand. This is

\footnotetext{
${ }^{22}$ Fiduciary coming from the Latin fiducia meaning trust, this form of money is based in the confidence required in accepting its value as a means of exchange between people. In contemporary society this distinction may not seem quite so apparent. However as we saw in the first chapter, bank notes or 'bills' were often issued as promissory notes by banking institutions in place of tangible assets kept safely in the bank's reserve. Failing to distinguish between notes and coinage at this time period would be an oversight akin to conflating debit card use and cash in a contemporary analysis.
} 
perhaps the single greatest contribution Simmel offers us through his fog of unnecessary convolution.

The contemporary view of Simmel has remained fairly negative. As we have seen among Emile Durkheim (1979), James Ferguson (1988) and David Graeber (2001) offering everything from critique to vitriol. Some academics, such as Karen Ho (2009, p.186-7) in her ethnography of Wall Street, cite Simmel (2004) simply to distance themselves from his ideas. Ho was opposed to the view of Simmel $(2009$, p.187) that stocks can be understood through innate properties of money, choosing rather to see stocks and the stock market as "cultural formations and social relations" existing in historical contexts. Although these theoretical underpinnings are correct, Ho (2009) fails to acknowledge the contribution of Marx in her ethnographic work, which is not only limiting but ultimately baffling given the nature of Wall Street.

No survey of Simmel's work is truly complete without making note of Dodd (2012a; 2012b), who frequently espouses an orthodox hermeneutic of the Philosophy of Money. Dodd (2014) has recently published a book to this effect. One can only fathom that Simmel is still used because he was one of the first social scientists to offer a social rather than economic account of money. More contemporary social theories of money are presented below.

\subsection{Gift Economies and Simple Societies}

In addition to Georg Simmel, Marcel Mauss (2011) has also been influential to modern sociological money theory. Mauss is important for having been the progenitor of Economic Anthropology through his seminal work The Gift. Mauss followed in the academic tradition of his uncle, Emile Durkheim, and, for the reasons mentioned in the previous section, either chose not to read Simmel or chose not to incorporate Simmel into his work. 
Economic Anthropology is a field that attempts to understand human economic action by reducing exchange to its broadest elements in terms of history or culture. This field of research builds upon the work of Marcel Mauss and his concept of reciprocity. In time and with the help of Louis Althusser (Graeber, 2001, p.24), more legitimated and flexible terms focusing around the 'mode of production' were made available to the discipline. Although Marx was predisposed with "Capitalism," this form of thinking allowed for anthropological Marxism to rise, a requisite for understanding exploitation outside of Capitalism and into different societies and cultural contexts. The Maussian school of thought, although it focusses on exchange, compliments the Marxist conception of production in such a way that we can better understand our own monetary system, our own forms of exchange and ultimately the manner with which money operates in our society.

Mauss (2011) borrowed from ethnographic reports available at the time of his writing to contrast the gift-giving practices among Kwakiutl in the Pacific Northwest of North America and Maori societies in Polynesia. Mauss used what he termed a potlatch (Mauss, 2011, p.4) to describe a set of gift-giving practices that exist cross-culturally, formulating a system of reciprocity and informal debt relations in simple societies. Potlatch originated as a Chinook term meaning to nourish or consume (Mauss, 2011, p.4-5), but is used by Mauss as a term describing a set of rituals that oblige gift giving, even among rivals, who were obligated to partake in reciprocation. Mauss noticed this phenomenon was cross-cultural, and that these obligations when they exist are religious and moral in nature (Mauss, 2011, p.5). This provided a more generalized understanding of gift-giving economies and reciprocity (Sahlins, 1972, p.154); the main purpose of the exposition was to understand exchange through how one experiences it, whether through separate acts of giving, receiving, or repayment. 
Mauss (2011, p.10) worked toward a general theory of obligation. This was accomplished through questioning the forms of social contract that were so persistent at the time of his writing (2011, p.1-2). The emphasis Mauss places on contracts would later lead Sahlins (1972, p.154) to conclude that Mauss was using The Gift as a subtle tool to critique Hobbesian Social Contract Theory.

This is important because Marcel Mauss (2011, p.3) argues the first individuals represented in simple societies were clans, tribes and families, contrary to Thomas Hobbes and Adam Smith (Graeber, 2001, p.153). These men argued the first contracts were between individuals, rather than groups existing to ensure adherence to vested economic or political obligations (Graeber, 2001, p.153). In contrast to Hobbes, Mauss did not rationalize peace through strictly political terms (Sahlins, 1972, p.169); rather he saw peace as the by-product of holding up social structures through alliances and solidarity. This is relevant to understanding money as a cultural artifact. Hobbes and Smith were a product of their age, deriving assumptions of money and 'human nature' from their own historical and cultural vantage points. ${ }^{23}$ The advent of economic anthropology, with Mauss, has been effective in allowing us to question how we view money and has given us the opportunity to understand economic exchanges cross-culturally.

Mauss was correct in asserting how the moral and religious compulsion to give is a good starting point for understanding modern contractual relations. We find this such compulsions everywhere in our own society, both benign and potentially problematic, from the simple to the heavily institutionalized. For example obligated reciprocation can be found as the apex of our most important holiday Christmas. As well, failing to send a birthday card to someone who sent one to

\footnotetext{
${ }^{23}$ One cannot truly escape doing this in matters of scholarship or in other aspects of daily life.
} 
you would be highly taboo. The moral compulsion upholds the contractual obligation. However the difference between an obligation and a debt is that the latter can be quantified, and in order to do this we need money (Graeber, 2011, p.21). We happen to find something similar with monetary transactions as one is obligated to pay their debts either through a moral compulsion, the threat of reprimand or a mix of both. Car payments and mortgages work on the principal that a fair exchange occurs when one pays the agreed amount in exchange for the use of either a good or service. ${ }^{24}$ The institutional monetary concerns of a materialistic society are borne out by the punishments for failing to meet one's obligation to reciprocate like the repossession of property or the lowering of one's credit rating.

\subsection{Capitalist Societies and Marxian Contributions}

As hinted at above, Marx made important contributions to understanding money from a sociological perspective. The work of Georg Wilhelm Hegel (1977) is not often used by contemporary Sociologists, however he is worthy of brief mention as a necessary precursor to understanding the dialectical methods of Karl Marx. Because Marx (1990) relies so heavily on this method to explain the process of Capital and therefore the monetary system that underlies it, a brief mention of that process follows.

Hegel (1977) is perhaps best known to sociologists for his work in laying the foundation of a triadic dialectical relationship of thesis, antithesis and synthesis as a means of resolving

\footnotetext{
${ }^{24}$ Some subgroups use this principle of compulsion against the system when a service is granted before the obligation to pay arises. For example, a group of university and college graduates on the social networking website Reddit are organizing a mass collective default to forego their student loan payments at https://www.reddit.com/r/studentloandefaulters, as education is intangible and therefore cannot be repossessed. This plays on the oft cited adage that if you owe the bank a small sum, the bank effectively owns you. But if you owe the bank an astronomical sum, you effectively own the bank.
} 
intellectual propositions (Hegel, 1977). As a rather armchair method of understanding the world that meant little by way of changing things, Marx (1978, p.109-125) felt that Hegelian dialectics failed to address human alienation through labour. Marx observed that the capitalist system is a set of dialectical, not causal, relations; socioeconomic systems are thought of in terms of processes.

In the postface to the second edition of the first volume of Das Kapital, Marx (1990, p.102) concludes that although he uses dialectics in his economic analyses, his method is the exact opposite of Hegel. Understanding Marx through a dialectical method allows a reader to conceptualize our economic system as both a process and a series of relations between commodities and money. ${ }^{25}$

Let us attempt to do justice to this line of thought by considering dialectics in and through its application to economic phenomena. Dialectics do not help to rationalize economic processes as distinct and separate pieces, but rather as a totality, structured around a mode of production (Mandel, 1990, p.18). Issues of an economic nature are, in this way, processes rather than as causal connections.

Marx wrote in the mid- $19^{\text {th }}$ century, and it is fair to ask if these theorizations are still relevant. It is still correct to think of the idea of money in the terms proposed by Marx. Money has differed in form or substance constantly through time, but the underlying need for money in our present social circumstance has not.

When reading both Adam Smith and the later Karl Marx, one finds that Marx accepts much of what Smith wrote (Harvey, 2010, p.5). The ways these writers differ is mainly that the view of capitalism offered by Marx filled in gaps and explained the theoretical contradictions of Smith,

\footnotetext{
${ }^{25}$ As well as class relations that arise organically from his line of argumentation.
} 
either leading him to different conclusions (Harvey, 2010, p.5) or in order to define his own concepts (Harvey, 2013, p.92). For example, Marx (1990, p.125-177) adopts the ideas of use value and exchange value from Smith, but supplemented these with a third aspect: value, creating a tripartite dialectical relation inherent within a given commodity. This demonstrates the inherent connectedness between the use value of a given commodity, its exchange value and its value. Value for Marx is socially necessary labour time (Marx, 1990, p.433-435). Marx added the idea of social necessity to his definition of value in order to distinguish his theorization from the political economist and moral philosopher David Ricardo (2004, p.7), who posited that value rests in human labour itself, irrespective of how that labour is used in creating a commodity. ${ }^{26}$ David Harvey (2010, p.23) provides a diagram of the dialectical relationship between value, use value and exchange value:

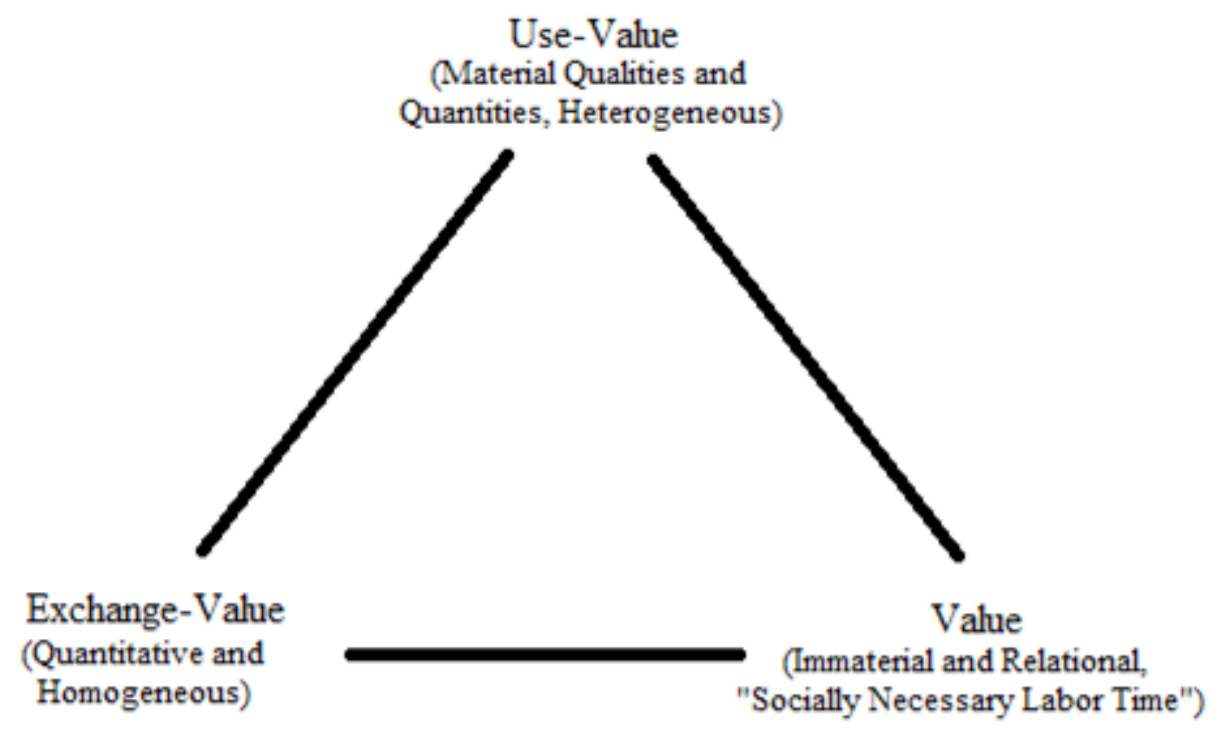

Illustration 3: Dialectical relationship between use value, value and exchange value in Das Kapital; Harvey (2010, p.11).

\footnotetext{
${ }^{26}$ The difference between Marx on the one hand and Ricardo and Smith on the other is that a labour theory of value that does not incorporate social necessity raises a problem (Harvey, 2010, p.20), that the time required to create a commodity has little or no bearing on its market value. Marx unlike Ricardo incorporates this into his theorizations.
} 
In this way we find the economics of Marx, incorporating the production process into how we valuate commodities. Let us use a book as an example. A book can be enjoyed or 'used' as a commodity. This is its use value. It may also be exchanged for another commodity or for currency, the value of which is called its exchange value.

These forms of value are related, but not often directly proportional to one another. By sticking with this example of a book, we find that its value as a commodity incorporates not only the finished product itself but also its binding glue, the paper, the ink, the labour expended in chopping the lumber, and so on. This form of thinking was borrowed from Smith (2007, p.8-9) who used it describe the deceptively simple process of pin manufacture and its many constituent labour contributions. These aspects of socially-imbued value are found in every commodity manufactured within a capitalist system.

Marx in his first volume of Das Kapital (1990) delegates the concept of money to a single chapter, choosing never to deviate from gold. His analysis of money as an index of all commodities or as "a universal measure of value" (1990, p.188) is right in a general sense, but his reliance on gold acts as constraint in attempting to understand the complexities of $21^{\text {st }}$ century finance, to say nothing of a world of point reward cards, debit machines and PayPal. Marxist perspectives of money that rely on the Labour Theory of Value still exist to this day as one of the many distinct factions of scholarship within the Sociology of Money (see: Lapavitsas, 2005 for one such example).

Currencies are generally propagated on the state level. Marx leaves the specifics of state money out of his theorization to address Capitalism as a transnational system of labour exploitation. This was done for no reason other than to simplify his analyses $(1990, \mathrm{p} .188)$. It is 
not until the second volume of Capital that Marx finds firm ground on which to analyze some of the more inherent contradictions in Capitalism (see footnote in Marx, 1992, p.391); it is here that money plays a primary factor in three circulation stages: money capital, productive capital based on labour and commodity capital. These three forms of capital comprise the totality known as industrial capital (Marx, 1992, p.132-133). Perhaps most importantly for the present research, Marx recognizes the flow of capital occurs in and through a transference of value that necessitates the use of a money form (1992, p.133):

The circuit of capital proceeds normally only as long as its various phases pass into each other without delay. If capital comes to a standstill in the first phase, M-C, money capital forms into a hoard; if this happens in the production phase, the means of production cease to function, and labour-power remains unoccupied; if in the last phase, C'-M', unsaleable stocks of commodities obstruct the flow of circulation.

David Harvey (1990; 2013, p.51) recognizes this passage in Marx as having particular importance for his own work in what he calls 'time-space compression.' This demonstrates that capital faces the possibility of slowdown within its three circuits of capital, greatly affecting a consumer society predicated on monetary velocity. Slowing or halting the exchange of capital can have far reaching implications, as the ways in which individuals engage with the socially-constructed money form will always have the potential to disturb, hinder or altogether halt capital processes through various forms of non-violent collective social action.

The social implications of halting the dialectic cycles of capital provides some insight into an idea initially discussed in his first volume: that of Say's Law. Economist Jean-Baptiste Say argued the uninterrupted exchange of commodities for money and vice-versa creates a perpetual market, as sales are so rapidly turned into purchases and vice versa (Say, 2001 [1834], p.56). As every sale is a purchase and every purchase is a sale, Say (2001) held that there can never be a 
crisis of overproduction in capitalism (Harvey, 2010, p.65). Marx objected to this line of thinking, as there is nothing compelling a person to exchange their money for commodities should they altogether choose to abstain from purchasing (Marx, 1990, p.208-9). Just such a problem would constitute what John Maynard Keynes would later call a 'Liquidity Trap,' the dynamics of which he discussed in the 1930s (Keynes, 2008). A liquidity trap occurs when monetary policy breaks down because interest rates are close to zero (Krugman, 1998). In simpler terms, people are choosing to hoard money rather than spending it (Krugman, 1998, p.148). Ever since the popularity of Keynes, proponents of his ideas and neoclassical economists have been arguing over whether the state can and should regulate economic activity ever since (Berger, 1991, p.108).

\subsection{The Formalist vs. Substantivist Debate}

It is necessary, if only briefly, to discuss a formative debate in the field between formalism and substantivism, with which the present thesis and its subject matter are situated. Discussions regarding socio-anthropological conceptions of value, although they may have moved past this debate, have been in the historical shadow of it ever since.

In effect, both the terms 'formalism' and 'substantivism' were coined by Canadian multidisciplinarian Karl Polanyi (1957). The debate was started by Scott Cook (Isaac, 2005, p.18-19) by his characterization that formalists saw the economic differences between Western and primitive societies as being a matter of degree, while substantivists that saw market activity as being of one kind. While formalists were more inclined toward abstractions, scientific in outlook, mathematically inclined and deductive in their reasoning, substantivists, known pejoratively by Cook (1966, as cited in Isaac, 2005, 19-20) as 'romanticists,' chose to view money inductively, 
contextually and with a humanistic outlook. In many ways this genre of debate exists in the social sciences to this day with few signs of abating.

Polanyi was a substantivist (Maucourant and Plociniczak, 2013, p.514), preferring Aristotelian ideas concerning household money over the attempts of Adam Smith to reduce value to a set of definitive utilitarian principles (Hann \& Hart, 2011, p.57). This can be implied by the central thesis Polanyi embraces in his book, that self-adjusting markets cannot last for long without annihilating what constitutes all that is human society; self-adjusting free markets destroy humanity and risk reducing civilization to nothing more than a 'wilderness' (Polanyi, 2001 [1944], p.3; Martinelli \& Smelser, 1991, p.21).

Formalism is the second such class of thought. Polanyi (1957, p.244) recognized that the term 'economy' was really comprised of two conflated meanings, a 'substantive' and a 'formal' meaning. The substantive meaning relates to individuals in economic relation to those around them, whereas the formal meaning refers to the act of economizing: the former idea resting in the realm of factual information and the latter resting in logic (Polanyi, 1957). Polanyi noticed that these two concepts had nothing in common, but sociologists such as Durkheim, Weber and Parsons, had failed to distinguish between these ideas in their own analyses (1957, p.244). Polanyi excuses Marshall, Pareto and Durkheim due to their 'layman' status in economic matters. Weber and Parsons, although they did economic work, devoted no scholarship toward an investigation of the term 'economics' itself. These jabs over the usage of the word 'economics' are semantic in the most literal sense.

A formalist approach to economic anthropology and, by extension, economic sociology would be that which emphasizes the universal claims of neoclassical economics. Such claims have 
already been seen above through Adam Smith, as with innate propensity of humans to barter (2003, p.23). Substantivism was championed by Polanyi (1957). Substantivism looks at economics through the material circumstances of markets and the social conditions that give rise to them (Hann \& Hart, 2011, p.56-57). This was a rather important development over Adam Smith who envisioned markets as being the result of the natural laws of economics, irrespective of their historical and social circumstances (Martinelli \& Smelser, 1991, p.3).

In the aftermath, formalism continued to live on as New Institutional Economics (NIE) (Hann \& Hart, 2011, p.97-98), an attempt to keep the supposedly scientific universal ideas of neoclassical economics. Isaac (2005) argues that formalists won the debate over substantivists. In actuality, victory in philosophical matters are difficult if not impossible to declare and can most often be determined only through a mixture of time and retrospection.

Supposing we consider again the methodological distinction between formalism and substantivism posited by Cook (1966) above, one can clearly see that both methods of inquiry lead to important contributions to the field. Devoting time to squabbling rather than the pursuit of knowledge, makes any victory here at least undeclared and at most Pyrrhic. The present study recognizes this in its use of both a qualitative and quantitative component, refusing to militantly lean on either side.

\subsection{The Sociology of Debt}

In the last few years, following the recent housing bubble and global financial crisis, sociologists have invested time into understanding debt relations as a phenomenon resting between individuals, between classes, between social groups and on a national level. Although the 
epistemological foundations of the work, in this area, stem from one or more of the areas mentioned above, writers of various types have uniformly recognized the direct and indirect dangers to human welfare that indebtedness poses. Understanding debt relations, within a Canadian context, is becoming increasingly pressing. Although money is often abstract, our relation to it affects the ways in which we think and act. This is why understanding money helps us realize the ways in which indebtedness can constrain thought and autonomy.

Karl Marx discusses the concept of credit in his third volume of Das Kapital (1991, p.52543), but contributions in this area benefit more greatly from a reading of more recent publications by Graeber (2011) and Lazzarato (2012). Lazzarato (2012, p.37-88) discusses debt by incorporating Foucauldian and Nietzschian theorizations with a Marxist backbone to create what he deems a "Genealogy of Debt". Lazzarato devotes time to look specifically at the debtor-creditor relation as a manifestation of power. He does this by drawing mainly on Foucault's Birth of Biopolitics (Lazzarato, 2012, p.89-91; cf. Foucault, 2008). For Foucault power was inextricably linked with knowledge in a non-static relationship (Foucault, 1990, p.99); power relations are subject to changes in history. This power relationship intensifies exploitation and domination by removing distinctions between workers, the unemployed, retirees, welfare recipients and so on (Lazzarato, 2012, p.7). ${ }^{27}$ This financial power relation is then seen to prolong and expand neoliberalism (Lazzarato, 2012, p.26-7).

This, of course, is a pertinent area of concern for Canadians, within our own neoliberal social context. Household and student debt have been expanding considerably over the last few decades, affecting millions of Canadians. The ratio of Canadian household debt to personal

\footnotetext{
${ }^{27}$ Lazzarato makes this claim of debt broadly in order to simplify his analyses; the quantitative extent to which an individual is in debt seems to matter less to him than the fact that one happens to be engaged in the debtor-creditor relationship in the first place.
} 
disposable income in 1980 was $66 \%$, yet has risen past $150 \%$ in 2011 (Chawla \& Uppal, 23 March 2012). The increase in debt also indicates an increase in the number of debtor-creditor relationships, which Lazzarato (2012) would argue indicate the emergence of a new form of class division between those with power via debt issuance and those who have no power and must be subordinate through credit. Fifty percent of all bachelor's graduates leave school with an average of $\$ 26,000$ in student loan debt (Statistics Canada, 14 Nov 2014). This is a phenomenon that disproportionately affects Canadian females, who surpass males in post-secondary enrolment (Statistics Canada, 25 Nov 2014).

Supposing that poverty is an undesirable state to be in, debt must be seen as that which exacerbates this undesirability. Consider again that the constraints placed on human existence by a lack of capital are manifested outwardly in appearance and health. Debt also acts as a means with which to constrain possibilities in life, such as social mobility. Ferguson (2008; as cited in Graeber, 2011) argues that poverty is caused by a lack of credit extended to the poor. Contrary to Ferguson, Graeber (2011) argues that poverty is often exacerbated by debt relations that are manifested through credit relations. Debt should be cautiously observed for its potential in causing harm and negative social outcomes.

Graeber (2011) challenges the 'myth of barter' championed by Adam Smith (2003), in which barter ${ }^{28}$ was the means of commodity exchange in archaic societies before the advent of money. Smith states the social relations between individuals was the realization of the innate tendency of humans to barter one thing for another (Smith, 2003, p.23). Graeber (2011) categorically refuses the arguments and evidence provided by Smith by citing historical evidence

\footnotetext{
${ }^{28}$ The etymology of the term barter stems from the old French 'Barater' meaning to cheat or deceive. The term Truck and Barter can still be found in the French language through use of the word "troc".
} 
contrary to Smith's narrative. Graeber (2001) also argues societies operate on systems of reciprocation akin to the ideas posited by Marcel Mauss rather than abstract evocations of general human propensities. Reciprocation, where one receives a gift and is expected to return something of equal or greater value later on, creates social relations in the form of alliances and obligations (Graeber, 2001).

Debt relations bring into question the origin of money through barter. This is elaborated on by Max Weber (1999, p.76-77) who argued that in agrarian environments fellow members of a society did not trade with the intention of obtaining profit, as no such motivation for profit even exists within such societal contexts. The difference then between barter and gift exchange as a basis for money, according to Graeber (2001), is in part the lapse of time involved in the process. As social hierarchies grew out of agricultural societies, generosity was often extended by 'chiefs' (Harman, 2008, p.15) as a means of ensuring social cohesion; food, tools weapons and ornaments would be extended in this manner. Such exchanges could hardly be seen as self-interested barter, as the exchange upheld societal customs and ensured survival.

Although barter demands an exchange in person, debt relations involve a broader temporal element. Contemporarily we find this in loan repayment where sums of money are paid back with interest only after time has elapsed. How one conceptualizes one or the other history of money lays as the basis for understanding the forms of social relations inherent in, and manifested between, each party in an exchange (see Graeber, 2001, p.27-8).

This obligation to pay debt is what Graeber uses as the foundation for his work on the history of debt. As Lazzarato argues (2012, p.89), obligations of this nature are also the basis for neoliberal exploitation through the formation of class divisions between debtors and creditors. The 
power dynamics inherent to these debt relationships manifest in various forms, existing not only between individuals, but an indebtedness that subsumes groups, institutions or, as is the with Greece today, entire nations. ${ }^{29}$ The result is then that the concept of money instills or propagates these power dynamics in our society, resulting in positive social outcomes for a few and negative social outcomes for the many. The crux of this power, contemporarily speaking, is manifested within the perception we have of money itself.

\subsection{Alternative Currencies and Digital Economies}

This brings us to the importance of contemporary alternative currencies and where they fit into this framework. To recall that which was stated above, alternative currencies are currencies that exist alongside or in opposition to a dominant national or multinational ${ }^{30}$ currency systems. Alternative currencies have a very unique role to play in attempting to understand money and the ways in which people use it.

Some Sociologists have recognized that currencies are not always a monolithic, state-run enterprise. Rather a multiplicity of monies exist at different times and places (Zelizer, 1993, p.198): stores, businesses or organizations can and have issued their own tokens, notes or privately issued coins. Both state fiat currency and alternative forms of currency as facilitators of exchange are similar in their ability to transfer value. This holds true so long as the value exchanged and the medium of choice is mutually agreed-upon by the parties involved. As money requires multiple

\footnotetext{
${ }^{29}$ Greece is not an example used by Lazzaratto, but as of writing can act as a contemporary case where his theorizations can be adequately applied.

${ }^{30}$ The most notable example of a multinational currency is probably the Euro. However in some ways American Dollars also work as an example, having also been adopted in countries like Ecuador.
} 
parties to operate, it cannot by design exist independently of social action: money requires people to function and is a uniquely social phenomenon.

There is a paucity of literature on alternative currencies from a social science perspective (Werner, 2009). It should be recognized that alternative currencies take many forms and fit the social context that allows for their existence. Historical examples of alternative currencies have been cigarettes, stamps, baseball cards or even subway tokens (Zelizer, 1993, p.198). When material arises, on the topic of alternative currencies, it often explicates a single alternative currency, such as Bitcoin, as if in a vacuum and discuss the situatedness of a currency within the wider social context.

Peter North (2007) has on the other hand written about alternative currencies in a more general sense by entertaining information on many alternative currencies including the Local Exchange Trading System (LETS), the Talentum and Kör projects in Hungary, Green Dollars in New Zealand and various barter networks in Argentina. North has also written (North, 2010) on how to successively implement an alternative currency that operates in contrast to normative staterun or transnational currency systems. These contributions are some of the few examples we have by social scientists on alternative currencies, providing an adequate foundation with which to conduct further scholarship.

Lehdonvirta and Castronova (2014) co-wrote on digital payment systems, such as Bitcoin, as well as in-game currencies and virtual currencies of varying purpose, style and dynamic. These authors also provide contributions in the field separately. For example Castronova (2014) writes on how to ensure scarcity in maintained in digital environments ${ }^{31}$ by game developers and details

\footnotetext{
${ }^{31}$ Which becomes a surprisingly difficult problem, as by its very nature digital information is easily divisible.
} 
the social implications of some video game currencies, such as the ISK currency in Eve Online and Linden Dollars within Second Life. Both currencies are "real-world" in that they can be purchased from game publishers or by exchange rate services indexed to the value of fiat currencies such as our own (Castronova, 2014, p.23-24, p.78; Lehdonvirta \& Castronova, 2014, p.95). What should catch attention is that these currencies require no additional labour expenditure to create tangible money in exchange. The potential for profit grounded in infinitely replicable digital commodities opens up new interpretations of the Labour Theory of Value.

\subsection{Bitcoin as a Social Construction}

In the last few pages, it has been taken for granted what it means for something to be 'socially constructed.' The ways in which Bitcoin has been viewed by the Canadian populace has been contingent on the knowledge made available on it, in this sense constructing it.

Berger and Luckmann (1967, p.24; Berger, 1990) argue that knowledge is part of daily life and activity. Knowledge is that which exists at a social level but makes sense on a personal level (1967, p.18). Berger and Luckmann mentioned that the habitualization of people to new ideas or new things is peacefully possible so long as shifts in thought can occur so as to incorporate novel ideas, technologies or concepts into pre-existing institutions.

Habituation requires an element of knowledge. For example, finding $\$ 5$ in the pocket of one's winter jacket can make one happy. If left undiscovered the banknote's existence is indistinguishable from its absence, at least from one's personal point of view. It is in the knowledge of the bill's existence that it becomes a socially actionable entity. 
This works for ideas as well as material goods. In a democratic society the knowledge of policies, ideas and government action allow for the construction of a currency. This element of knowledge is not new, per se: short sellers in $18^{\text {th }}$ century Amsterdam used to intentionally spread negative rumors to drive down share prices of the Dutch East India Company (Ferguson, 2008, p.138). This demonstrates that the belief people hold in a stock is often more vital in perpetuating the stock's value than how a company or commodity is actually faring in the marketplace. Franklin Roosevelt drew the link between collective social belief and economic stability when he asserted in 1933 that all Americans have to fear is "fear itself" (Ferguson, 2008, p.160). The dissemination of knowledge allows a valuation process to occur. It is for this reason that media reports become so vital in understanding social policy regarding Bitcoin.

The term 'social construction' is fluid and used in a rather loose sense to indicate institutions are not given but rather exist as a result of social factors (Swedberg, 1993, xix). For example money can change according to context or change in its uses given certain populations (Zelizer, 1993). This is why subcultures or distinct groups can incorporate, introduce and operate their own distinct forms of commodity currency, as with cigarettes in prison or beaver pelts in early modern Canada. Monetary value can only be mutually negotiated between parties in circumstances that allow for it. This means money rests in social perceptions, nesting in temporal, spatial, geographic and often technological circumstances that can accommodate it. Max Weber $(1999$, p.75) wrote that exchange using currency requires a temporal element, as acceptability is contingent that belief will hold true over time. It is as Wimpy from Popeye often said, "I'll gladly pay you Tuesday for a hamburger today." The entire loan repayment system that underlies our society rests in this contextual dynamic. 


\subsection{Review}

The last few pages have demonstrated many of the ways that money and the value that underlies it act as a human creation. This has required making use of scholarship on alternative currencies and a system of social theories that originate with various authors. Contemporarily, many sociologists of money are writing parallel to one another but in philosophical solitude. As such the theories presented above are notably diverse, having looked at Marx, Simmel, Mauss, Graeber, Castronova and Lehdonvirta, Dodd, Ingham and Lazzarato among others. The true breadth of knowledge available on this topic expands past that which has been herein presented. The true extent of the ideas on money as a social entity spans several centuries over several continents; a tradition of literature so vast that no single chapter can truly do it justice. 


\section{Chapter 4: Methods of the Present Study}

\subsection{Study Layout and Design}

The present study was conducted using a mixed method, two-stage approach. This study makes use of online news publications using a six-stage thematic analysis. The present study makes use of all national-level coverage for three Canadian publications on Bitcoin prior to 24 September 2014, the point at which data for this study had been collected. Following this, a quantitative content analysis was performed on the dataset incorporating the themes generated in the initial thematic stage. This second stage made use of generated textual frequencies of thematic content to determine narratives and trends by publication. Statistical elements such as a factor analysis were also performed to determine if any latent themes arose from the data.

The thematic analysis was conducted using a mix of both latent and semantic codes, allowing for surface-level trends to appear as well as allowing for a more in-depth analysis of narratives that lack an overt nature (Appendix D). Each of the 166 articles had been read and understood to ensure that the contents of the dataset had been appropriately represented in this paper. Of the 166 pieces analyzed, 93 were from the National Post and the Financial Post paper it purchased in 1998. 42 were from the CBC News website, and 31 were from the Globe and Mail. At the outset, there was an expectation that the three sources would differ in terms of content and journalistic focus. Of the 166 articles a random subsample of 36 articles were selected for the initial thematic analysis, utilizing twelve articles from each of the three main sources, allowing for an in-depth look of articles made within the context of the broader picture of Bitcoin media exposure in Canada. By analyzing Bitcoin, in this way, a thematic analysis was capable of 
assessing the role the media plays as a facilitator of, or hindrance to, Canadian Bitcoin adoption as well as state actions, motivations and intentions surrounding digital currencies in Canada.

As this is an under-researched area, the intended application of this method was to provide a rich description of the data set to better determine the most predominant and relevant themes surrounding Bitcoin in online media publications. This study is primarily inductive in that it incorporates many unique journalistic perspectives. This was the best means available with which to understand the role the state has played in facilitating a social acclimatization to Bitcoin. Although this was done thematically, this study was theory-driven. Some of the theory described in a previous chapter was used as the guide with which to engage in the codification process and to address the research question. Bitcoin is a new technology, with no online media publications from the CBC, Globe and Mail or National Post appearing before 2012, despite the technology having been released in 2009 .

This is a unique opportunity to understand the social construction of money and with which to understand Bitcoin not as a monolithic entity but as an ongoing process. The data were understood within the context of the three-stage media reporting model consistent with Vigna and Casey (2015, p.3), who argue that press publications and media coverage of Bitcoin over the period analyzed in this study involve three temporally and mutually distinct classifications: (1) articles about the relationship Bitcoin had in facilitating commerce on the now defunct online Silk Road drug marketplace, (2) articles primarily focussed on price volatility and use of the word 'bubble' to describe Bitcoin in an economic context and (3) the collapse of the Mt. Gox Bitcoin exchange and the fallout that such an event had on the press, thus spawning a considerable amount of negative press. 
The analysis of the data had been completed before Vigna and Casey had published (2015), however this study agrees with their general assertion, with only the slight addition of (4) benign articles of general Canadian interest and (5) publications concerning tax season, especially the 2014 tax season. The similarity between Vigna and Casey (2015) and the present temporal classifications demonstrate the reliability as well as overt systemic nature of the reporting styles.

\subsection{Data}

Articles were retrieved using the search functions of each respective online publication. Every national-level article containing the term "Bitcoin" was extracted and used in this analysis

(see Appendices A, B and C). This analysis excludes the online videos published on Bitcoin also available through these data collection methods. This data collection strategy required going through freely available publications from these news websites. "Paywalls" which exist to limit content retrieval were bypassed for the Globe and Mail and the National Post by intermittently removing HTTP cookies. The complete data set used in this study spans 898 days, from 12 August 2012 to 24 September 2014, capturing the extent of national level syndications from the first publication available on Bitcoin to the day preceding data collection.

\subsection{Thematic Analysis}

This project commenced with a thematic analysis of the amassed articles. A constructionist thematic analysis was conducted using the six-stage methodological design for thematic analyses devised by Braun and Clarke (2006): familiarization with the data, generating initial codes, searching for themes, reviewing themes, defining and naming themes, and producing the report. 
This analysis was performed on a subset of the initial data set. A random number generator was used to select the subsample of 36 articles for this thematic component.

After having been familiarized with the data, 40 preliminary codes were mapped onto each of the 36 articles, which were then understood within their respective temporal contexts along the general three-stage timeline found to be consistent with Vigna and Casey (2015). The nature of these codes, as with their codification criteria were all stored within a methods codebook (see Appendices D and E). All initial codes were generated in an ongoing, iterative process. This was done by placing each article on a timeline, from August 2012 to September 2014, which could then be contrasted with temporally relevant data such as exchange rates to comprehend value narratives, or whether articles appear at periods relevant to monetary concerns, such as tax season or Christmas. Once placed in historical context, differences in content were also compared across publications.

The news publications were assessed for their use of particular words and concepts, the institutions mentioned, the types of individuals interviewed or cited, the types of social groups discussed and any mention of various Canadian institutions such as the Bank of Canada or the Canada Revenue Agency. Codification of data was decidedly diverse in order to capture as many aspects of Bitcoin reporting as possible (Appendix D).

A sub-theme is that which shares the same concept as a theme, yet are more specific in nature. As such, sub-themes often relate to a single element within a theme. Sub-themes were formed by analyzing their relation to main themes within the data set. These themes were preliminary and as such not every code was incorporated into the preliminary thematic map. Indeed some elements, although present within the works, had no direct relation to other themes within 
the context of the present methodological framework. The data had been simplified into five main, preliminary themes: institutions, authority, legal or criminal activity, value and lastly taxation.

After an initial thematic map had been generated, each element in the dataset was reread in order to ensure the themes were accurate. Reconceptualization was necessary in simplifying the map and incorporating a few minor revisions. The idea behind this is that the simplification and reduction of themes facilitates more directed textual analyses (see Braun \& Clarke, 2006, p.9091). Several minor revisions were made to the initial thematic map to produce a final map (Illustration 4). These minor revisions including expanding "Bank of Canada" into "Canadian Institutions", as the usage of these institutions, although deployed in varying contexts, were thematically linked. The evocations of 'crime' in relation to Bitcoin within these articles were simplified as existing in either of just two categories: laundering and terrorist financing ${ }^{32}$, or other criminal activities. The biggest change between the first and second map was the conceptualization of 'value,' which was understated in the initial theorizations.

\footnotetext{
32 These two forms of crime are important to the Canadian financial crime agency FINTRAC. More on this later.
} 


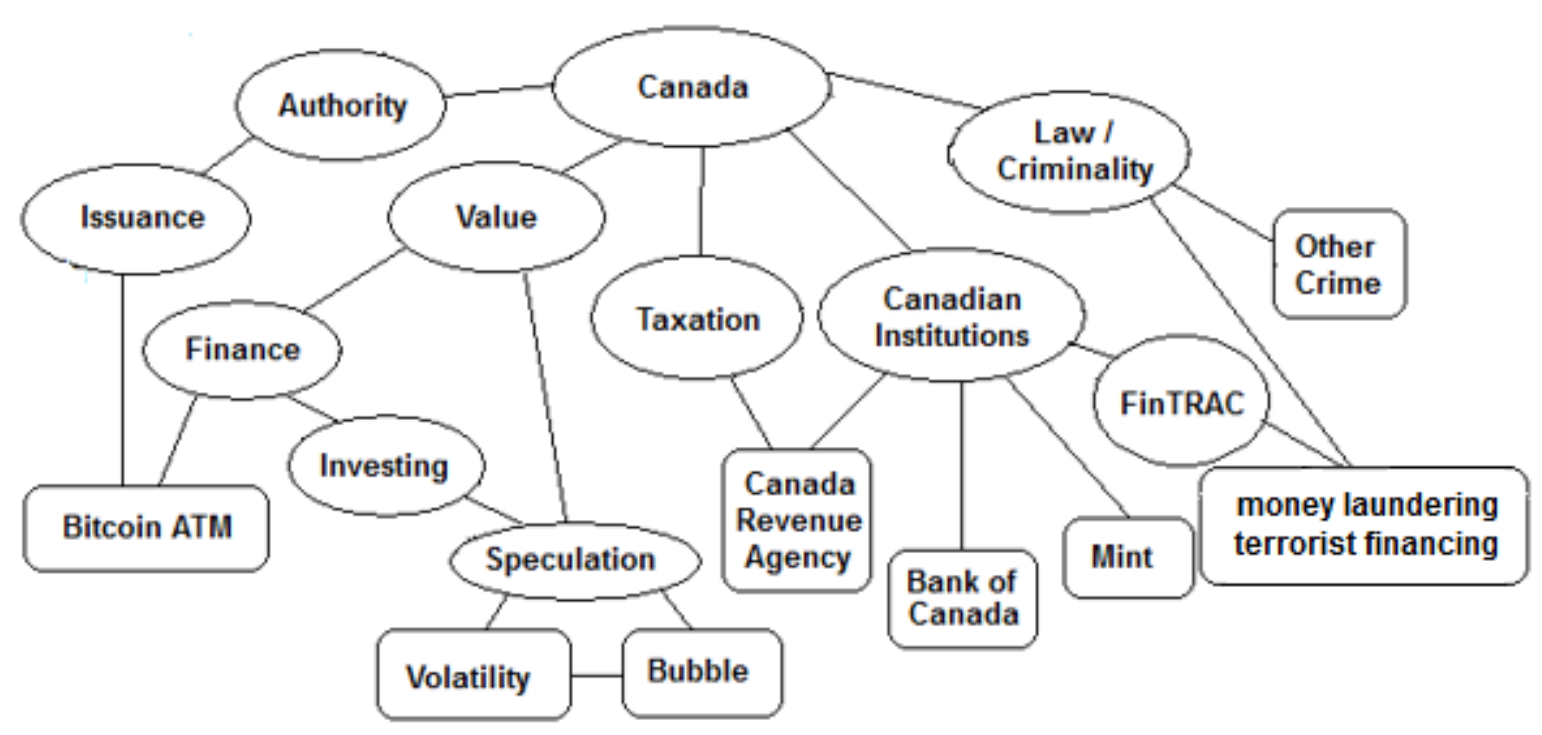

Illustration 4: Thematic map, indicating main thematic branches of property, taxation, crime, finance and the Bank of Canada.

\subsection{Content Analysis}

Words associated with a given theme, as determined by their contextual usage within the thematic analysis, were used to generate quantitative indicators for each article. The five themes were registered by overall usage of key words associated with the theme. As an example, articles containing either of the terms "Bank" or "Mint" were assessed as having content related to the Institutions theme. This process was iterated for each of the themes across each of the 166 articles.

In so doing, a quantitative dataset was created, whereby each row was populated by each of the articles $(n=166)$ and columns were present containing interval variables for each of the five themes, as well as variables concerning the length of each article in words, the news source with which the piece originated, and the total number of unique words found within each piece, and the total number of themes for each given news piece.

Once a dataset was made, statistical analyses were conducted on the dataset to determine if any overt trends existed within or between each of the three news sources. An exploratory factor 
analysis was undertaken with this dataset with the factors having been created using the main five keywords words attributable to each of the themes, then used as a quantitative variable with which to appropriately apply the statistical technique. An analysis of Scree Plot data was used to determine the appropriate number of factors for this project. Using the Keiser Rule, Eigenvalues below 1.0 were left out of this analysis. Factor loadings below 0.5 for each latent factor were left out of the factoring process. The result was a two factor solution which were orthogonally rotated using the VARIMAX function in SAS. The communality factors for each variable were also generated for the purposes of this study.

\subsection{Justification of Methods}

Pairing a Social Constructionist theoretical viewpoint with quantitative methodologies is an unconventional sociological undertaking. Very briefly, this section will discuss a justification for having done so in the present study. By providing a heterodoxical methodological approach it is hoped that more information is made available to future researchers, should they choose to pursue this area further and in a manner suited to their specific social scientific and methodological inclinations.

This study is principled on the axiom that the accumulation of knowledge need not be pigeon-holed by a stringent set of orthodox methods in order to find meaning in the social world. This study has attempted to specialize each research question (see: Castronova, 2014; Ingham, 2001; North, 2007) to a method best suited to addressing the respective issue raised by each social scientist. Rather than choosing to limit the study to a single method and risk applying methods broadly and in a manner unsuited to each given stipulation, the Bitcoin-related news articles in the present study have been analyzed using multiple methods to categorically address each stipulation using a method best suited to each specific research question. 
Even the most scientific matter is, by virtue of the interpretation and social context of its underpinning, a social construction (Hacking, 1999). This is not however to say that the means of recognizing that constructed social realities be assessed using only a specific, orthodox worldview or set of methods. In the present study, quantitative elements were chosen to investigate whether any trends existed over and above that which was found in the thematic analysis for one of the three research questions investigated. As all data sources were extensively analyzed prior to any quantitative analyses, this study was principled on qualitative, rather than quantitative, elements and recognizes that both have been beneficial in assessing the questions investigated in the present analysis. A factor analysis was appropriate for approaching the postulations of Edward Castronova (2014) about the factors underlying state tax consternation toward digital currencies while qualitative methods were appropriate in assessing the other two postulations regarding state monetary monopolies (Ingham, 2001) and the characteristics that allow for the longevity of an alternative currency (North, 2007), by virtue of the questions proposed by each respective researcher.

Any discussion concerning a theory of methodologies exists outside the scope of the present piece and is recognized as being best suited to philosophers of social science. The present study simply intends to provide a sufficient breadth into this new area of sociological investigation so that future research may be aided by that which has herein been provided.

\subsection{Recapitulation}

This study was conducted using a mixed methods design conducted in two parts. The first part was qualitative, the second, based on the findings and direction of the first, was quantitative. 
A thematic analysis was conducted on 36 randomly selected articles coded with forty initial themes. These themes were then reduced to five principal themes through an iterative coding process. A quantitative content analysis was then conducted on the data set, utilizing the full set of 166 articles by using an exploratory factor analysis. 


\section{Chapter 5: Analysis of Data}

\subsection{Preliminary Remarks}

This chapter provides a substantive answer to the thesis question concerning state and media differences concerning Bitcoin, as well as the process by which the Canadian government has attempted to acclimatize Bitcoin to a Canadian social context, while preserving its interests by way of taxation and monetary surveillance activities. This is accomplished by the state by recognizing Bitcoin purchases as barter transactions. This chapter demonstrates this process by having accumulated data, both textual and statistical ${ }^{33}$.

In the first chapter, three propositions were introduced in accordance with the overarching thesis question and each will be analyzed in succession in the pages that follow. The first postulation to be discussed is the role the Canadian state has played in attempting to oversee and control Bitcoin by means of regulation and legal oversight. This will assess the postulation by Geoffrey Ingham (2001) that money requires a state monopoly in order to attain its value. This is done by understanding Bitcoin as a Canadian technology to be constructed and adapted to a Canadian social context.

This question relates to whether the social nature of money allows for value to proliferate effectively, in a multiplicity of forms or solely within a state-run monopolized totality. Evidence is presented from the accumulated online Canadian media publications and through recently

\footnotetext{
${ }^{33}$ Media sources have been utilized for this study. Some government documents, where appropriate, are also consulted. However, these consultations are limited and these additional sources are referenced solely for contextual or supplementary purposes. Canadian legal documents are not analyzed extensively, and the majority of the analysis is conducted in and through the media sources discussed in Chapter 4. For more information on the media sources used for the present study, please see Appendices A through C.
} 
proposed legislation. This evidence is used to argue that although a multiplicity of monetary forms exist within the Canadian state they can operate in unison. The Canadian state has moved to accommodate Bitcoin into the present legal framework consistent with current state objectives concerning technological competitiveness and crime prevention measures.

Second, this study tests whether the Canadian data coincides with the assertion made by Castronova (2014, p.207-209), namely that pseudonymous digital currencies, such as Bitcoin, cause problems for the state in auditing and imposing taxes. The analysis of latent factors between the variables is then used to shed light into the possible advancement or determent of Bitcoin adoption in accordance with the central thesis question. An analysis is conducted through the use of an exploratory factor analysis, with a two factor solution.

Lastly, the data used for this study compared and contrasted Bitcoin with a select number of other alternative currencies such as Dogecoin and Litecoin within the context of the news articles. These payment alternatives are contrasted for the purposes of testing a stipulation by North (2007, p.148), that alternative currencies exist and propagate in part by social networks of users existing in geographically dense areas. As these digital currencies exist independently of special constraints, it is argued this stipulation requires re-examination. North (2007) also argues alternative currency longevity and adoption can result from adherents accepting wages in that given alternative currency. This particular characteristic of currencies, as Lee and colleagues have asserted (as cited in North, 2007, p.176-7), act as a basis for constructing the socioeconomic relations that surround, oversee and formulate social and economic communities.

In effect, these postulations provide the grounds with which to assess the overall influence certain forms of media exposure can have on Bitcoin adoption nation-wide and the dynamics 
through which Bitcoin has been constructed by the state as an innovative technology in need of only light regulation.

\subsection{State Monetary Oversight}

Although all of the Canadian news sources, in this study, have mentioned illegal activity conducted in and through Bitcoin, much of the available socio-legal literature concerning Bitcoin rests in bills, legislation, federal agency mandates and contemporary senate hearings. Ingham (2001) is correct in his assertion that states use and legitimize money for the purpose of taxation. There is historical evidence that states facilitate the use of currencies by accepting tariffs imposed on them (Graeber, 2011). However this assertion is only partially complete.

If state acceptance is a prerequisite for monetary value (see Ingham, 2001 in North, 2007, p.26), this provides little help to those seeking to rationalize the ongoing non-zero exchange rate between Canadian dollars and bitcoin (BTC) on Canadian-run Bitcoin exchanges. Should Canadians find no value in Bitcoin, such exchange services would cease to exist. This, by its nature, indicates Bitcoin does hold value for Canadians, at least relative to Canadian money. This is strengthened by the fact that all three of the media sources used in this study have reported on the number of Bitcoin ATMs proliferating in Canada, with the news media eager to discuss the increasing number of shops and patrons willing to accept Bitcoin nation-wide.

The $\mathrm{CBC}$ has also provided indication that some Canadian firms are willing to pay wages in Bitcoin. This will be discussed in more detail later on. For now it should suffice to recognize that it is the populace, rather than the state, that truly dictates whether something has ongoing, socially-imbued value. 
As has been hinted, the above is not to suggest the state has no means, at its disposal, with which to determine the overall societal acceptance of a monetary system or its legitimization process. That which is an affront to the collective conscience of a society is that which we call criminal (Durkheim, 1972, p.123-4) and the state can, in some ways, guide the social perception of an entity, commodity, ideology or money by linking it to certain behaviours that run contrary to collective ideals. We find this to be true with Bitcoin. Of the 166 online publications analyzed, $50.5 \%$ of National Post publications, $32.2 \%$ of Globe and Mail publications and $57.1 \%$ of CBC publications have discussed the relation Bitcoin has to uses in crime and illegality. For the purposes of expanding on the aforementioned postulation by Geoffrey Ingham (2001), we shall limit the scope of this issue by focussing primarily on money laundering.

Money laundering is the act of disguising a source of money or assets derived from criminal activity (FINTRAC, 2015c). Laundering is not merely a Canadian issue, but a global one. Laundering has the potential power to fund criminal activities and facilitate corruption (FINTRAC, 2015c). This phenomenon has been associated with Bitcoin. The advent of digital money has made this particular type of criminal activity a recent topic of social scientific inquiry (Castronova, 2014, p.202-204). For example, by using the Bitcoin public transaction ledger, Ron and Shamir (2013) were able to isolate large transactions in the Blockchain and trace them through time in patterns consistent with money laundering. All transactions that occur on the Blockchain are anonymous in the sense that no names are attached to the sender or receiver, however because all transactions are publically available to any observer, tracing transaction origins can be accomplished simply by following the inputs and outputs of Bitcoin transactions over time. Launderers will swap bitcoins between locations, constantly, in order to disguise the origin of funds. However Ron and Shamir (2013) have demonstrated that persistence can overcome these attempts at obfuscation. 
Concerns over money laundering appear to be important to Western nations, worrying groups as diverse as US Senators to the German Federal Association of Digital Economy (Reid \& Harrigan, 2013). Recently, the Canadian government has released the Report of the Senate Standing Committee on Banking, Trade and Commerce on Digital Currencies (Canadian Senate, June 2015), which has highlighted the potential of Bitcoin to be used in money laundering or terrorist financing. This emphasis on laundering and terrorism, as will be discussed, remains an eminent interest to the current government yet has escaped the purview of the Canadian online news media almost entirely.

Ingham (2001, p.314), argues that, in regard to money laundering, a state has no need to inquire into whether money is 'dirty' or 'clean' in the paying of taxes. Yet in the last two years the Canadian government has demonstrated its intention to do just that by expanding the legislation that oversees the Financial Transactions and Reports Analysis Centre of Canada (henceforth just 'FINTRAC'), whose mandate is to combat money laundering and the financing of terrorism.

FINTRAC oversees what are called Money Services Businesses (MSBs). MSBs in Canada must register with FINTRAC if they deal in foreign exchanges, money transferring, cashing or selling money orders, traveller's cheques or similar payment methods. This oversight allows the government to monitor potential laundering or terrorist financing consistent with the FINTRAC mandate (FINTRAC, 2015b).

Bitcoin as a virtual currency will soon fall under the purview of the Proceeds of Crime (Money Laundering) and Terrorist Financing Act (PCMLTFA), which until this time has not required Bitcoin exchanges in Canada to register for MSB licenses (Ligaya, 5 Mar 2014). FINTRAC operates within the domain of the PCMLTFA and its associated regulations 
(FINTRAC, 2015a) and therefore changes to the PCMLTFA affect the mandate of the Agency. Such is the power of the state that some Canadian cryptographic exchange businesses such as QuadrigaCX have made sure to get an MSB license well in advance of any legal changes to avoid potential legal complications (Financial Post, 20 May 2014).

Historically the state has been the only game in town as far as currency is concerned. Bearing this in mind it is unsurprising that the Bitcoin legitimization process has led to the imposition of state authority. The Government of Canada began in 2014 through legal means to regulate Bitcoin and other digital currencies for the purposes of anti-money laundering and antiterrorism. In Part 6, Division 19 of Bill C-31, otherwise known as the Economic Action Plan 2014 Act (House of Commons, 11 Feb 2014), amendments were proposed to regulate digital currencies such as Bitcoin. The Proceeds of Crime (Money Laundering) and Terrorist Financing Act (Government of Canada, 23 June 2014) was successfully amended to fill in holes that existed in prior anti-money laundering legislation.

Despite these drastic changes to state power and oversight, these government actions have almost entirely been ignored within the media analyzed. Only two articles ( $1.2 \%$ of total analyzed) mentioned FINTRAC (Paris, 11 Feb 2014; Ligaya, 5 Mar 2014). None of the 31 articles from the Globe and Mail provided any mention of the agency in the timeframe analyzed for this study. There is reason to suspect with the data available that this gulf between the increase of the state security apparatus and the lack of discussion concerning it in the media is demonstrative of a separation between state and media interests over Bitcoin. 
The gulf between media reporting and state action is evidenced by the fact that, although the state considers laundering acceptable grounds for expanding state oversight, only six articles, within the entire corpus, tie Bitcoin to money laundering.

Media sources in early 2014 that mention FINTRAC only seek to regurgitate the mandate of the agency while providing little more than surface-level analyses of the agency or its actions. Terrorism, one of the principal concerns of FINTRAC, according to its mandate, only appears twice in the entire dataset of 166 news pieces (Hurtado and Sandler, 28 May 13; Kline, 9 May 14). Perplexingly, despite recent pushes by the Canadian federal government to expand powers of an agency explicitly purposed with fighting terrorist funding, mentions of terrorism in the media analyzed have only appeared within the context of the United States and provisions found in the Patriot Act.

The Economic Action Plan 2014 Act would impose wider state oversight of Bitcoin in order to bring Canada in line with international standards. Several of these provisions can also be found in Title III of the United States' Patriot Act, ${ }^{34}$ which, like Canada, is explicitly concerned with the financing of terrorism and money laundering. The proposed amendments to the PCMLTFA introduced in the Economic Action Plan 2014 Act seek to clarify that the monetary threshold needed to alert other government bodies to potential laundering or terrorist financing.

For example, the money transfer threshold that triggers suspicion among the Canadian federal government is currently set at $\$ 10,000$ in monetary transfers (Bronskill, 19 Oct 2014), a threshold also found specified in the United States Patriot Act. Title III Section 359 of the Patriot

\footnotetext{
${ }^{34}$ Title III: International Money Laundering Abatement and Financial Anti-Terrorism Act of 2001, the provision that itself contains 'terrorism' and 'money laundering,' the two main criminal narratives found in the mandate of FINTRAC in Canada.
} 
Act demands that American Money Service Businesses, as with Canadian Money Service Businesses, must report to FINCEN, ${ }^{35}$ the American equivalent to FINTRAC. These similarities between Canadian legislation and the Patriot Act are not merely coincidental. Peter McKay has demonstrated in testimony that Canada sought to ratify provisions on cybercrime in Bill C-13 consistent with those found in Europe, indicating that Canada is not new to borrowing legislation from allies on digital matters. ${ }^{36,37}$

The state has shown interest in regulating Bitcoin by using the pretext of terrorism and money laundering. However the $\mathrm{CBC}$, Globe and Mail and National Post have focused on different issues, primarily on the connection Bitcoin has to non-white collar crime. Each of the three sources have focussed far more attention to crimes such as hacking, fraud or the purchase of contraband substances than concerns raised by the state.

Contrary to the State Theory of Money (see: Knapp, 1924) which postulates that money has value in and through a government that oversees it, evidence indicates that Bitcoin value has been highest in times and places where state intervention was lowest. This is in stark contrast to expectation. Although in Canada there is expectation that transactions made in Bitcoin are reported as barter transactions on tax forms, the state presently does not accept Bitcoin as a direct means with which to pay taxes, having linked it and other cryptographic currencies as potential means with which to sponsor terrorism, launder money or partake in other nefarious activities.

\footnotetext{
35 The American equivalent to FINTRAC.

36 Standing Committee on Justice and Human Rights (May 1 2014) Number 21, 2nd Session, 41st Parliament. See Peter McKay's comments in response to Pierre Jacob on Page 8 concerning Bill C-13.

37 The FINTRAC website was updated on 2015-06-26, which had once indicated the agency "had close to 70" foreign information-sharing agreements to "over 90" foreign information-sharing agreement, demonstrating an international proliferation of anti-money laundering initiatives.
} 
As long as the state remains indifferent to an alternative currency or can view it as a potential taxable asset or commodity, the media analyzed indicates that value may self-perpetuate and a lack of state regulation can allow for monetary value to be upheld in alternative currencies. This requires perpetual use and mutual belief between exchangers of the alternative currency in question, as the perpetuation of monetary value is constituted by social relations (Lapavitsas, 2005) rather than by direct state imposition, however fierce the state efforts may be.

The postulation that state legitimation is a mandatory prerequisite for monetary value also falls flat in one other regard. Financial Post online publications support the idea that economic uncertainty, in Italy, Spain and Greece, have actually fuelled Bitcoin adoption (Financial Post, 8 June 2012), indicating that the legitimation of money means little in social climates where the state does not have its own socioeconomic affairs in order. More widely, the National Post has demonstrated particular pleasure in discussing economic instability as a facilitator to the adoption of Bitcoin, as was the case in 2013 when reporting that Bitcoin had an almost emancipatory power from traditional banks for the people in Cyprus (Kline, 1 November 2013).

In such scenarios state instability, irrespective of whether the state accepts a currency or not, can proliferate alternative currency use. Conversely economic revivals, such as those experienced in Argentina under the Kirchner administration, in the United Kingdom under 'New Labour,' as well as in New Zealand and Hungary, economic prosperity has succeeded in lowering the desire and use for alternative currencies (North, 2007, p.177). If it is argued that the state has ultimate authority over value, it needs to be recognized that ultimately it is the populace that upholds the state. All authority presiding over monetary value truly rests in how the people use and interpret it at an elementary level. 
The Canadian government has attempted to solidify an ongoing legitimizing process. This section has viewed the ways in which Bitcoin value has not only perpetuated but continues to be used as a medium of exchange in Canada in light of ongoing state legislation. Alternative currency value can proliferate irrespective of state function contrary to the State Theory of Money, but this is only possible in and through the perpetual exchange and mutual belief shared among the adherents of a currency. This holds true for Canadian Dollars, Bitcoin or any other form of currency.

In discussing this, we have also seen a divergence between state interests and that which has been reported by the media. Although the criminality of Bitcoin has been a key facet of all three media outlets in this study, the types of criminality discussed in the media differ from that discussed by the state.

\subsection{Analysis of Latent Factors}

An exploratory factor analysis was conducted on the six themes in order to provide insight into the more latent aspects of the data. The purpose of a factor analysis was to determine the extent to which the underlying motivations surrounding the online news reports meet the taxation postulations of Edward Castronova (2014). It is hoped that this may also provide some data for use in future theorization.

\begin{tabular}{|c|c|c|c|c|c|c|}
\hline \multirow{7}{*}{$\begin{array}{l}\text { Total Words } \\
\text { Institutions } \\
\text { Authority } \\
\text { Value } \\
\text { Crime } \\
\text { Taxation }\end{array}$} & Tot. Words & Institutions & Authority & Value & Crime & Taxation \\
\hline & -- & $0.373 \dagger$ & $0.540 \dagger$ & $0.425 \dagger$ & $0.328 \dagger$ & $0.229 * *$ \\
\hline & $0.373 \dagger$ & -- & $0.503 \dagger$ & $0.197^{*}$ & 0.115 & $0.170 *$ \\
\hline & $0.540 \dagger$ & $0.503 \dagger$ & -- & $0.281 \dagger$ & $0.352 \dagger$ & $0.260 \dagger$ \\
\hline & $0.425 \dagger$ & $0.197 *$ & $0.281 \dagger$ & -- & $0.162 *$ & $0.154 *$ \\
\hline & $0.328 \dagger$ & 0.115 & $0.352 \dagger$ & $0.162 *$ & -- & 0.054 \\
\hline & $0.229 * *$ & $0.170 *$ & $0.260 \dagger$ & $0.154 *$ & 0.054 & -- \\
\hline
\end{tabular}

Table 2: Correlation Matrix for the Two Factor Model 
There were several strong correlations between the themes used (Table 2). The use of institutions in the news publications such as banks, the Mint or government agencies like FINTRAC were strongly, positively correlated with authority $(\mathrm{r}=0.5, \mathrm{p}<.001)$, a theme tied to issues of monetary issuance, legitimacy or governance. Institutions were not significantly correlated with crime and only weakly correlated with the other thematic categories of value $(\mathrm{r}=0.197, \mathrm{p}<0.05)$ and taxation $(\mathrm{r}=0.17, \mathrm{p}<0.05)$. There were no negative correlations observed between any of the five themes used, indicating that frequently we find multiple themes used in conjunction with one another within a given article, an assessment that was corroborated by the adjoining qualitative data analysis. The extent to which any given correlation happens by chance can be determined by the level of significance found for each correlation in Table 2. The length of a piece in terms of the number of words it uses was significant among all themes, indicating intuitively that as the piece increases in length it is more likely to incorporate a given theme.

Although there was a strong correlation between authority and institutions, the link between authority and various forms of crime is only moderate in strength $(\mathrm{r}=0.35, \mathrm{p}<.001)$ and institutions lack a statistically significant relationship with crime. Taxation was a theme developed through the qualitative keywords found in the articles which, in turn, appear to represent the terminology and keywords used by the CRA (Canada Revenue Agency, 2014). Although the Canada Revenue Agency is concerned with the anonymity of Bitcoin and, even though it was postulated by Edward Castronova (2014) that anonymity would be a basis for state consternation regarding digital currencies, the present analysis found within the taxation theme that the anonymous nature of Bitcoin is not significantly correlated with state criminal concerns over things such as laundering, fraud, drugs, theft or hacking. 
Authority and value are correlated in a moderate, positive relationship $(r=0.28, \mathrm{p}<.001)$. This finding indicates the possibility of an association between governmentality, monetary issuance, and the state and publications that reference the value of Bitcoin. The data indicates that all themes are significantly correlated with value, however none quite as strongly as the association between the trend in Bitcoin value with article length $(\mathrm{r}=0.43, \mathrm{p}<.001)$.

There are some distinctions among the media sources. The economic component of Bitcoin just mentioned appears to have been of eminent interest to the National Post, which focused on the monetary value or volatility of Bitcoin more than either the CBC or Globe and Mail (Table 3). The monetary value of Bitcoin is nonetheless important for each source and can be found in roughly $80 \%$ of CBC and Globe and Mail articles and nearly $90 \%$ of National Post articles. Pieces written by the $\mathrm{CBC}$ were more likely than the National Post or Globe and Mail to discuss authority, perhaps tacitly hat-tipping its benefactors as a state-sponsored Crown Corporation. Another distinction is that the Globe and Mail did not to publish on Bitcoin at all until December 2013, over a full year after the other two sources. It was not the distinctions between reporting styles that should arrest one's attention, but rather the similarities:

\begin{tabular}{|c|c|c|c|c|c|c|}
\hline Theme & $\mathrm{CBC}$ & $\%$ & $\begin{array}{l}\text { Nat. } \\
\text { Post }\end{array}$ & $\%$ & $\begin{array}{c}\text { Globe } \\
\text { and Mail }\end{array}$ & $\%$ \\
\hline Institutions & 36 & $85.7 \%$ & 71 & $76.3 \%$ & 27 & $87.1 \%$ \\
\hline Authority & 35 & $83.3 \%$ & 75 & $80.6 \%$ & 23 & $74.2 \%$ \\
\hline Value & 33 & $78.6 \%$ & 81 & $87.1 \%$ & 25 & $80.6 \%$ \\
\hline Crime & 28 & $66.7 \%$ & 60 & $64.5 \%$ & 20 & $64.5 \%$ \\
\hline Taxation & 19 & $45.2 \%$ & 42 & $45.2 \%$ & 13 & $41.9 \%$ \\
\hline Total & 42 & & 93 & & 31 & \\
\hline Avg. Length & 550.9 & & 635.7 & & 740.9 & \\
\hline
\end{tabular}

Table 3: Frequency of Themes Used with prevalence (\%) indicated

There is considerable uniformity in the thematic usage of both crime and taxation between the three sources. Table 3 demonstrates that many similarities exist irrespective of the ideological or 
editorial distinctions that exist between the sources, with some exceptions. For example the National or Financial Post were less likely than its contemporaries to mention institutions, while the Globe and Mail are less likely to discuss sources of authority such as the government, banks or the use of the word legitimacy. Just shy of half of articles, irrespective of source, discuss concepts related to taxation.

Because Bitcoin has an ambiguous legal standing in Canada, articles concerning how one pays taxes for Bitcoin transactions appear from time to time. Although taxation provided the basis for some pieces, especially prior to tax season in both 2013 and 2014, it is curious that tax evasion has rarely been discussed anywhere as a penalty for failing to properly claim one's taxes. The types of crime mentioned in roughly two-thirds of articles, regardless of which publication, revolve around various property or digital crimes such as fraud in the form of pyramid or Ponzi schemes, Bitcoin purchases of drugs, acts of digital Bitcoin theft and hacking of various kinds and for various purposes. ${ }^{38}$ As discussed previously, money laundering appears at almost no point, and terrorism referenced even less still.

A two factor exploratory factor analysis was conducted to understand the underlying aspects of the data and to provide some further insight into the underlying variance structure of the variables. As a result of factors weighing too heavily on certain lone loadings, the interpretative value of the data was lessened when either orthogonal or oblique rotation methods were applied. As a result, findings were left unrotated for this analysis. Interval variables from factor-based scale indexes were used that incorporate five main words attributable to each of the five themes. This

\footnotetext{
${ }^{38}$ That which constitutes hacking is herein understood as computer related offenses under Section 342.1 of the Criminal Code of Canada: "unauthorized use of computer". It was presupposed in the coding stage that this is the definition used by the Canadian media sources in deploying the term, and this appears consistent with the contexts provided with its use. Hacking is a distinct offense from either fraud or theft and carries its own sentence.
} 
meant a given theme ranged from a minimum value of zero to a maximum value of five for each piece depending on whether none or all of the words connected to a given theme were used.

The number of articles for this exercise was 166 , incorporating each piece in the data set. Taxation and crime act as cross-loading items, appearing on both factors with a loading value with an absolute value greater than .6 (see Tabachnick \& Fidell, 2001). Although some researchers recommend dropping cross-loading factor items where both items appear at $\alpha=.5$ (Costello \& Osborne, 2005, p.4-5), these variables were retained for their analytical value.

\begin{tabular}{llccc} 
& Variables & $\mathrm{F}_{1}$ & $\mathrm{~F}_{2}$ & \\
(Lecturing) & (Administrative) & $\mathrm{h}^{2}$ \\
\hline $\mathrm{X}_{1}$ & Total Words & 0.802 & -0.091 & 0.652 \\
$\mathrm{X}_{2}$ & Institutions & 0.644 & 0.239 & 0.472 \\
$\mathrm{X}_{3}$ & Authority & 0.815 & -0.009 & 0.664 \\
$\mathrm{X}_{4}$ & Value & 0.571 & -0.039 & 0.328 \\
$\mathrm{X}_{5}$ & Crime & 0.501 & -0.667 & 0.695 \\
$\mathrm{X}_{6}$ & Taxation & 0.420 & 0.672 & 0.628 \\
& & & & \\
& Eigenvalues & 2.476 & 0.963 & \\
Percentage Explained & 41.3 & 16.1 &
\end{tabular}

Table 4: Principal Axis Factoring with Iterated Communalities

Eigenvalues indicate the variances of the factors. The eigenvalues demonstrate the strength of the first factor in relation to the second. The second eigenvalue $\left(\mathrm{F}_{2}\right.$ eigenvalue $\left.=0.96\right)$ was marginally less than 1 , the threshold with which analyses are generally conducted according to the Keiser rule (Kim \& Mueller, 1978, p.49). This factors had been retained for two reasons. The first is that this is the point at which eigenvalues 'elbow' in their cumulative explained variation and thus holds considerable analytical value. Secondly, a single factor solution provided few results of any analytical value, as the weight of the lone factor was placed relatively strongly among all of 
the themes, providing few points of interest. Retaining only a lone factor allowed for few meaningful results and provided no room for contrast.

The communality estimates $\left(\mathrm{h}^{2}\right)$ in Table 4 above indicate that the variance explained by the two extracted factors are above the generally-accepted 0.5 threshold. All but Value (0.33) and Institutions (0.47) provided estimates that failed to meet this criteria, both nonetheless providing strong correlations with at least one of the two factors. Several loadings are heavily weighted on the first common factor, indicating the strength between the variable concerning the total number of words used and the thematic use of Authority. The Authority theme encapsulates issues of monetary issuance, legitimacy, governance, the state, or instances where 'authority' itself is provided in relation to another entity.

This first factor loading $\left(\mathrm{F}_{1}\right)$ has been given the name, 'Lecturing,' for its heavy relatedness with authority and overall article length, with a moderate relation to institutions. Rather than state power being the subject of stub pieces or short online publications, this latent concept demonstrates the extent to which the importance of legitimate state power in monetary concerns is driven home through lengthier publications. Lesser contributions, to this factor, relate the concept of value, or the shaky monetary nature of Bitcoin, to institutions. As the monetary value of Bitcoin in the corpus is almost exclusively discussed in relation to its volatility and price fluctuations, one can determine that this financial speculative interest provides both grounds for lengthier articles and an important link to the interests of the state through its relation with the Authority theme. Institutions, having strong positive correlations not only with the Authority theme but also article length, in total words (Table 2), is intuitive in that these three variables in the form of factor loadings are all united under same latent Lecturing factor. 
The second factor loading $\left(\mathrm{F}_{2}\right)$ has been granted the name 'Administrative' for its relation between crime and taxation. As previously mentioned, crime and taxation hold a unique relationship within the dataset. This relationship is nowhere more evident than in the Administrative factor, where the latent component is positively correlated with Taxes and negatively correlated with Crime. Above, it was discussed that crime, although theoretically enhanced through the anonymity that Bitcoin upholds and the Canada Revenue Agency is concerned with, is shown through the Administrative factor that crime and anonymity, as found within the taxes theme, are in actuality distinct.

Anonymity can act as a point of contention for the Canadian state. To reiterate Edward Castronova on digital currencies (2014): a world with many virtual currencies can become problematic for states interested in collecting taxes. A plurality of digital money systems, each being anonymous, can become potentially problematic for the Canadian state as the cost of auditing would-be tax evaders outpaces the revenue that can be recovered by such attempts. It is therefore the case that the state has demonstrated its interest in regulating Bitcoin as a monetary system within Canadian borders and beyond through international agreements (Canadian Senate, June 2015). As mentioned previously, the Canadian government has demonstrated a desire to oversee Bitcoin for actions such as money laundering or terrorist financing. In light of the growing Canadian governmental oversight and intervention surrounding Bitcoin, the ways in which the online media continue to report on Bitcoin should act as the basis for future analyses. 


\subsection{A New Type of Canadian Alternative Currency}

Peter North (2007) describes a few notable characteristics of alternative currencies that allow for social longevity. Using Green Dollars as his example North (2007, p.147-8) argues some characteristics that make currencies successful are a "geographically dense" community of users as well as an environment in which salary payments are made in said currency (Lee et al. in North, 2007, p.176-7). Testing this assertion is possible by contrasting Bitcoin with other alternative currencies in Canada. North himself $(2007 ; 2010)$ looked at several alternative currencies such as LETS among others in his research. The present section will analyze Canadian Tire 'Money' and LETS, two alternative currencies previously introduced.

Information derived from the Canadian national media, namely the $\mathrm{CBC}$, Globe and Mail and the National Post were analyzed for manifest content to understand Bitcoin as a Canadian phenomenon and to analyze the overt comparisons made in the media between Bitcoin, Dogecoin and Gold, among other payment systems. The data analyzed for the purpose of this study indicates that the geographic density stipulation proposed by North $(2007, \mathrm{p} .148)$ is no longer a mandatory prerequisite for alternative currency longevity.

In stark contrast to both Canadian Tire 'Money' and LETS, Bitcoin has not traditionally been known for its connection with philanthropy. This could be due to the Bitcoin community's Libertarian nature and origin. Bitcoin in the CBC, Globe and Mail and National Post uniformly refrain from discussing any altruistic acts conducted with the currency. We find that Bitcoin has been contrasted in some news sources with other alternative currencies better known for their philanthropic dealings. In one piece, The Globe reports that although Bitcoin may be fine for drug deals or market speculation, Dogecoin fosters a community of digital philanthropists (Parkinson, 
31 Jan 2014) ${ }^{39}$. As previously mentioned Dogecoin was associated with funding the Jamaican Bobsled team as well as a well in Kenya. In one bizarre case the Dogecoin community also donated over \$55,000 worth of Dogecoin to fund NASCAR driver Josh Wise and his 'Dogecar' in 2014. Despite being technologically very comparable to Bitcoin, the communities surrounding these two currencies have become highly distinct.

Returning to the stipulation by Peter North (2007) that geographic density is an effective means with which to propagate an alternative currency, we find that this is made suspect with Bitcoin because of the socio-technical dynamics of the currency. Consider again the currencies introduced previously: LETS and Canadian Tire 'Money.' Unlike LETS, which requires in-person exchanges, and CTM which often necessitates in-person exchanges, Bitcoin has no direct face-toface element required. The specific alternative currencies Peter North (2007, p.147-8) was referencing with his geographic remark were LETS and Green Dollars, where alternative livelihoods were created around the currency initiative. This was appended with a mention that the survival value of an alternative currency also requires belief among its participants, as well as 'commitment-building mechanisms' (p.148), which can be described as dynamics through which communities and societies maintain themselves in and through prolonged alternative currency usage. Ease of access and ease of use aide in facilitating alternative currency use among community members.

We find some such community-building examples with Bitcoin. For example, Vancouver was cited by the $\mathrm{CBC}$ as being the first city to ever have a Bitcoin ATM (29 October 2013). These

\footnotetext{
${ }^{39}$ While Bitcoin proponents often view their currency in terms of American dollars or other fiat currencies, Dogecoin adherents often use the phrase "one Doge = one Doge" to demonstrate they feel it need not be comparable to denominations of other currencies. While Bitcoin had once described its value leading into 2014 as going "to the moon," Dogecoin has since appropriated this neologism in a laid back and joking manner. It has since been used in relation to Bitcoin only sardonically in 2015 in accordance with the currency's lackluster financial performance.
} 
Bitcoin ATMs are generally approached in the media with a benign curiosity or acknowledgement of potential, although the National Post has at one point found it expedient to discuss Bitcoin ATMs within the context of the now-defunct online drug marketplace Silk Road (Moss, 28 October 2013); the connection being hazy at best but portraying captivating content for would-be readers. The number of Bitcoin ATMs in Canada has proliferated to 12 as of August 2014, more than any other country and partly due to the manufacture of Bitcoin ATM devices by Ottawa-based company BitAccess (Pilieci, 31 August 2014). Contrary to the CBC and National Post, the role or very existence of Bitcoin ATMs has not been discussed in any of the twelve Globe and Mail articles used for qualitative analysis.

The potential uses of Bitcoin aide in understanding the broader social impact of the currency, as well as its possible tenure as an integrated aspect of Canadian finance. In an attempt to analyze the businesses, social groups and institutions associated with Bitcoin these concepts were coded for as part of the initial qualitative design of the present project. Naturally these groups were quite diverse in origin and purpose. Examples range from the now defunct Mt. Gox exchange service, the Winklevoss Bitcoin Trust and Bitcoin-accepting businesses such as fitness studios or Bitcoin ATM-hosting coffee shops.

One Canadian business, Structur3d Printing, in Waterloo, Ontario, has even been reported as paying employee salaries in Bitcoin for those who choose to receive it as an option, either wholly or in part (Kang, 16 September 2014). CBC News has also reported that employees from ten firms have signed up to receive wages in Bitcoin, with many more asking about it (CBC News, 1 September 2014). The payment of Bitcoin in exchange for human labour in Canada is an indicator, as Lee and colleagues previous mentioned (in North, 2007, p.176-7), that a currency has survival value in the society that has adopted it. 
By March 2014 the CBC had mentioned that Bitcoin was no longer merely transacted by "digital nerds and speculators," but was rather being used by "real businesses" with "real products" (Evans, 10 March 2014). Two months later the Financial Post had reported that Bitcoin was successfully implemented and accepted at restaurants, hair salons, hotels and other businesses nation-wide (Gokturk, 20 May 2014). This integration is required for an alternative currency to survive, with increased utility allowing for a positive feedback loop between store owners and purchasers, inevitably allowing for the full social integration of the currency. But this gives rise to the question of how such a broadly dispersed system of payment over such a wide geographic space, and with only 12 Bitcoin ATMs nation-wide, can continue to have value over such a broad landmass as Canada.

The postulation that currency requires geographic 'density' or a staunch adherence to an alternative currency within a localized area, is correct for tangible forms of currency that require direct, face-to-face exchanges in order to function. However with instances described from the Canadian media above, we find that North's idea concerning geography, namely that longevity is derived from constant personal exchanges, tangible locations and corporeal currency systems simply do not apply when superimposed on an intangible digital value transfer system. Single locations in isolation can still accept Bitcoin as an alternative to Canadian fiat currency and continue to function with minimal cost to either shopkeepers or users.

Bitcoin rests within both digital environments and in manifestly real ones. It is in this manner that an immaterial substance has shown to have real social consequences: Bitcoin may not require geographic density, but the concept of idealistic belief proposed by North remains: the value of Bitcoin as a currency, propagated through use in salons, grocery stores, at Canadian finance exchanges and at fitness studios do not presuppose that it cannot also be used for purchases 
online, a characteristic inherent to digital currencies but not shared by gold, LETS, or until recently Canadian Tire 'Money.' This means that geographic density of an alternative currency is not required due to the digital nature of Bitcoin.

\subsection{Summary}

The preceding pages have endeavored to respond to three postulations made by Geoffrey Ingham (2001; 2004), Edward Castronova (2014) and Peter North (2007), respectively. By responding to the postulation by Ingham that state acceptance is required as a prerequisite to monetary value, it has been discussed that overt state acceptance of a currency need not concern monetary value so long as the people in a society uphold the social perception of value, irrespective of the state and its actions. It has also been argued that this does not require, necessitate or imply either prohibition or overt permissibility of a currency by the state: there is therefore a middle-way for currencies like Bitcoin to exist as a means of accruing taxes by the state without having to overtly accept it as a true and legal form of tender.

The data used and subject matter of the present study provided evidence that the idea of Geoffrey Ingham on state monetary oversight lacks a foundation in reality. This is due to two main arguments. First, that people create monetary value rather than the state. Although the state may introduce a means with which to sway the perception of the public on a monetary matter, it is inevitably the people that decide what does or does not have value. Secondly, state crises demonstrate just how little power the government has in establishing authority over money, as times of financial crisis often lead to a proliferation of alternative currencies in light of a decline in the value of a fiat state currency. 
The postulation by Edward Castronova that the inherently anonymous nature of cryptographic currencies make it difficult for the state to impose taxes was reviewed. A factor analysis was conducted to determine whether the criminal aspects of Bitcoin that appear in the media were often linked with the theme of taxation, having looked at anonymity and tax evasion in relation to hacking, theft, fraud and so forth. The evidence for this connection is scant. A twofactor solution was investigated providing some analytical value. These two factors as mentioned above were called 'Administrative' and 'Lecturing' for their respective characteristics and attributes. Other textual analyses such as frequency counts were used to discriminate between the thematic differences that appear between the media sources.

Finally, the postulation by Peter North that long-term acceptance of a digital currency requires both belief and geographic density among users was assessed by addressing it within the context of contemporary digital alternative currency use in Canada. This chapter has endeavored to demonstrate that although North is correct that staunch belief and adherence to a currency entrenches its use through time, geographic density need not apply in order for global, digital currencies to operate. This line of thinking undermines $21^{\text {st }}$ century developments in e-commerce and requires re-evaluation in order to compensate for digital contingencies. Evidence from the articles demonstrates that some Canadians are choosing to be paid wages for Bitcoin, a sign by North that the currency is likely to exist for quite some time. Only time will suffice in adequately testing this aspect of his postulation within a Canadian context.

Although currencies in varying forms may serve similar functions, it is in the community that uses them and the intention placed behind each exchange that ultimately differentiates one money form from one another. In this way people imbue money forms with a sense of ethics or community and attribute a sense of morality to exchange networks and the money form that 
underlies them. Whether the intention of a money be for altruism or strictly for the accumulation of wealth for its own sake, or perhaps even still for some other motive, each monetary exchange is reflective of both the adherents and the broader context that makes the act of exchange rationalizable. 


\section{Chapter 6: Conclusion}

In the preceding chapters we have investigated some of the several social aspects inherent in money, looking at Bitcoin and Canadian alternative currencies more generally. This final chapter will accomplish a few remaining things: summarize some of the main issues discussed in the previous chapters and devote some space to the findings relevant to the principal research question. This chapter will also present the limitations of the study. Lastly the implications of this research on Bitcoin will be discussed.

\subsection{Discussion}

This investigation began with a simple question concerning the role the state has played in legitimizing Bitcoin in the eyes of Canadians. It is the case that the overall content of each of the three media sources have remained unambiguous in their attempt to pursue stories that entice a readership rather than providing any overt editorial predisposition either for or against Bitcoin. Although the media provided little information concerning FINTRAC, terrorist financing or money laundering, with digital currencies, this has nonetheless remained an important area of focus for the state.

One can take away from the preceding pages that financial issues are social ones. Although not every social crisis is a financial crisis, every financial crisis doubles as a social crisis by virtue of the social construction of money. This is because money requires a mutually-shared belief in an abstract system of value transference. As we saw in the second chapter, Marx indicated (1990) that money is the index with which all other commodities are related. This provides money with great power in a consumer society, as a failure of monetary value has a direct dialectical relation to the 
value of everything else. Failing to uphold this belief in money is therefore socially dangerous, as money affects every commodity in a society predisposed to ardent materialism, even when money itself happens to be abstract and often difficult to rationalize.

The state attempts to control the abstraction of money by imposing a monetary policy. The state can no more create monetary value than it can create a sense of national pride; this valuation ultimately rests with the people. This is simple in theory; as Edward Castronova explains (2014, p.117), we find that the Canadian dollar is less valuable than is the American dollar simply because fewer people have an idea of what it can buy. Because the use value of money is its exchange value, what money can buy has a bearing on its social perception of utility, therefore affecting its price internationally.

Bitcoin volatility has been discussed in almost every article analyzed for the present study, regardless of publication. Bitcoin is often discussed in relation to a previous value, regardless of whether the price went up or down or even if the point of reference for the comparison is arbitrary. The schismatic value fluctuations of the currency for the duration of the reporting analyzed (Illustration 5 below), have been of the utmost journalistic interest. Virtually all discussions of Bitcoin value are made within the context of price volatility relative to Canadian dollars.

Much of the media's speculative interest in Bitcoin can be seen in a positive trend leading up to December 2013, at which point the news reported that China would no longer allow its financial institutions to trade in Bitcoin. This was found to be consistent with findings recognized by Vigna and Casey (2015).

December 2013 was around the time that the Globe and Mail first began reporting on Bitcoin, a full year or more after the CBC or National Post. Up until this point the number of 
articles devoted to either investing with Bitcoin or the potential of the currency were predominantly positive. At this point in time the economic "bubble" had burst and price began to recede. The result was an influx of negative press in response. This downward trend in both media perception and Bitcoin price was to continue through until September 2014 when articles were collected for this study. The postulation that negative media exposure has indirectly exacerbated the decline of Bitcoin price throughout much of 2014 is likely. However quantifying the effect of negative press on Bitcoin value is not easily determined as Bitcoin is globally exchanged with many fiat currencies, confounding direct analyses. As well attempting to assess the degree with

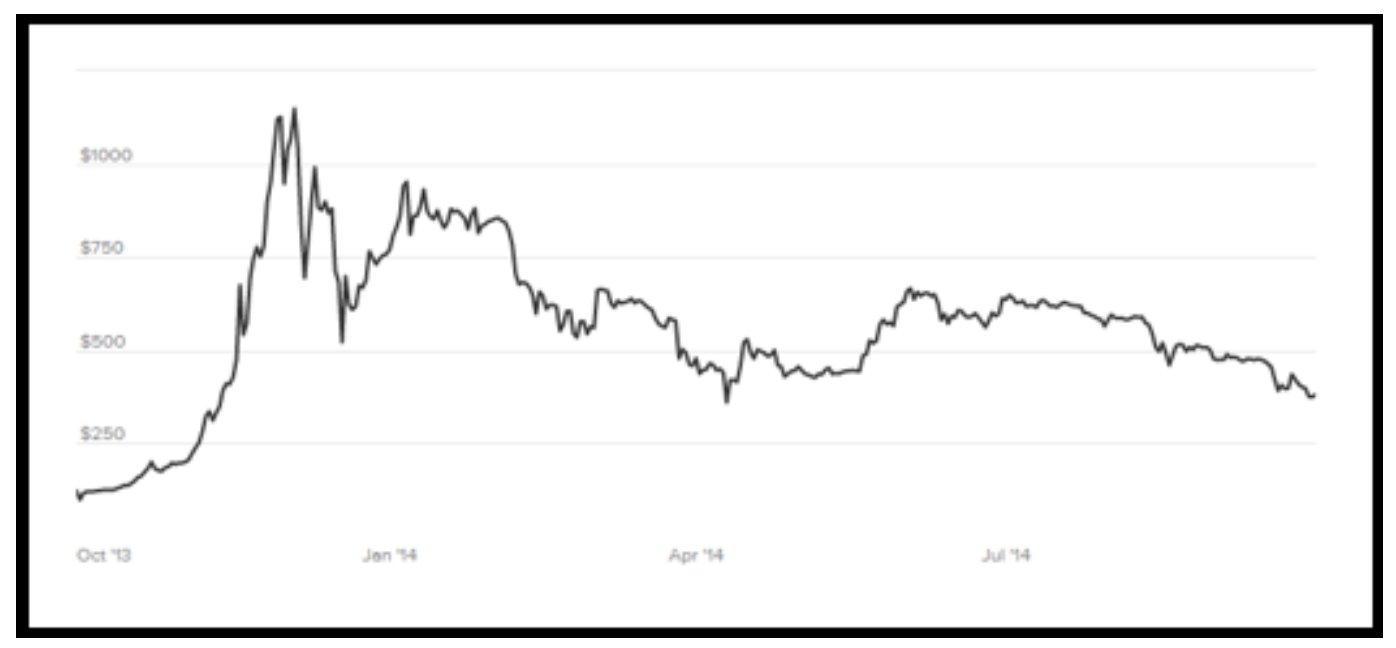

Illustration 5: Bitcoin price in USD, October 1, 2013 to September 30, 2014 showing a Bitcoin "Bubble" rising until December 2013. Negative press and consumer fears drove down price with the collapse of Mt. Gox Bitcoin exchange, February 2014. Data retrieved from www.coindesk.com

which an article demonstrates press negativity is a very subjective measure of assessment too difficult to quantify for present statistical purposes. This downward trend in Bitcoin price has persisted throughout 2014 and into 2015, raising questions about the social causes of price differentials. Unlike Canadian dollars, Bitcoin has no Central Bank or government with which to adjust the market price in times of distress, making its value in relation to other currencies relatively "free-floating". 
The question of what causes value or its quantified representation in price is truly an assessment of social tastes. Proponents of neoclassical economics tend to consider consumer preferences as exogenous factors in their supply and demand models (Lehdonvirta \& Castronova, 2014, p.44). To take an extreme example, Pet Rocks became popular despite their lack of use value or exchange value. In another seemingly irrational example, in 2014 the Cards Against Humanity game makers had poked fun at holiday consumerism by selling boxes of what it marketed as "literal feces, from an actual bull” for six dollars per box (O’Neil, 15 Dec 2014): thirty thousand consumers purchased these boxes, which sold out in a mere 30 minutes. Such purchases had value for the purchasers simply due to a novelty factor. We find something similar in family heirlooms which retain value for family members due to sentimentality in spite of market forces.

Although economists may understand changes in demand relative to price, the desire for something often escapes the purview of supposedly rational explanation. Economic models do not address the origin of preferences (Lehdonvirta \& Castronova, 2014, p.44). Fads and bubbles demonstrate trends in desire and value that also add to our understanding of how things become quantitatively worth something.

Consider, again, what Bitcoin is: an intangible entity resting in naught, but in ones and zeroes on distant servers, drives or memory sticks. As bitcoins exist solely as numbers on a digital ledger, value exists in little more than the hope that others will accept it. This temporal aspect of the social exchangeability of money was found by Weber (Weber in Swedberg, 1998, p.35). We find that the number in a given Bitcoin wallet as with any commodity has no intrinsic value: people buy Bitcoin under the assumption it can be used for purchases at a later date, in a direct temporal and social sense. 
With fewer adherents, the system depreciates as there are fewer individuals open for an exchange using Bitcoin as a medium. As the number of adherents grows, so too does the value grow in proportion to the rise of Marxian exchange value. This works for both alternative and normative forms of currency alike. The media is one potential avenue with which this adherence expands or contracts, manipulating aggregated opinion over both the function of Bitcoin and the people who use it.

Economists describe the social purpose of economic matters by relying on the abstract notion of confidence: one's confidence in the market, in the dollar and so on. This concept of confidence is in effect the extent to which society adheres to and trusts in the overall value of a currency sui generis. This notion of confidence is merely an abstraction measuring both the temporal belief in exchangeability of a money form and its utility in exchange across space, whether geographic or digital. A failure of aggregated belief in either of these respects among monetary adherents will limit value while an extension of either or both of these aspects will enhance it. It is in understanding the role the media plays in disseminating information about Bitcoin that we notice the value of the currency is linked to information made available about it. In simpler terms, negative press can indirectly devalue something, while good press can indirectly enhance it. It is the social view of something that changes and it is only in this way that value acts as a direct function of social perception and nothing else. Qualitatively this speculation is quite clear, but finding the means to apply quantitative rigor to it is difficult. 


\subsection{Findings}

In the Analysis chapter the role of the Canadian state was discussed. Neo-Chartalists such as Geoffrey Ingham view the state as a necessary institution in monetary oversight, viewing money as a form of credit paid to the state through taxation (Dodd, 2014, p.208). It was suggested during the data analysis stage that contrary to Ingham and others the State need not overtly decree that an alternative currency is acceptable as a means of payment in order for it to retain value. As a monetary valuation and exchange requires as little as two people to operate, this can hardly ever truly fall under the purview of the government, even with the imposition of regulation. However the evidence found in the media articles suggested that it is people themselves, irrespective of state function that allow for monetary value. Evidence from the articles demonstrate that in times of social crisis, as with Spain or Cyprus, the value of Bitcoin as an alternative currency can increased in value, indicating a state decree means little in times of social unrest.

It is in light of this that a limited number of assertions by Peter North (2007) were tested. North concluded that geographic density and staunch belief in a currency are necessary in order for it to maintain longevity and therefore perpetuate in value. This need not necessary imply any state intervention. Although it was found that North was not necessarily incorrect at the time of his writing, one finding of the present study was that the advent of digital currencies has demonstrated that the assertion concerning geographic density of alternative currency proponents is not relevant to Bitcoin. The evidence provided by the news sources used in this study indicate however that North is correct in stating that alternative currencies require an idealistic nature among some or all of its adherents in order to flourish.

Secondly we find that the point raised by Edward Castronova (2014), that anonymous or pseudonymous digital currencies complicate state tax revenue collection, is occurring in Canada. 
The news media have been one of the most freely available avenues of accessing information in this regard. It was argued that recent evidence, namely attempts by the Canada Revenue Agency to impose barter tax laws on digital currencies, act as a de facto means of accepting it as legal tender to raise tax funds while denying it this de jure legal status. The attempts of the state to expand powers over digital currencies, under the guise of money laundering legislation, allows for a simpler system of tax auditing in order to secure state tax revenues in an ever-digitizing society. This study found that information about tax payment on digital currencies was more available through media than government sources. Had online news media not been consulted, this information about state interests would have been missed.

In conjunction with this second finding, it was also determined that although the state has shown that it is interested in raising taxes on Bitcoin transactions, primarily though barter transactions, there was no significant correlation between the thematic use of 'crime' and the thematic use of 'taxation.' Discussions of taxes, although important to the Canadian government, appear far less frequently than crime and illegality, contrary to initial expectation. Media news sources consulted for this study were beneficial in laying this distinction between media and state motivations so clearly. No such contrast would have been possible had an alternate research question been posed that focussed solely on the news media.

A further finding in the present study was that there exists a divergence between media and state interests over the types of information disseminated about Bitcoin. Although the state has demonstrated its intention in expanding the state security apparatus over issues of money laundering and terrorist financing, terrorism only appears in two out of 166 articles in the corpus $(1.2 \%)$. Discussions of money laundering is nearly as sparse within the data analyzed. However had this study made no attempt to address this state involvement, governmental monetary and 
security policy would have been missed. Rather than news media simply being a proxy for state messages, in this instances it was the actions of the state that provided the basis for understanding the news media, making both sets of institutions for the present purposes irreplaceable. Rather than taxation or money laundering, the news media has instead focussed its attention on non-whitecollar crime such as the purchase of drugs, hacking or various forms of fraud. Attempting to assess media coverage as a contextless social phenomenon would have been an error as social realities are too complex and multifaceted. Until a form of precise, test-tube sociology is devised, one must recognize that various aspects of society are interwoven in a rich social tapestry; context is required to appreciate the manner in which many dynamic systems operate and coincide with one another. It is for this reason that an analysis of news media was appropriate for the analysis of state affairs, if only in an admittedly compartmentalized fashion.

Lastly, legislation, senate testimony and online news articles have demonstrated that the state does not need to overtly accept Bitcoin as legal tender in order for Bitcoin value to proliferate. This information afforded the media coverage some context. The state can within its power acclimatize Bitcoin to the present social environment without negatively impacting its own interests, namely taxation and crime reduction. As has been present throughout this study, we find that the broader adoption of a social phenomenon requires information and knowledge. It is therefore the case that media information are particularly invaluable in assessing state affairs, however assessing media information in its own right would have been ineffective in assessing the theoretical questions raised in lieu of the research topic at hand. How the state approaches the issue of digital currencies going forward can and should be grounds for future research. 


\subsection{Limitations}

\subsection{Methodological Limitations}

As with any sociological investigation, there were a few methodological limitations to the present study design. This section is devoted to discussing them so that others engaging in similar research may conduct their own studies in light of these limitations.

This study drew upon three online syndications: the CBC, Globe and Mail and National Post. This breadth of sources was used to capture a view of Bitcoin in the Canadian online news media. The term 'media' denotes a variety of platforms with which wider dissemination occurs.

This causes a generalizability issue. Content analyses of one format or medium may not be effective in understanding information disseminated through another medium. If the medium is the message, one cannot simply infer that the information disseminated through one news medium is analytically comparable to another. As such, this study cannot claim with certainty that all forms of knowledge made available concerning Bitcoin in the media are reducible to that which is found by the publications relied upon in this study.

Secondly, the heterogeneity of content among and between the three sources, as already discussed in the Analysis chapter, may have affected the factor analysis output in that the discontinuity between sources, in an ideological manner, create a sub-optimal foundation with which to base statistical inferences and conduct exploratory analyses.

\subsection{Theoretical Limitations}

As well, there were theoretical limitations to this study. A lack of direct literature stemming from sociology or similar fields about alternative currencies meant a limited number of sources 
with which to reliably draw from for this exercise. Although there were several monetary theorists making general and abstract remarks concerning the nature of money itself, little if any sociological literature has been conducted on alternative currencies, much less Bitcoin directly. There are few examples of sociologists with which readers can draw some limited insight, such as Raddon (2003) and Maurer (2005). North $(2007 ; 2010)$ provides a more comprehensive look at alternative currency systems, however because he wrote before the advent of digital alternative currencies, these findings are limited in their theoretical foundation and lack applicability to internet-based systems of alternative currency such as Bitcoin. No exhaustive study of digital currencies appears to have yet been published from a sociological perspective.

Importantly, some errors exist in the few publications that $d o$ concern themselves with Bitcoin. For example some of the finer technical details in Castronova $(2014)^{40}$ and Swan $(2015)^{41}$ demonstrate that the recent nature of this area of study has caused some minor confusion, leading to errors in works that have eluded the editing staff. This indicates a lack of specialized knowledge on the subject of Bitcoin and other digital currencies on part of both writers and editors.

Finally, as the creation of categories for quantitative analyses have made use of a content analysis, the codes used for this project, as with any categorical assessments of documents, are a product of personal interpretation. One must always concede the possibility of being unintentionally inaccurate in the codification stage of any social analysis. This addendum also

\footnotetext{
${ }^{40}$ On page 162, Edward Castronova describes the algorithm that regulates Bitcoin mining difficulty as something that "gets harder and harder every year". This is more of a general tendency than an inherent aspect of the protocol. The network difficulty actually adjusts every 2016 blocks, or approximately once every two weeks. Because this algorithm adjusts for overall network computational power, the difficulty can and has decreased on a few occasions as of my writing at times when miners have devoted a smaller amount of computational resources than the preceding 2016block period. Otherwise Castronova demonstrates an apt understanding of the Bitcoin protocol.

${ }^{41}$ On page 6, while describing Bitcoin denominations (as with a penny being a fraction of a dollar), Melanie Swan describes a Satoshi as being one millionth of a Bitcoin. It is actually one hundred-millionth of a Bitcoin.
} 
presupposes the possibility of personal, unintended limitations or errors, of which no fallible human is truly immune. It is therefore conceded that certain aspects of a news publication, or clerical errors in the codification or quantification stages are possible.

In an attempt to pre-emptively mitigate such a possibility, the appendices of the present study contain all information relevant to the coding phase as well as all news pieces used, sorted categorically by publication and date. As well all codes were generated at the same time to avoid a temporal bias with all 166 articles read prior to the coding phase. To avoid a selection bias each of the 36 articles used in the content analysis were selected using a random number generator, with each of the 36 articles read twice prior to the coding phase to ensure the data was appropriately understood within its context.

Overall, several of these limitations can be remedied with an increase in scholarship and sociological devotion to the subject of alternative currencies. More research is desperately needed on the topic of Bitcoin specifically in determining the sociodemographics of Bitcoin users, the dynamics of Bitcoin mining, and the social dynamics with which the Bitcoin core developers operate.

\subsection{Implications}

The actions of the Canadian government are best understood through the avenues of public media. The ability of media outlets to disseminate knowledge and form public opinion is well known, and the existence of a relationship between a limited number of information senders and a large number of receivers is generally accepted as a facet of daily life, even in the internet age. Walter Lippmann (see Lippmann, 2004, p.135; Bernays, 1923, p.13) recognized the manipulation 
of public opinion in democratic societies in having coined the term 'manufacture of consent': an expression later to be taken up by Edward Herman and Noam Chomsky in their own work (2002). With the rise of computers, smart phones and other internet-connected devices the decentralization of information through rumors, innuendos, half-truths and falsities in the digital world risk offsetting information stemming from supposedly reputable institutions like the CBC, National Post or Globe and Mail.

In terms of social policy, there are a few implications stemming from this research. Few writers have yet discussed how technologies such as Bitcoin harbor potential in offsetting future employment. Technology in its capacity for labour-replacement is not a new phenomenon, and can be seen in early industrial examples provided by Karl Marx (1990). Contemporarily speaking the potential for the "computerization" of jobs according to one study places $47 \%$ of total US occupations at "high risk" for technologically-fuelled redundancy (Frey \& Osborne, 2013). Virtually autonomous protocols and self-regulating technologies such as Bitcoin, which function without any employees and virtually no human intervention, demonstrate by their existence the possibility of human labour displacement.

Bitcoin allows for the transfer of finances between individuals without third party involvement. This has social implications in that technologies such as Bitcoin and other autonomous services can with time displace rather than supplement human labour. Should an asymptotic rise technological advancement create an environment where job losses outpace job creation, there looms the potential for social unrest.

Recently autonomous vehicles have been grounds for just such speculation. Truck drivers (see: Woodley and Acar, 2004) and valets (Min and Choi, 2013) are jobs that in the next few years 
may no longer require human involvement. Uber has been testing self-driving automobiles (Gibbs, 22 May 2015) while also disrupting the taxi industry. Uber CEO Travis Kalanick has recently shown interest in purchasing a half a million self-driving cars from Tesla in 2020 for this purpose (Edelstein, 7 July 2015). These implications are extended when we apply these advances to flight vehicles (Bayezit and Fidan, 2013) and aquatic vehicles (German, Jakuba, Kinsey, Parsan, Belani and Yoerger, 2012). The idea of human labour displacement by technologies like Bitcoin were never discussed by the CBC, Globe and Mail or National Post. However as with the birth of ATMs, automated telemarketing devices and self-checkout machines, how the labour market responds to an asymptotic rise in technological advancement is becoming increasingly sociologically pertinent.

Not all implications are this dreary. As has been argued throughout the course of this paper, money is an inherently social entity upheld by social processes. Even by removing the human element of transaction verification, humans are required, in however limited a capacity, for said systems to operate. Knowledge of this has potentially emancipatory effects. To reiterate that which has been stated in the fifth chapter, different forms of money give rise to different forms of community. The lighthearted philanthropy of Dogecoin, the ardent libertarian nature of Bitcoin and the altruistic nature of LETS all demonstrate not only how currencies represent the communities that use them but also how communities in turn develop currency in accordance with specific social needs.

Individuals within our community use money, with money in turn structuring communities through its uses. This relation is more cyclical than causal, with money acting as a tool used to facilitate the flow of wants and needs. This indicates that money itself is not "the root of all evil" 
but rather a reflection of the supposed evil found in the society that gives money its meaning. ${ }^{42}$ Money like all useful things are inherently amoral. As with a hammer that can either be used to house the homeless or harm them, it is the manner in which something is used that provides it with an ascribed and social moral meaning. It is the social context that makes money good or evil, with money itself being merely the reflection of the society that constructs and makes use of it. If one is fraught with moral repugnance at the idea of money being used to buy political influence, it is not money necessarily that is evil but rather act of corruption facilitated by money that we recoil with moral distaste. Having knowledge of the moral aspects of money can help us manipulate the ways in which we use money to improve the social environments in which we live.

This interpretive aspect of money leads to one final note. There is not a single form of money, but many constitutive forms of money bound to the communities that use them. We find this in Zelizer, who borrows the term "special-purpose" money from Karl Polanyi (Zelizer, 1989, p.348) to describe a similar but distinct phenomenon. Special purpose money for Zelizer shares with alternative currencies the characteristic of being used apart from an often-accepted money form like Canadian dollars.

Bearing this in mind, consider again our present social environment and its relation to the Canadian dollar. Apart from the strictly economic metrics that guide our lives like interest rates, the consumer price index (CPI), GDP-per-capita and so on, the symbolic significance we attribute to the Canadian dollar affects staunchly social aspects of who we are as Canadians. Debt has been previously introduced as an endemic component of our present society. In debtor-creditor

\footnotetext{
${ }^{42}$ This expression is biblical in origin and often incorrectly paraphrased. "For the love of money is a root of all kinds of evil, and in their eagerness to be rich some have wandered away from the faith and pierced themselves with many pains" (1 Timothy 6:10, NRSV). Money is inherently amoral; it is us that provide it with meaning and ultimately bear responsibility for its uses. It is in this way that we make money in our own image.
} 
relations, the abstract concept of money is used as the metaphorical chain with which so many Canadians are presently bound. The present research on Bitcoin demonstrates that we bestow money with social meaning and value.

The ramifications of this become apparent: if the power bestowed upon a socially constructed money form is derived from our aggregated perception and belief, we are presented with an interesting opportunity for social change. What should arrest one's attention is that if we construct money, then there rests the possibility that we can keep money from, in turn, controlling us.

As has been seen, people propagate monetary value independently of the state. Although the state has a few powers at its disposal with which to enforce the circulation of currency, namely that of annual taxation, value rests with people directly. Minimalists and simple-living advocates recognize this, as refusing to spend money is in essence a vote to opt out of Capitalism. This brings us back to where we began with the issue of Karl Marx (1992): money facilitates commodity exchanges, allowing for exchange values to be replaced with use values in varying circuits of the capital, production and labour processes. In the assertion made by Marx (1992, p.133) that the circulation of capital within the industrial social system necessitates speed and perpetuity.

We find that although money is vaguely defined and abstract in nature, it is nonetheless vital for the capitalist system to operate. This provides a curious weak point within the system: should a society be so inclined, consciously refusing to partake in the exchange of commodities for money and vice versa provides us with the collective ability to change the underpinnings of society as we see fit. 


\section{Bibliography}

Ali, R.; Barrdear, J.; Clews, R.; Southgate, J. (2014a). Innovations in payment technologies and the emergence of digital currencies. Bank of England Quarterly Bulletin. Q3. 1-14.

Ali, R., Barrdear, J., Clews, R., \& Southgate, J. (2014b). The economics of digital currencies. Bank of England Quarterly Bulletin. Q3, 1-11.

Altmann, S.P.(1904). Simmel's philosophy of money in David Frisby's Georg Simmel: Critical Assessments. London: Routledge. 129-143.

Antonopoulos, A. (2015). Mastering Bitcoin: Unlocking digital currencies. Cambridge, Mass.: O’Reilly.

Aristotle. (1946). The politics of Aristotle. (Ernest Barker, Trans.). England: Oxford Press.

Bayezit, I., \& Fidan, B. (2013). Distributed cohesive motion control of flight vehicle formations. In IEEE Transactions on Industrial Electronics. 60(12), 5763-5772. doi:10.1109/TIE.2012.2235391

Beckert, J. (2006). The nature of money by Geoffrey Ingham. American Journal of Sociology. 111(4). 1227-1229.

Bernays, E. (1923). Crystallizing public opinion. New York: Ig Publishing.

Braga, M. (20 January 2014). As merchants embrace Bitcoin, digital currency still struggles for regulatory approval worldwide. In Financial Post. Retrieved from http://business.financialpost.com/fp-tech-desk/bitcoin-currency-merchants-regulators2014

Braun, V., \& Clarke, V. (2006). Using thematic analysis in psychology. Qualitative Research in Psychology. 3, 77-101.

Berger, J. (1991). Market and state in advanced capitalist societies. Economy and Society. London: Sage Publications. 108-109.

Berger, P.L. (1990). The sacred canopy: Elements of a sociological theory of religion. New York: Anchor Books.

Berger, P.L., \& Luckmann, T. (1967). The social construction of reality: A treatise in the sociology of knowledge. New York: Anchor Books.

Boesveld, S. (21 June 2011). Graphic: Canada's new money is polymer in your pocket. Retrieved from http://news.nationalpost.com/news/canada/graphic-canadas-new-moneyis-polymer-in-your-pocket 
Bradbury, D. (2013). The problem with Bitcoin. Computer Fraud \& Security. 5-8.

Bronskill, J. (19 October 2014). FinTRAC, Canadian financial intelligence agency, tracks funds to ISIS. In $C B C$ News. Retrieved from http://www.cbc.ca/news/canada/fintrac-canadianfinancial-intelligence-agency-tracks-funds-to-isis- 1.2805327

Canadian Senate. (June 2015). Digital currency: You can't flip this coin! Senate Standing Committee on Banking, Trade and Commerce. $41^{\text {st }}$ Parl., $2^{\text {nd }}$ Sess. Retrieved from http://www.parl.gc.ca/Content/SEN/Committee/412/banc/rep/rep12jun15-e.pdf

Canada Revenue Agency. (2014). What you should know about digital currency. Retrieved from http://www.cra-arc.gc.ca/nwsrm/fctshts/2013/m11/fs131105-eng.html

Canadian Tire Corporation. (2015a). Customer service. Retrieved from https://www.canadiantire.ca/en/registration.html

Canadian Tire Corporation. (2015b). Privacy Charter: Policy on privacy of customer personal information. Retrieved from http://www.canadiantire.ca/en/customer-service/privacycharter.html

Carignan, M.A. (2014). The bitcoin tutor. New Hampshire: Bitcoin Tutor Publishing:

CBC News. (24 January 2013). Canadian Tire money-financed album debuts. Retrieved from http://www.cbc.ca/news/arts/canadian-tire-money-financed-album-debuts-1.1359989

CBC News. (1 December 2011). Ottawa bank note printer plans layoffs. Retrieved from http://www.cbc.ca/news/canada/ottawa/ottawa-bank-note-printer-plans-layoffs1.1049238

CBC News. (29 October 2013). World's first bitcoin ATM opens in Vancouver. Retrieved from http://www.cbc.ca/news/technology/world-s-first-bitcoin-atm-opens-in-vancouver1.2286877

CBC News. (1 September 2014). Salaries paid in bitcoin a growing trend in Canada. Retrieved from http://www.cbc.ca/news/business/salaries-paid-in-bitcoin-a-growing-trend-incanada-1.2752441

Carlos, A. M., \& Nicholas, S. (1990). Agency problems in early chartered companies: The case of the Hudson's Bay Company. The Journal of Economic History. 50(4), 853-875.

Canadian Bank Note Company. (2015). Coupons and gift certificates. Retrieved from http://www.cbnco.com/paysys/paysys-docs-coupons.php

Canadian Bank Note Company. (n.d. a). About $C B N$. retrieved from http://www.cbnco.com/corp/corp-about.php 
Canadian Bank Note Company. (n.d. b). Coupons and Gift Certificates. Retrieved from https://www.cbnco.com/paysys/paysys-docs-coupons.php

Castronova, E. (2014). Wildcat currency: How the virtual money revolution is transforming the economy. New Haven: Yale University Press.

Champagne, P. (2014). The book of Satoshi: The collected writings of Bitcoin creator Satoshi Nakamoto. United States: e53 Publishing.

Chan, Cheryl. (2007, December 23). Canadian Tire money used to benefit poor. The Province. Vancouver, B.C.

Chawla, R.J. \& Uppal, S. (2014, March 23). Household debt in Canada. Retrieved from http://www.statcan.gc.ca/pub/75-001-x/2012002/article/11636-eng.pdf

Collins, R. (1979). Review of The Bankers by Martin Mayer. 85(1), 190-194.

Cook, S. (1966). The Obsolete "anti-market" mentality: A critique of the substantive approach to Economic Anthropology. In American Anthropologist. 68(2), 323-345.

Coquitlam Now. (2003, August 9). Canadian Tire money helps hospital. Coquitlam Now. New Westminster, BC. 13.

CoinDesk. (19 August 2014). What can you buy with bitcoins? Retrieved from http://www.coindesk.com/information/what-can-you-buy-with-bitcoins/

Costello, A. B., \& Osborne, J. W. (2005, July). Best practices in exploratory factor analysis: Four recommendations for getting the most from your analysis. In Practical Assessment Research \& Evaluation. 10(7), 1-9.

Daniels, C. (2000, March 13). Canadian Tire mulls money changes. Marketing Magazine. 105(10), 3.

Dodd, N. (2005). Laundering 'money': on the need for conceptual clarity within the sociology of money. Archives europeennes de sociologie. 46(3), 387-411. DOI: $10.1017 / \mathrm{S} 0003975605000159$

Dodd, N. (2012a). Simmel's perfect money: Fiction, socialism and utopia in The Philosophy of Money. Theory, Culture \& Society. 29(7/8), 146-176. DOI: 10.1177/0263276411435570

Dodd, N. (2012b). Neitzsche's money. Journal of Classical Sociology. 13(1), 47-68. DOI: $10.1177 / 1468795 X 12461412$

Dodd, N. (2014). The social life of money. Princeton: Princeton University Press. 
Duhigg, C. (2009, May 12). What does your credit-card company know about you? The New York Times. Retrieved from http://www.nytimes.com/2009/05/17/magazine/17creditt.html?pagewanted $=$ all\&_r $=0$

Durkheim, E. (1972). Forms of social solidarity. In A. Giddens (Ed.), Emile Durkheim: Selected Writings (pgs.123-140). Cambridge: Cambridge University Press.

Durkheim, E., \& Baehr, P.(1979). Durkheim's review of Georg Simmel's Philosophie des Geldes. Social Research. 46(2), 321-328.

Easterbrook, W. T., \& Aitken, H.G. (1956). Canadian economic history. Toronto: Macmillan Company of Canada Limited.

Edelstein, S. (7 July 2015). Uber CEO to Tesla: Sell me half a million autonomous electric cars in 2020. In Yahoo! Autos. Retrieved from https://www.yahoo.com/autos/s/uber-ceo-teslasell-half-million-autonomous-electric-110000053.html

Elgar, E. (2005). Karl Polanyi. In James G. Carrier (Ed.) A handbook of Economic Anthropology (pgs.14-25). Cheltenham: MPG Books, Ltd.

Evans, P. (10 March 2014). Why bitcoin isn't dead yet. In CBC News. Retrieved from http://www.cbc.ca/news/business/why-bitcoin-isn-t-dead-yet-1.2563875

Ferguson, J. (1988). Cultural Exchange: New developments in the Anthropology of Commodities. Cultural Anthropology. 3(4), 488-513.

Ferguson, N. (2008). The ascent of money: A financial history of the world. New York: Penguin Books.

Financial Post. (20 May 2014). Brave new digital currency world. Retrieved from http://business.financialpost.com/business-trends/brave-new-digital-currency-world

Financial Post. (8 June 2012). Euro fears boost virtual currency Bitcoin. Retrieved from http://business.financialpost.com/news/fp-street/euro-fears-boost-virtual-currency-bitcoin

FINTRAC. (2015c). What is money laundering? Financial Transactions and Reports Analysis Centre of Canada. Retrieved from http://www.fintrac-canafe.gc.ca/fintraccanafe/definitions/money-argent-eng.asp

FINTRAC. (2015a). Money services businesses (MSBs). Financial Transactions and Reports Analysis Centre of Canada. Retrieved from http://www.fintrac-canafe.gc.ca/msbesm/intro-eng.asp

FINTRAC. (2015b). Proceeds of Crime (Money Laundering) and Terrorist Financing Act. Retrieved from http://www.fintrac-canafe.gc.ca/act-loi/1-eng.asp 
Foucault, M. (1990). The history of sexuality: Volume I. United States: Random House.

Foucault, M. (2008). The birth of biopolitics (Graham Burchell, Trans.). Great Britain: Palgrave Macmillan.

Frey, C.B., \& Osborne, M. A. (2013). The future of employment: How susceptible are jobs to computerization?

Retrieved

from http://www.oxfordmartin.ox.ac.uk/downloads/academic/The_Future_of_Employment.pdf

Galbraith, J. K. (1975). Money: Whence it came, where it went. London: Andre Deutsch.

George-Cosh, D. (2012, May 10). In Canada, alternate currency keeps traction with fans. In Wall Street Journal. Retrieved from http://www.wsj.com/articles/SB10001424052702303630404577390572271565222

German, C. R., Jakuba, M. V., Kinsey, J. C., Partan, J., Suman, S., Belani, A., \& Yoerger, D. R. (2012). A long term vision for long-range ship-free deep ocean operations: Persistent presence through coordination of autonomous surface vehicles and autonomous underwater vehicles. In 2012 IEEE/OES Autonomous Underwater Vehicles (AUV), 1-7. doi:10.1109/AUV.2012.6380753

Gervais, A.; Karame, G.O.; Capkun, V.; Capkun, S. (2014). Is Bitcoin a decentralized currency? In IEEE Computer and Reliability Societies. May/June. 54-60.

Greenwald, G. (2014). No Place to Hide. New York: Metropolitan Books.

Gibbs, S. (22 May 2015). Uber's first self-driving car spotted in Pittsburgh. In The Guardian. Retrieved from http://www.theguardian.com/technology/2015/may/22/uber-self-drivingcar-pittsburgh

Gokturk, M. (20 May 2014). Small merchants struggle with decision to accept Bitcoin or not. In Financial Post. Retrieved from http://business.financialpost.com/entrepreneur/smallmerchants-struggle-with-decision-to-accept-bitcoin-or-not

Government of Canada. (23 June 2014). Proceeds of Crime (Money Laundering) and Terrorist Financing Act (S.C. 2000, c. 17). Retrieved from Justice Laws Website. Retrieved from http://laws-lois.justice.gc.ca/eng/acts/p-24.501/

Grady, W. (Jul/Aug 1999). Canadian Tire money. In Saturday Night. 114(6), 22.

Graeber, D. (2001). Toward an anthropological theory of value. New York: Palgrave Macmillan.

Graeber, D. (2011). Debt: the first 5000 years. Brookyn, New York: Melleville House.

Greenberg, A. (2013). This machine kills secrets. New York, New York: PLUME. 
Greenberg, A. (2 Feb 2015). Read the transcript of Silk Road's boss ordering 5 assassinations. Retrieved from http://www.wired.com/2015/02/read-transcript-silk-roads-bossordering-5-assassinations/

Hacking, I. (1999). The social construction of what? Cambridge: Harvard University Press.

Hammond, B. (1967). Banking in Canada before Confederation, 1792-1867. In W.T. Easterbrook and M.H. Watkins (Eds.), Approaches to Canadian Economic History (pp.127-182). Toronto: McClelland and Stewart Limited.

Hann, C., \& Hart, K. (2011). The golden age of economic anthropology. Economic anthropology: History, ethnography, critique. 55-70.

Harman, C. (2008). A people's history of the world. New York: Verso.

Harvey, D. (1990). The condition of postmodernity: An enquiry into the origins of cultural change. Blackwell Publishers: Cambridge.

Harvey, D. (2010). A companion to Marx's capital. New York: Verso.

Harvey, D. (2013). A companion to Marx's Capital Volume 2. New York: Verso.

Hegel, G.W.F. (1977). Phenomenology of Spirit. (Trans: A.V. Miller). Toronto: Oxford University Press.

Heggestuen, J. (2014). Emerging payment technologies will create new winners and losers in the giant credit card industry. Retrieved from http://www.businessinsider.com/new-creditcard-industry-market-competition-2014-5

Herman. E.S., \& Chomsky, N. (2002). Manufacturing consent: The political economy of the mass media. New York: Pantheon Books.

Ho, K. (2009). Liquidated: An ethnography of Wall Street. London: Duke University Press.

House of Commons. (11 February 2014). An Act to implement certain provisions of the budget tabled in Parliament on February 11, 2014 and other measures. $41^{\text {st }}$ parl, $2^{\text {nd }}$ sess. Retrieved from http://www.parl.gc.ca/HousePublications/Publication.aspx?DocId=6684616

Hughes, E. (1993). A cypherpunk's manifesto. Retrieved from http://www.activism.net/cypherpunk/manifesto.html

Hurlburt, G.F., \& Bojanova, I. (2014). Bitcoin: benefit or curse? In IT Professional. 16(3). 10-15. doi:10.1109/MITP.2014.28

Hurtado, P. \& Sandler, L. (28 May 2013). Digital currency firm Liberty Reserve accused by U.S. of running US. \$6-billion money-laundering scheme. In Financial Post. Retrieved from 
http://business.financialpost.com/news/fp-street/digital-currency-firm-liberty-reserveaccused-by-u-s-of-running-us6-billion-money-laundering-scheme

Industry Canada. (2015). Canadian Bank Note Company, Limited: Company information. Retrieved from http://www.ic.gc.ca/app/ccc/srch/nvgt.do?lang=eng\&prtl=1\&estblmntNo=101115400000 \&profile $=$ cmpltPrfl\&profileId $=2056 \&$ app $=$ sold

Ingham, G. (2001). Fundamentals of a theory of money: untangling Fine, Lapavitsas, and Zelizer. Economy and Society, 30(3), 304-323.

Ingham, G. (2004). The nature of money. Cambridge: Polity Press Ltd.

Innis, M.Q. (1945). An economic history of Canada. Ryerson Press: Toronto.

Innis, H.A. (1967). The fur trade. In W.T. Easterbrook and M.H. Watkins (Eds.), Approaches to Canadian Economic History (pp.20-48). Toronto: McClelland and Stewart Limited.

Isaac, B.L. (2005). Karl Polanyi. In James G. Carrier (Ed.), A Handbook of Economic Anthropology (14-25). Northampton: Edward Elgar Publishing Ltd.

Kang, M. (16 September 2014). Waterloo tech startup leader is paid in bitcoin. In CBC News. Retrieved from http://www.cbc.ca/news/canada/kitchener-waterloo/waterloo-techstartup-leader-is-paid-in-bitcoin-1.2766547

Keynes, J. M. (2008). The general theory of employment, interest, and money. California: BN Publishing.

Kim, J-O., \& Mueller, C.W. (1978). Introduction to factor analysis: What it is and how to do it. London: Sage.

Kline, J. (1 November 2013). Jesse Kline: Behold the power of Bitcoin. In National Post. Retrieved from http://news.nationalpost.com/full-comment/jesse-kline-behold-the-powerof-bitcoin

Kline, J. (9 May 2014). Jesse Kline: From Putin to porn stars - why everyone needs to start adopting bitcoin. In National Post. Retrieved from: http://news.nationalpost.com/fullcomment/from-putin-to-porn-stars-why-everyone-needs-to-start-adopting-bitcoin

Knapp, G. F. (1924). The state theory of money. London: Macmillan \& Company Ltd. Retrieved from http://socserv2.socsci.mcmaster.ca/econ/ugcm/3113/knapp/StateTheoryMoney.pdf

Kopun, F. (2014, September 9). Canadian Tire launches new loyalty program. In The Toronto Star. Retrieved from 
http://www.thestar.com/business/personal_finance/spending_saving/2014/09/09/canadian _tire_launches_new_loyalty_program.html

Krugman, P. (1998). It's baaack: Japan's Slump and the return of the Liquidity Trap. In Brookings Papers on Economic Activity. 2(1998), 137-205.

Lapavitsas, C. (2005). The social relations of money as universal equivalent: a response to Ingham. Economy and Society. 34(3), 389-403.

Lazzarato, M. (2012). The making of the indebted man. (Trans: Joshua David Jordan). Los Angeles: Semiotext(e).

Lehdonvirta, V. \& Castronova, E. (2014). Virtual economies: Design and analysis. London: MIT Press.

Ligaya, A. (5 March 2014). After Alberta's Flexcoin, Mt. Gox hacked, bitcoin businesses face sting of free-wheeling ways. In Financial Post. Retrieved from http://business.financialpost.com/news/fp-street/after-albertas-flexcoin-mt-gox-hackedbitcoin-businesses-face-sting-of-free-wheeling-ways

Lippmann, W. (2004). Public opinion. New York: Dover Publications, Inc.

Mandel, E. (1990). Introduction. In Karl Marx and Ben Fowkes (Trans.), Capital volume I (pp.1186). Toronto: Penguin Books.

Martinelli, A., \& Smelser, N. J. (1991). Economy and society: Overviews in economic sociology. London: Sage Publications.

Marx, K. (1978). Phenomenology. The Marx Engels Reader $2^{\text {nd }}$ ed. (Robert C. Tucker, Ed.). 109-125. New York: W.W. Norton \& Co.

Marx, K. (1990). Capital volume I. (Ben Fowkes, Trans.). Toronto: Penguin Books.

Marx, K. (1991). Capital volume III. (David Fernback, Trans.). Toronto: Penguin Books.

Marx, K. (1992). Capital volume II. (David Fernback, Trans.). Toronto: Penguin Books.

Marx, K. (1993). Grundrisse. (Martin Nicolaus, Trans.). Toronto: Penguin Books.

Maucourant, J., \& Plociniczak, S. (2013). The institution, the economy and the market: Karl Polanyi's institutional thought for economists. Review of Political Economy. 25(3), 512531.

Maurer, B. (2005). Mutual life, limited: Islamic banking, alternative currencies, lateral reason. Princeton: Princeton University Press. 
Mauss, M. (2011). The gift: Forms and functions of exchange in archaic societies. (Ian Cunnison, Trans.). Illinois: Glencoe Free Press.

Mead, G. H. (1901). Philosophie des Geldes. Journal of Political Economy. 1901, 9(4), 616-619.

Miller, M. (2015). The ultimate guide to bitcoin. Indianapolis, Indiana: QUE.

Min, K., \& Choi, J. (2013). A control system for autonomous vehicle valet parking. 2013 13th International Conference on Control, Automation and Systems (ICCAS 2013), 1714-1717. doi:10.1109/ICCAS.2013.6704211

Moore, T.; \& Christin, N. (2013). Beware the middleman: Empirical analysis of Bitcoin-exchange risk. In Financial Cryptography and Data Security.

Moss, K. (28 October 2013). World's first Bitcoin ATM to open in Canada this week. Retrieved from http://business.financialpost.com/fp-tech-desk/bitcoin-atm-canada-this-week

Myers, Sean. (2005, November 18). Pub sells beer for Canadian Tire money. The Ottawa Citizen. Section A5.

Nakamoto, S. (2008a). Bitcoin P2P e-cash paper. In The Cryptography Mailing List. Retrieved from http://article.gmane.org/gmane.comp.encryption.general/12588/

Nakamoto, S. (2008b). Bitcoin: A peer-to-peer electronic cash system. Retrieved from https://bitcoin.org/bitcoin.pdf

National Post. (1 January 2013). Bank of Canada won't discuss melting plastic bills, says national security behind silence. Retrieved from http://news.nationalpost.com/news/canada/bank-of-canada-wont-discuss-melting-plasticbills-says-national-security-behind-silence

National Science Foundation. (March 2014). Semiannual report to congress. From the Office of the Inspector General. Arlington, Virginia. Recieved from http://www.nsf.gov/pubs/2014/oig14002/oig14002.pdf on September 17, 2014.

Neufeld, E. P. (1964). Money and banking in Canada. Toronto: T. H. Best Printing Company.

Nicolaus, M. (1993). Forward. In Marx, Karl, Grundrisse (7-66). Toronto: Penguin Books.

North, P.(2007). Money and liberation: The micropolitics of alternative currency movements. London: University of Minnesota Press.

North, P. (2010). Local money: How to make it happen in your community. United Kingdom: Green Books.

O’Connor, C. (17 February 2014). How to use Bitcoin to shop at Amazon, Home Deopt, CVS and more. In Forbes Magazine. Retrieved from 
http://www.forbes.com/sites/clareoconnor/2014/02/17/how-to-use-bitcoin-to-shop-atamazon-home-depot-cvs-and-more/

O'Neil, L. (2014, December 15). Cards Against Humanity sells 30,000 boxes of actual poop to mock holiday consumerism. In $C B C$ News. Retrieved from http://www.cbc.ca/newsblogs/yourcommunity/2014/12/cards-against-humanity-sells30000-boxes-of-actual-poop-to-mock-holiday-consumerism.html

Paris, M. (11 February 2014). Budget 2014: Bitcoin, charities face scrutiny to prevent money laundering. In $C B C$ News. Retrieved from http://www.cbc.ca/news/politics/budget-2014bitcoin-charities-face-scrutiny-to-prevent-money-laundering-1.2530744

Parkinson, D. (31 January 2014). The Roundup: Tracking true inflation in troubled EM currencies. In The Globe and Mail. Retrieved from http://www.theglobeandmail.com/report-on-business/economy/economy-lab/theroundup-tracking-true-inflation-in-troubled-em-currencies/article16639360/

Peck, M.E. (June 2012). Bitcoin: the chryptoanarchists' answer to cash. In IEEE Spectrum. Pgs. 51-55.

Pilieci, V. (2014, August 13). Ottawa Bitcoin ATM maker is swamped with new orders. Ottawa Citizen. Retrieved from http://ottawacitizen.com/business/local-business/ottawa-bitcoinatm-maker-is-swamped-with-new-orders

Polanyi, K. (1957). Trade and market in the early empires: Economies in history and theory. Karl Polanyi, Conrad M. Arsenberg, Harry R. Pearson (Eds). Chicago: Henry Regnery Company.

Polanyi, K. (2001 [1944]). The great transformation: The political and economic origins of our time. Boston: Beacon Press.

Popper, N. (2015). Digital gold: Bitcoin and the inside story of the misfits and millionaires trying to reinvent money. New York: Harper Collins.

Raddon, M-B. (2003). Community and money: Men and women making change. Montreal: Black Rose Books.

Reid, F., \& Harrigan, M. (2013). An analysis of anonymity in the Bitcoin system. Security and Privacy in Social Networks. 197-223. DOI: 10.1007/978-1-4614-4139-7_10.

Ricardo, D. (2004). The principles of political economy and taxation. New York: Dover Books.

Roberts, A. (2014). Napoleon: A life. New York: Viking Press. 
Ron, D., \& Shamir, A. (2013). Quantitative analysis of the full Bitcoin transaction graph. Financial Cryptography and Data Security. Vol. 7859, 6-24.

Royal Canadian Mint. (n.d.). Currency Timeline. Retrieved from http://www.mint.ca/store/dyn/PDFs/RollTimeline_e.pdf

Sahlins, M. (1972). Stone age economics. Chicago: Aldine.

Say, J. B. (1834 [2001]). A treatise on political economy: Or, the production, distribution, and consumption of wealth. Retrieved from http://socserv2.socsci.mcmaster.ca/econ/ugcm/3113/say/treatise.pdf

Simmel, G. (2004). The philosophy of money. (David Frisby, Trans.). New York: Routledge.

Smith, A. (2003). The wealth of nations. (Edwin Cannan, Ed.). New York: Bantam Books.

Smith, A. (2007). An inquiry into the nature and causes of the wealth of nations. New York: MetaLibri. Retrieved from http://www.ibiblio.org/ml/libri/s/SmithA_WealthNations_p.pdf

Smyth, L. (2013). The demographics of Bitcoin (Part 1 updated). Retrieved from http://simulacrum.cc/2013/03/04/the-demographics-of-bitcoin-part-1-updated/

Statistics Canada. (2014, November 14). Graduating in Canada: Profile, labour market outcomes and student debt of the class of 2009/2010, 2013. In The Daily. Retrieved from: http://www.statcan.gc.ca/daily-quotidien/141114/dq141114b-eng.htm

Statistics Canada. (2014, November 25). Canadian postsecondary enrolments and graduates, 2012/2013. In The Daily. Retrieved from http://www.statcan.gc.ca/dailyquotidien/141125/dq141125d-eng.htm

Strauss, M. (15 Feb 2012). Canadian Tire's 'funny money' dilemma. In The Globe and Mail. Retrieved from http://www.theglobeandmail.com/globe-investor/canadian-tires-funnymoney-dilemma/article546335/

Swan, M. (2015). Blockchain: Blueprint for a new economy. Cambridge: O’Reilly.

Swedberg, R. (Ed.). (1993). Explorations in economic sociology. New York: Russell Sage Foundation.

Swedberg, R. (1998). Max Weber and the idea of economic sociology. New Jersey: Princeton University Press.

Tabachnick, B. G., \& Fidell, L. S. (2001). Using multivariate statistics. Boston: Allyn and Bacon. Trail Times. (2006, December 22). Liquor store accepts Canadian Tire money. Trail Times, 11. 
Vigna, P. \& Casey, M.J. (2015). The age of cryptocurrency. New York: St. Martin’s Press.

Weber, M. (1999). The market. In Essays in Economic Sociology. (R. Swedberg, Ed.). New Jersey: Princeton University Press. 75-79.

Werner, K. (2009, March). Money and Liberation: The micropolitics of the alternative currency movement (Review). American Journal of Sociology. 114(5), 1585-1587.

Woodley, B., \& Acar, L. (2004). Autonomous control of a scale model of a trailer-truck using an obstacle-avoidance path-planning hierarchy. Proceedings of the 2004 American Control Conference, 4, 3399-3404 vol.4.

World Bank. (2015). Bilateral remittance matrix 2014: Migration \& remittances data. Retrieved from http://econ.worldbank.org/WBSITE/EXTERNAL/EXTDEC/EXTDECPROSPECTS/0,,c ontentMDK:22759429 pagePK:64165401 piPK:64165026 theSitePK:476883,00.html

Zelizer. (1989). The social meaning of money: "special moneys". American Journal of Sociology. 95(2), 342-377.

Zelizer, V.A. (1993). Making multiple moneys. In Richard Swedberg's (Ed.), Explorations in Economic Sociology (193-212). Russel Sage Foundation: New York. 


\section{Appendix A: List of CBC Resources Used}

\begin{tabular}{|c|c|c|c|}
\hline CBC News Title & Date & $\begin{array}{l}\text { Tot. } \\
\text { Wds }\end{array}$ & $\begin{array}{l}\text { Unique } \\
\text { Words }\end{array}$ \\
\hline 1. Canadians among top participants on illegal drug website & 16-Aug-12 & 811 & 393 \\
\hline 2. Bitcoin digital currency site to operate like bank in France & 7-Dec-12 & 318 & 191 \\
\hline 3. Alberta man to sell home for Bitcoin virtual currency & 23-Mar-13 & 357 & 222 \\
\hline 4. Bitcoin virtual currency hitting the mainstream & 11-Apr-13 & 1621 & 751 \\
\hline 5. Gold and bits, two sides of the same coin & 12-Apr-13 & 555 & 253 \\
\hline 6. Sask. real estate agent adopts the bitcoin & 25-Apr-13 & 306 & 185 \\
\hline 7. Digital currency dealers charged with money laundering & 28-May-13 & 833 & 414 \\
\hline 8. Winklevoss twins seek to sell shares in Bitcoin fund & 2-Jul-13 & 571 & 299 \\
\hline 9. Silk Road illegal drug website shut down by FBI & $2-O c t-13$ & 822 & 400 \\
\hline 10. Silk Road's alleged mastermind: How the FBI caught him & 3-Oct-13 & 801 & 408 \\
\hline 11. World's first bitcoin ATM opens in Vancouver & 29-Oct-13 & 452 & 259 \\
\hline 12. New Silk Road drug bazaar opens a month after FBI bust & 6-Nov-13 & 399 & 208 \\
\hline 13. Virtual currencies won't replace cash, central bank says & 13-Nov-13 & 373 & 210 \\
\hline 14. Bitcoins now worth $\$ 1,000$ US & 27-Nov-13 & 209 & 132 \\
\hline 15. Bitcoin sinks again as China bans new yuan deposits & 19-Dec-13 & 264 & 170 \\
\hline 16. Alibaba unit bans bitcoin trading ahead of IPO & 8-Jan-14 & 332 & 198 \\
\hline 17. Why are Canadians buying Bitcoin? & 20-Jan-14 & 926 & 427 \\
\hline 18. Bitcoin sellers in Silk Road case charged with conspiracy & 27-Jan-14 & 117 & 80 \\
\hline $\begin{array}{l}\text { 19. Budget 2014: Bitcoin, charities face scrutiny to prevent money } \\
\text { laundering }\end{array}$ & $11-F e b-14$ & 317 & 181 \\
\hline 20. Bitcoin: Be prepared for the rise of digital currency, adopters say & $15-F e b-14$ & 1321 & 621 \\
\hline 21. Mt. Gox shutdown a major blow for bitcoin & 25-Feb-14 & 1048 & 487 \\
\hline 22. Bitcoin exchange, Mt. Gox, CEO Mark Karpeles still in Japan & 27-Feb-14 & 260 & 163 \\
\hline 23. Bitcoin exchange, Mt. Gox, files for bankruptcy & $28-F e b-14$ & 895 & 452 \\
\hline 24. Bitcoin bank Flexcoin shuts down after $\$ 600,000$ theft & 4-Mar-14 & 381 & 228 \\
\hline 25. Why bitcoin isn't dead yet & 10-Mar-14 & 1303 & 578 \\
\hline $\begin{array}{l}\text { 26. U.S. bitcoin lawsuit over Mt. Gox losses names Mizuho as } \\
\text { defendant }\end{array}$ & 13-Mar-14 & 414 & 202 \\
\hline 27. Bitcoin lawsuit seeks $\$ 500 \mathrm{M}$ for Canadian investors in Mt. Gox & 14-Mar-14 & 423 & 218 \\
\hline 28. Bitcoins aren't tax exempt, Revenue Canada says & 26-Mar-14 & 586 & 301 \\
\hline 29. Bitcoin exchange Mt. Gox heads for liquidation & 16-Apr-14 & 369 & 205 \\
\hline 30. Saskatchewan's first bitcoin ATM opens in Saskatoon & 4-May-14 & 395 & 213 \\
\hline 31. Silk Road bitcoins worth $\$ 18 \mathrm{M}$ US to be auctioned off & 13-Jun-14 & 523 & 299 \\
\hline 32. Bitcoin miner takeover latest threat to cryptocurrency & 17-Jun-14 & 532 & 274 \\
\hline 33. Regina's first bitcoin machine, a BTM, installed at pizza restaurant & 17-Jul-14 & 233 & 141 \\
\hline 34. U.S. Marshals bitcoin auction sees SecondMarket, Pantera outbid & 30-Jun-14 & 582 & 292 \\
\hline 35. Tim Draper wins Vaurum's Silk Road bitcoin auction & 2-Jul-14 & 285 & 166 \\
\hline 36. Bitcoin theft: Canadian hacker could be to blame & 11-Aug-14 & 495 & 268 \\
\hline 37. U.S. warns consumers about risks of using Bitcoins & 11-Aug-14 & 125 & 86 \\
\hline 38. 6 new bitcoin machines arrive in Toronto & 13-Aug-14 & 470 & 280 \\
\hline
\end{tabular}


39. Salaries paid in bitcoin a growing trend in Canada

1-Sep-14 $609 \quad 312$

40. Bitcoin mining company 'fully vindicated' after expiry of cease 12-Sep-14 $477 \quad 205$ trade order

41. Waterloo tech startup leader is paid in bitcoin

16-Sep-14 $714 \quad 335$

42. Bitcoin exchange Mt. Gox could face Ontario class action suit

24-Sep-14 315

173 


\section{Appendix B: List of Globe and Mail Resources Used}

Globe and Mail Title

1. Chinese ban weighs on Bitcoin's global fight for acceptance

2. 'It's a mania': Bitcoin price compared to tulip bulb bubble of 1637

3. Bitcoin Foundation: The little-known group lobbying for virtual money

4. Royal Canadian Mint's digital MintChip passes new milestone

5. Bursting the bitcoin bubble

6. For beleaguered bitcoins, Canada is friendly territory

7. The Roundup: Tracking true inflation in troubled EM currencies

8. Startup invents heartbeat-sensing wristband to store passwords, bitcoin

9. Canada to regulate bitcoin in war on dirty money

10. How a Canadian was charged with money laundering in sale of bitcoins

11. Alberta-based bitcoin bank closes after being 'robbed' by hackers

12. Bitcoin boosters' faith unshaken by scandals

13. Searching for Mr. Bitcoin: A suburban mystery

14. The Nakamoto identity: Should we respect bitcoin creator's bid for privacy?

15. Canadian lawsuit to seek $\$ 500$-million from Mt. Gox bitcoin exchange

16. Bitcoin believers: Why digital currency backers are keeping the faith

17. Bitcoin is just the beginning

18. Regina bitcoin startup denies wrongdoing

19. Security risks a 'yellow card' for bitcoin, prof warns

20. A beginner's guide to owning bitcoin

21. Bitcoin believers say digital money is gaining currency

22. U.S. gold dealer launches first digital currency backed by bullion

23. New York first state to propose regulations for virtual currency

24. The truth about bitcoin and its impact on business

25. U.S. agency to field complaints over bitcoin, warns of risks

26. Hacker with Canadian ISP stole thousands in virtual currency

27. Six ATM-like bitcoin teller machines installed across GTA

28. Is it loonie to collect your salary in bitcoin?

29. Bitcoin isn't risky when you know your customers

30. The real goods on fake currencies

31. U.S. judge awards \$40-million in SEC case over bitcoin Ponzi scheme

\begin{tabular}{ccc} 
Date & Tot. & Wnique \\
& Wds \\
\hline 11-Dec-13 & 926 & 436 \\
20-Dec-13 & 307 & 183 \\
12-Jan-14 & 929 & 462 \\
13-Jan-14 & 484 & 269 \\
15-Jan-14 & 726 & 370 \\
17-Jan-14 & 529 & 284 \\
31-Jan-14 & 721 & 376 \\
10-Feb-14 & 690 & 360 \\
11-Feb-14 & 233 & 152 \\
12-Feb-14 & 955 & 417 \\
4-Mar-14 & 374 & 205 \\
6-Mar-14 & 651 & 340 \\
7-Mar-14 & 722 & 367 \\
7-Mar-14 & 878 & 409 \\
14-Mar-14 & 408 & 213 \\
& & \\
5-Apr-14 & 1655 & 697 \\
24-Apr-14 & 875 & 449 \\
8-May-14 & 586 & 289 \\
16-Jun-14 & 543 & 261 \\
20-Jun-14 & 1088 & 500 \\
20-Jun-14 & 814 & 408 \\
16-Jul-14 & 235 & 148 \\
17-Jul-14 & 589 & 320 \\
30-Jul-14 & 1822 & 603 \\
11-Aug-14 & 125 & 86 \\
11-Aug-14 & 486 & 266 \\
13-Aug-14 & 712 & 321 \\
2-Sep-14 & 619 & 318 \\
16-Sep-14 & 2108 & 415 \\
16-Sep-14 & 871 & 391 \\
19-Sep-14 & 307 & 189 \\
& &
\end{tabular}




\section{Appendix C: List of National Post Resources Used}

\section{National Post Article Title}

Date TotWds $\begin{array}{r}\text { Unique } \\ \text { Wds }\end{array}$

1. Dropping the penny was just the beginning as the Canadian Mint seeks digital future

2. Euro fears boost virtual currency Bitcoin

3. Alberta man may be first to sell house for bitcoin virtual currency

4. Why Bitcoin is like no other bubble we've seen before

5. Bitcoin 101: The new gold or just a flash in the pan?

6. Ugly day for Bitcoin as virtual currency's price plunges

7. Six things that could cause Bitcoin prices to crash

8. Extremely Bad Advice: Bitcoin Fever

9. 'Bitcoin is gold for nerds': Wall Street analyst says virtual currency is 'absolutely' valid for a diversified portfolio

10. It's a mad, mad market world

11. Terence Corcoran: Gold versus bitcoin

12. Bitcoin's real-world problem: Virtual currency facing bank backlash in Canada

13. Canada Revenue Agency zeroes in on bitcoin

14. U.S. watchdog eyes regulation for digital currency Bitcoin

15. Your Bitcoin Primer

16. The future of money, digitized money and the Bitcoin boom

17. U.S. seizes accounts of major Bitcoin exchange based in Japan

18. Digital currency firm Liberty Reserve accused by U.S. of running US\$6billion money-laundering scheme

19. Winklevoss twins create fund to invest in Bitcoin market swings

20. Winklevoss twins' big Bitcoin bet has no shortage of potential pitfalls

21. SEC sues Texas man over alleged bitcoin ponzi scheme

22. Bitcoin ATMs coming to five Canadian cities this fall, will let you exchange cash for digital currency

23. Canadian Mint ready to test its own digital money project

24. How a homeless Florida man is surviving on Bitcoins

25. Silk Road drug website shuttered by U.S. authorities, alleged owner arrested

26. FBI's shutdown of illicit drug website Silk Road will reveal Bitcoin's resilience

27. Bitcoin price sinks after FBI arrest Silk Road owner and shut down underground drug market website

28. Silk Road case arrest exposes shady life of an Internet drug lord

29. World's first Bitcoin ATM to open in Canada this week

30. Jesse Kline: Behold the power of Bitcoin

31. Canadian miner to pay contractor in Bitcoins

32. Governments ponder legitimacy of Bitcoins

33. Bitcoin rallies to record high as digital currency gains validity among U.S. regulators

34. Can bitcoin become more than an alternative currency?

35. Bitcoin hits US $\$ 1,000$

36. Alberta woman willing to trade \$1-million property for Bitcoins - the volatile new digital currency

\begin{tabular}{|c|c|c|}
\hline 9-Apr-12 & 709 & 382 \\
\hline 8-Jun-12 & 597 & 349 \\
\hline 21-Mar-13 & 531 & 280 \\
\hline 3-Apr-13 & 250 & 153 \\
\hline 5-Apr-13 & 738 & 342 \\
\hline 10-Apr-13 & 166 & 116 \\
\hline 10-Apr-13 & 1028 & 338 \\
\hline 11-Apr-13 & 415 & 233 \\
\hline 11-Apr-13 & 377 & 223 \\
\hline 13-Apr-13 & 967 & 486 \\
\hline 16-Apr-13 & 900 & 426 \\
\hline 27-Apr-13 & 403 & 232 \\
\hline 29-Apr-13 & 434 & 252 \\
\hline 7-Мау-13 & 374 & 209 \\
\hline 9-Мay-13 & 971 & 406 \\
\hline 16-Мау-13 & 456 & 255 \\
\hline 17-Мay-13 & 663 & 301 \\
\hline 28-May-13 & 862 & 371 \\
\hline 2-Jul-13 & 312 & 180 \\
\hline 3-Jul-13 & 645 & 378 \\
\hline 23-Jul-13 & 331 & 190 \\
\hline 9-Sep-13 & 775 & 358 \\
\hline 19-Sep-13 & 1301 & 538 \\
\hline $23-$ Sep-13 & 250 & 161 \\
\hline 2-Oct-13 & 536 & 298 \\
\hline 3-Oct-13 & 835 & 419 \\
\hline $3-$-Oct-13 & 325 & 207 \\
\hline 5-Oct-13 & 838 & 449 \\
\hline 28-Oct-13 & 254 & 161 \\
\hline 1-Nov-13 & 986 & 435 \\
\hline 13-Nov-13 & 287 & 178 \\
\hline 19-Nov-13 & 476 & 231 \\
\hline 19-Nov-13 & 1422 & 627 \\
\hline 21-Nov-13 & 581 & 290 \\
\hline 27-Nov-13 & 360 & 211 \\
\hline 4-Dec-13 & 591 & 323 \\
\hline
\end{tabular}


37. Bitcoin trading banned at China's banks, but individuals can still use the virtual currency

38. Tesla Model S paid for entirely with bitcoin at California car dealership

-Dec-13

699

342

39. Sheep Marketplace customers fleeced in bitcoin heist

6-Dec-13 564

301

6-Dec-13 $715 \quad 377$

40. Bitcoin is getting crushed after major blow from China

18-Dec-13

386

208

41. Even if Bitcoin fails, cryptocurrencies are here to stay

20-Dec-13

1236

586

42. Why Bitcoin is a 'high-tech dinosaur soon to be extinct'

2-Jan-14

1104

504

43. Bitcoin tops $\$ 1,000$ again after Zynga accepts virtual currency

6-Jan-14

596

330

44. From bitcoin to the NSA: What 2013 teaches us about technology as great liberator and the great oppressor

7-Jan-14

848

415

16-Jan-14

130

91

Bitcoin for ticket, merchandise purchases

46. As merchants embrace Bitcoin, digital currency still struggles for regulatory approval worldwide

47. Bitcoin is not a currency, it's a commodity, says Finland's central bank

48. Bitcoin is an 'amazing example of a bubble:' Robert Shiller

49. Two Bitcoin sellers arrested and charged in money laundering scheme

50. Winklevoss lawyer in talks with SEC over Bitcoin ETF

51. Apple Inc has pulled popular Bitcoin app Blockchain out of its mobile store

52. Guy shoots up his iPhone with a huge sniper rifle after Apple Inc bans popular Bitcoin app

53. Federal budget 2014 puts Bitcoin in crosshairs with new anti-money laundering regulations for virtual currencies

54. Bitcoin plummets after Mt.Gox exchange reveals withdrawals to be halted indefinitely due to 'unusual activity'

55. It's only a matter of time before disruptive technologies... er... disrupt Canada's banking sector

56. Why Bitcoins don't add up to money

57. To call Bitcoins highly speculative would be the understatement of the century

58. After the collapse of Mt. Gox — and the theft of $\$ 365 \mathrm{M}$ - where does the future lie for bitcoins?

59. Mystery of the missing bitcoins: Fate of $\$ 365 \mathrm{M}$ unknown after major exchange closes

60. Failed bitcoin exchange Mt. Gox, other platforms said to be under investigation by U.S. prosecutors

61. Bitcoin exchange Mt. Gox files for bankruptcy, admits losing 850,000 units of digital currency

62. Bitcoin's Mt. Gox: Inside the quick rise and even faster fall

63. Bitcoin: 6 totally false myths everyone thinks are true

64. After Alberta's Flexcoin, Mt. Gox hacked, bitcoin businesses face sting of free-wheeling ways

65. Alberta bitcoin bank Flexcoin shuts down after hackers stole all of its online coins

20-Jan-14 $\quad 658 \quad 346$

20-Jan-14 $\quad 812 \quad 408$

24-Jan-14 $\quad 154 \quad 92$

27-Jan-14 $\quad 117 \quad 80$

4-Feb-14 $351 \quad 224$

6-Feb-14 $247 \quad 154$

7-Feb-14 $702 \quad 372$

11-Feb-14 $\quad 181 \quad 107$

11-Feb-14 $639 \quad 297$

13-Feb-14 $\quad 776 \quad 407$

20-Feb-14 $1187 \quad 537$

21-Feb-14 $425 \quad 230$

25-Feb-14 $677 \quad 364$

25-Feb-14 $\quad 793 \quad 390$

26-Feb-14 $\quad 595 \quad 311$

28-Feb-14 $566 \quad 298$

28-Feb-14 $1447 \quad 635$

4-Mar-14 $466 \quad 266$

5-Mar-14 932

5-Mar-14 $\quad 314 \quad 187$

6-Mar-14 $779 \quad 416$

66. Has Newsweek uncovered the mysterious inventor of Bitcoin?

67. Autumn Radtke, 28-year-old CEO of virtual currency exchange, found dead in suspected suicide in Singapore

68. With claim that Satoshi Nakamoto is Bitcoin's founder, Newsweek relaunches with a bang

69. Bitcoin owners learning the hard way — it's a virtual Wild West out there

70. Failed Bitcoin exchange Mt. Gox files for bankruptcy protection in U.S. to halt class action

$\begin{array}{rrr}\text { 6-Mar-14 } & 593 & 310 \\ \text { 7-Mar-14 } & 686 & 374 \\ & & \\ \text { 7-Mar-14 } & 727 & 402 \\ \text { 10-Mar-14 } & 420 & 208\end{array}$


71. Dorian Nakamoto, alleged Bitcoin founder, gets US\$28,000 donations

10-Mar-14

474 from enthusiasts

72. Bitcoin cheaper, less vulnerable to cybercrime than traditional currency,

Goldman Sachs report says

14-Mar-14 $\quad 501 \quad 254$
\$500-million compensation

74. U.S. lawsuit traces mystery of \$3-billion penny-stock fraud to 26-year-old Bugatti-driving Montrealer

75. Ottawa bitcoin exchange defrauded of $\$ 100,000$ in easiest heist ever

76. Mt. Gox Bitcoin exchange now allowing customers to check balances on website

77. Toronto hip-hop band accepting Bitcoin donations for digital album downloads

78. Mt. Gox says it found \$134-million in Bitcoins in 'forgotten' wallet after judge allows exchange to be tracked

79. BMO open to Bitcoin if virtual currency is regulated, reliable, says CEO Bill Downe

80. Failed Bitcoin exchange Mt. Gox to liquidate after court rejects bankruptcy protection

81. Bitcoin's Mt. Gox's 'geek' CEO turned to 'Hitchhikers Guide' to keep angry customers at bay

82. Mt. Gox bitcoin exchange customers ask U.S. judge to approve settlement

83. Jesse Kline: From Putin to porn stars - why everyone needs to start adopting bitcoin

84. Brave new digital currency world

85. Small merchants struggle with decision to accept Bitcoin or not

86. Bitcoin needs simple and straightforward rules

87. Why Bitcoin doesn't need regulation

88. Banking giants brace for technological 'disruption'

89. 'Bitcoin Jesus' invites the rich to live in tax-free tropical paradise

90. Jesse Kline: Emerging technologies are reducing governments' stranglehold on the economy

91. What do bitcoin and gold investors have in common? Disdain for conventional money

92. A hacker stole US\$83,000 worth of bitcoin using a Canadian Internet provider, researchers say

93. How to buy islands, gold mines and villas with Bitcoin

17-Mar-14 $1004 \quad 492$

18-Mar-14 $372 \quad 204$

18-Mar-14 $274 \quad 167$

21-Mar-14 $362 \quad 216$

21-Mar-14 $\quad 414 \quad 223$

1-Apr-14 $693 \quad 349$

16-Apr-14 $365 \quad 205$

21-Apr-14 $1575 \quad 677$

29-Apr-14 $394 \quad 212$

9-May-14 $732 \quad 360$

20-May-14 $1058 \quad 475$

20-May-14 $653 \quad 381$

4-Jun-14 $\quad 607 \quad 306$

4-Jun-14 $604 \quad 296$

13-Jun-14 $\quad 874 \quad 431$

16-Jun-14 $1328 \quad 613$

25-Jul-14 $\quad 980 \quad 474$

28-Jul-14 $\quad 774 \quad 421$

11-Aug-14 $\quad 138 \quad 90$

23-Sep-14 $\quad 857 \quad 435$ 


\section{Appendix D: Codebook}

\begin{tabular}{|c|c|c|c|}
\hline & Code & Symbol & Explanation \\
\hline 1 & Value & Orange Circle & $\begin{array}{l}\text { Any remark using the term or concept of "value" in } \\
\text { relation to Bitcoin was coded with an orange circle. }\end{array}$ \\
\hline 2 & Currency & Aqua circle & $\begin{array}{l}\text { Any remark using the term Currency was coded with } \\
\text { an Aqua circle. }\end{array}$ \\
\hline 3 & Authority & Blue circle & $\begin{array}{l}\text { Any usage of the term authority in relation to an } \\
\text { individual, group or institution. For example the } \\
\text { authority in issuing money derived from a central } \\
\text { bank. }\end{array}$ \\
\hline 4 & Volatility & Yellow circle & $\begin{array}{l}\text { Almost all publications discuss Bitcoin in relation to } \\
\text { price volatility. This was coded as either a direct } \\
\text { mention of the word "volatility", but also in instances } \\
\text { where Bitcoin price relative to Canadian Dollars was } \\
\text { discussed as having changed dramatically, either } \\
\text { upwards or downwards, from a previous, often } \\
\text { arbitrary, point of time. }\end{array}$ \\
\hline 5 & Institution, business & Pink circle & $\begin{array}{l}\text { This code helped keep track of the types of } \\
\text { institutions mentioned or discussed at length in the } \\
\text { pieces. A pink circle has been coded to social groups } \\
\text { of a formal or institutionalized nature that has some } \\
\text { relation to Bitcoin. }\end{array}$ \\
\hline 6 & Issuance & Black circle & $\begin{array}{l}\text { Any remark using the term Issuance was coded with } \\
\text { an Black circle. This was generally coded in } \\
\text { instances relating to a central bank or Bitcoin } \\
\text { algorithms. }\end{array}$ \\
\hline 7 & Laundering & Dark red square & $\begin{array}{l}\text { Any mention of money laundering was coded with a } \\
\text { dark red square. A search for terrorism (see Code } 38 \text { ) } \\
\text { was performed as well, as both concepts are found in } \\
\text { the mandate of FINTRAC, Canada's financial crimes } \\
\text { agency. }\end{array}$ \\
\hline 8 & Risk mitigation & Pink circle & $\begin{array}{l}\text { The concept of risk mitigation is rather fluid. } \\
\text { Financial articles that either discuss Bitcoin as either } \\
\text { an investment to be skeptical of or a part of a } \\
\text { balanced portfolio at times make mention of risk } \\
\text { mitigation. For example, hesitancy to buy or sell, or } \\
\text { whether it is right to invest in Bitcoin or not in lieu } \\
\text { of any number of exogenous factors. }\end{array}$ \\
\hline 9 & Other crime & Black square & $\begin{array}{l}\text { Mentions of crime other than money laundering and } \\
\text { terrorist financing (codes } 7 \text { and 38, respectively) } \\
\text { were marked here. This means various forms of } \\
\text { fraud, drug-related offenses, theft, or hacking. Note } \\
\text { that hacking is legally and conceptually distinct from } \\
\text { fraud. Many of these concepts, such as fraud and } \\
\text { hacking exist in their own codes. This was therefore } \\
\text { an aggregation of other forms of crime. }\end{array}$ \\
\hline 10 & Authority & Green $x$ & $\begin{array}{l}\text { This code relates to the term "authority" used in the } \\
\text { articles. Authority also pertains to various forms of } \\
\text { control. This code was taken from Max Weber's } \\
\text { conceptualization of traditional, charismatic or legal- } \\
\text { rational forms of authority. }\end{array}$ \\
\hline 11 & Bank & $\operatorname{Red} x$ & $\begin{array}{l}\text { Any remark using the term Bank was coded with a } \\
\text { Red } x \text {. }\end{array}$ \\
\hline
\end{tabular}




\begin{tabular}{|c|c|c|c|}
\hline 12 & Credit & Pink $x$ & $\begin{array}{l}\text { Any remark using the term Credit or referring } \\
\text { directly to the concept of credit was coded with an } \\
\text { Pink x }\end{array}$ \\
\hline 13 & Fraud & Aqua $x$ & $\begin{array}{l}\text { Any remark using the term Fraud was coded with an } \\
\text { Aqua x. This may also be found in relation to } \\
\text { schemes such as journalistic mentions of Ponzi } \\
\text { schemes or pyramid schemes. }\end{array}$ \\
\hline 14 & Hacking & Blue $x$ & $\begin{array}{l}\text { Any remark using the term Hacking was coded with } \\
\text { a Blue x. In Canada, hacking is legally and } \\
\text { conceptually distinct from fraud. }\end{array}$ \\
\hline 15 & Bankruptcy & Brown $x$ & $\begin{array}{l}\text { Any remark using the term Bankruptcy was coded } \\
\text { with a Brown } x \text {. }\end{array}$ \\
\hline 16 & Sue/litigate & Black $x$ & $\begin{array}{l}\text { Any mention of litigation was coded. This can be } \\
\text { individuals, businesses or the government acting as } \\
\text { either the offensive party to legal action or as the } \\
\text { recipient. }\end{array}$ \\
\hline 17 & Speculation & Grey $x$ & $\begin{array}{l}\text { This code refers to market speculation surrounding } \\
\text { Bitcoin. }\end{array}$ \\
\hline 18 & Satoshi Nakamoto & Pink $x$ & $\begin{array}{l}\text { Satoshi Nakamoto was the name attributed to the } \\
\text { individual or individuals that started Bitcoin. This is } \\
\text { likely a pseudonym. }\end{array}$ \\
\hline 19 & Gavin Andresen & Purple $x$ & $\begin{array}{l}\text { Gavin Andresen is the chief scientist of the Bitcoin } \\
\text { Foundation and current person in charge of the } \\
\text { Bitcoin protocol. He began working on Bitcoin when } \\
\text { the project's open source code was made available on } \\
\text { GitHub. }\end{array}$ \\
\hline
\end{tabular}

\begin{tabular}{|c|c|c|c|}
\hline 20 & Bubble (speculative) & Orange $x$ & $\begin{array}{l}\text { Any remark using the term Bubble (speculative) was } \\
\text { coded with an Orange x. Bitcoin was said to have } \\
\text { bubbled leading up to a crash beginning in December } \\
2014 \text {. }\end{array}$ \\
\hline 21 & Imaginary & Orange triangle & $\begin{array}{l}\text { Some columnists, writers or journalists have } \\
\text { discussed Bitcoin as an imaginary phenomenon. } \\
\text { Descriptions of this kind were coded with an orange } \\
\text { triangle. }\end{array}$ \\
\hline 22 & Gold & Blue triangle & $\begin{array}{l}\text { Any remark using the word Gold was coded with a } \\
\text { Blue triangle. }\end{array}$ \\
\hline 23 & Invest(or/ing) & Red triangle & $\begin{array}{l}\text { Any mention of investing or investors was coded } \\
\text { with a Red triangle. Bitcoin was for a time the basis } \\
\text { for much investing. See Code } 20 \text { on 'Bubbles' for } \\
\text { more information. }\end{array}$ \\
\hline 24 & Canadian Dollar & Aqua triangle & $\begin{array}{l}\text { Any mention of the fiat currency of the Canadian } \\
\text { State. This includes mention of CDN or CAD after a } \\
\text { numerical value that itself had been preceded with a } \\
\text { dollar sign. }\end{array}$ \\
\hline 25 & $\begin{array}{l}\text { Canada Revenue } \\
\text { Agency }\end{array}$ & Black triangle & $\begin{array}{l}\text { The Canada Revenue Agency or "CRA" is the } \\
\text { institution in charge of overseeing the collection of } \\
\text { tax revenues in Canada. A similar institution in the } \\
\text { United States would be the IRA or Internal Revenue } \\
\text { Agency. }\end{array}$ \\
\hline
\end{tabular}

\begin{tabular}{lll}
\hline 26 Blockchain & Pink triangle & $\begin{array}{l}\text { The blockchain is the entire public transaction ledger } \\
\text { of all Bitcoin transactions. It is appended every ten } \\
\text { minutes by further transactions that occur globally. }\end{array}$
\end{tabular}


They are appended by 'miners'. Mention of the Bitcoin Blockchain were given a pink triangle code.

\begin{tabular}{|c|c|c|c|}
\hline 27 & $\begin{array}{l}\text { Anonymity/ } \\
\text { Pseudonymity }\end{array}$ & Green triangle & $\begin{array}{l}\text { Mentions of anonymity or pseudonymity in relation } \\
\text { to Bitcoin were coded with a green triangle. }\end{array}$ \\
\hline 28 & Libertarianism & Grey triangle & $\begin{array}{l}\text { Any mention of the social and/or political } \\
\text { philosophy. }\end{array}$ \\
\hline 29 & Bitcoin ATM & Deep pink triangle & $\begin{array}{l}\text { Any mention of Bitcoin ATMs becomes coded with } \\
\text { a deeply-coloured pink triangle. }\end{array}$ \\
\hline 30 & Anarchism & Black asterisk & $\begin{array}{l}\text { Any mention of the social and/or political } \\
\text { philosophy. }\end{array}$ \\
\hline 31 & Canada & Pink square & Any mention of Canada. \\
\hline 32 & United States & Orange square & Any mention of the United States of America. \\
\hline 33 & Mt. Gox & Brown square & $\begin{array}{l}\text { The Mt. Gox Bitcoin Exchange was the world's } \\
\text { largest Bitcoin exchange overseen by Mark } \\
\text { Karpeles. It collapsed in February } 2014 \text { following } \\
\text { the supposed theft of approximately } \$ 400 \text { million in } \\
\text { Bitcoin. This created a lot of media discussion in } \\
\text { Canada and call for regulations in Japan. }\end{array}$ \\
\hline 34 & Silk Road & Blue square & $\begin{array}{l}\text { Mentions of the Silk Road marketplace were coded } \\
\text { with a blue square. The Silk Road marketplace was } \\
\text { run by an anonymous source with the moniker } \\
\text { "Dread Pirate Roberts". The site was available } \\
\text { through the Deep Web made available with the TOR } \\
\text { internet browser. Purchases made on the Silk Road } \\
\text { were transacted exclusively in Bitcoin. }\end{array}$ \\
\hline 35 & Bank of Canada & Dark blue square & Remarks or mentions of Canada's central bank. \\
\hline 36 & Fintrac/ Fincen & Yellow square & $\begin{array}{l}\text { FINTRAC is Canada's financial crimes agency. It is } \\
\text { tasked with stopping money laundering and terrorist } \\
\text { financing. It derives its power from the PCMLTFA. } \\
\text { FINCEN is the American corrolary, and works in } \\
\text { collusion with FINTRAC. FINCEN is upheld by } \\
\text { Title III of the US Patriot Act. }\end{array}$ \\
\hline 37 & Dogecoin & $\begin{array}{l}\text { Black Square with } \\
\text { Crosshair }\end{array}$ & $\begin{array}{l}\text { All text that mentions Dogecoin, the online } \\
\text { cryptographic currency based off of the Bitcoin } \\
\text { source code. }\end{array}$ \\
\hline 38 & Terrorism & Grey square & $\begin{array}{l}\text { Any remark using the term Terrorism was coded } \\
\text { with a Grey square. }\end{array}$ \\
\hline 39 & Wealth & $\begin{array}{l}\text { Cherry-coloured } \\
\text { square }\end{array}$ & $\begin{array}{l}\text { Any mention of wealth was coded with a Cherry- } \\
\text { coloured square. }\end{array}$ \\
\hline 40 & Poverty & $\begin{array}{l}\text { Hollow square with } \\
\mathrm{X}\end{array}$ & $\begin{array}{l}\text { Any mention of poverty was coded with a Hollow } \\
\text { square with X. }\end{array}$ \\
\hline
\end{tabular}




\section{Appendix E: Articles for Qualitative Analysis}

\begin{tabular}{clrr} 
CBC News Title & Date & $\begin{array}{r}\text { Tot. } \\
\text { Words }\end{array}$ \\
\hline 1 & Bitcoin digital currency site to operate like bank in France & $7-$ Dec-12 & 318 \\
2 & Bitcoin virtual currency hitting the mainstream & $11-$ Apr-13 & 1621 \\
3 & Winklevoss twins seek to sell shares in Bitcoin fund & $2-$-Jul-13 & 571 \\
4 & World's first bitcoin ATM opens in Vancouver & $29-$ Oct-13 & 452 \\
5 & Bitcoins now worth \$1,000 US & $27-$-Nov-13 & 209 \\
6 & Mt. Gox shutdown a major blow for bitcoin & $25-$ Feb-14 & 1048 \\
7 & Bitcoin exchange, Mt. Gox, CEO Mark Karpeles still in Japan & $27-$ Feb-14 & 260 \\
8 & Why bitcoin isn't dead yet & $10-$ Mar-14 & 1303 \\
9 & Bitcoins aren't tax exempt, Revenue Canada says & $26-$ Mar-14 & 586 \\
10 & Bitcoin exchange Mt. Gox heads for liquidation & $16-$ Apr-14 & 369 \\
11 & Bitcoin miner takeover latest threat to cryptocurrency & $17-J u n-14$ & 532 \\
12 & Waterloo tech startup leader is paid in bitcoin & $16-$ Sep-14 & 714
\end{tabular}

\begin{tabular}{clrr} 
Globe and Mail Title & Date & $\begin{array}{c}\text { Tot. } \\
\text { Words }\end{array}$ \\
\hline 1 & Bursting the bitcoin bubble & 15-Jan-14 & 726 \\
2 & For beleaguered bitcoins, Canada is friendly territory & 17-Jan-14 & 529 \\
3 & The Roundup: Tracking true inflation in troubled EM currencies & $31-J a n-14$ & 721 \\
4 & Bitcoin is just the beginning & $24-$ Apr-14 & 875 \\
5 & Regina bitcoin startup denies wrongdoing & 8-May-14 & 586 \\
6 & Security risks a 'yellow card' for bitcoin, prof warns & 16-Jun-14 & 543 \\
7 & A beginner's guide to owning bitcoin & 20-Jun-14 & 1088 \\
8 & U.S. gold dealer launches first digital currency backed by bullion & $16-J u l-14$ & 235 \\
9 & U.S. agency to field complaints over bitcoin, warns of risks & 11-Aug-14 & 125 \\
10 & Bitcoin isn't risky when you know your customers & $16-$ Sep-14 & 2108 \\
11 & The real goods on fake currencies & 16-Sep-14 & 871 \\
12 & U.S. judge awards \$40-million in SEC case over bitcoin Ponzi scheme & 19-Sep-14 & 307
\end{tabular}

\begin{tabular}{|c|c|c|c|}
\hline \# & National Post Article Title & Date & $\begin{array}{c}\text { Total } \\
\text { Words }\end{array}$ \\
\hline 1 & $\begin{array}{l}\text { Dropping the penny was just the beginning as the Canadian Mint seeks } \\
\text { digital future }\end{array}$ & 9-Apr-12 & 709 \\
\hline 2 & Canadian Mint ready to test its own digital money project & 19-Sep-13 & 1301 \\
\hline 3 & World's first Bitcoin ATM to open in Canada this week & $28-O c t-13$ & 254 \\
\hline 4 & Jesse Kline: Behold the power of Bitcoin & $1-N o v-13$ & 986 \\
\hline 5 & Governments ponder legitimacy of Bitcoins & 19-Nov-13 & 476 \\
\hline 6 & Can bitcoin become more than an alternative currency? & 21-Nov-13 & 581 \\
\hline 7 & $\begin{array}{l}\text { Sacramento Kings to become first major pro sports franchise to accept } \\
\text { Bitcoin for ticket, merchandise purchases }\end{array}$ & 16-Jan-14 & 130 \\
\hline 8 & $\begin{array}{l}\text { As merchants embrace Bitcoin, digital currency still struggles for } \\
\text { regulatory approval worldwide }\end{array}$ & 20-Jan-14 & 658 \\
\hline 9 & Bitcoin is an 'amazing example of a bubble:' Robert Shiller & 24-Jan-14 & 154 \\
\hline 10 & $\begin{array}{l}\text { Federal budget } 2014 \text { puts Bitcoin in crosshairs with new anti-money } \\
\text { laundering regulations for virtual currencies }\end{array}$ & 11-Feb-14 & 181 \\
\hline
\end{tabular}


11 It's only a matter of time before disruptive technologies... er... disrupt

12 Small merchants struggle with decision to accept Bitcoin or not

20-May-14

653 